Portland State University

PDXScholar

10-2008

\title{
Assessment and Refinement of Real-Time Travel Time Algorithms for Use in Practice
}

Kristin A. Tufte

Portland State University, tufte@pdx.edu

Sirisha Murthy Kothuri

Portland State University

Follow this and additional works at: https://pdxscholar.library.pdx.edu/trec_reports

Part of the Transportation Commons, Urban Studies Commons, and the Urban Studies and Planning Commons

Let us know how access to this document benefits you.

\section{Recommended Citation}

Tufte, Kristin and Sirisha Kothuri. Assessment and Refinement of Real-Time Travel Time Algorithms for Use in Practice. OTREC-RR-08-02. Portland, OR: Transportation Research and Education Center (TREC), 2008. https://doi.org/10.15760/trec.91

This Report is brought to you for free and open access. It has been accepted for inclusion in TREC Final Reports by an authorized administrator of PDXScholar. Please contact us if we can make this document more accessible: pdxscholar@pdx.edu. 

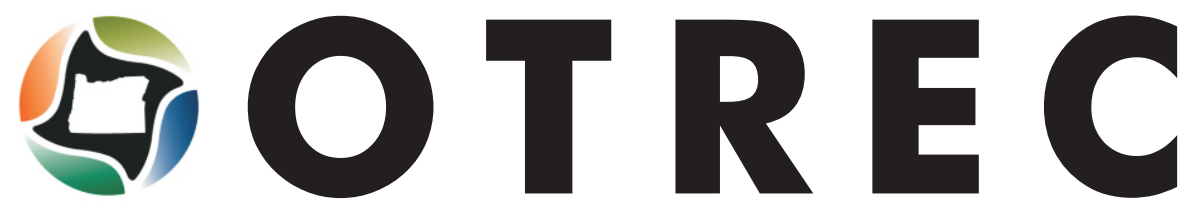

TRANSPORTATION

FINAL REPORT

\section{Assessment and Refinement of Real-Time Travel Time Algorithms for Use in Practice}

OTREC-RR-08-02 October 2008 


\title{
ASSESSMENT AND REFINEMENT OF REAL-TIME TRAVEL TIME ALGORITHMS FOR USE IN PRACTICE
}

Final Report

\section{OTREC-RR-08-02}

\author{
By \\ Kristin Tufte \\ Research Associate \\ $\&$ \\ Sirisha Kothuri \\ Graduate Research Assistant \\ Portland State University \\ P.O. Box 751 \\ Portland, OR 97207-0751
}

For

Oregon Transportation Research and Education Consortium (OTREC)

P.O. Box 751

Portland, OR 97207-0751

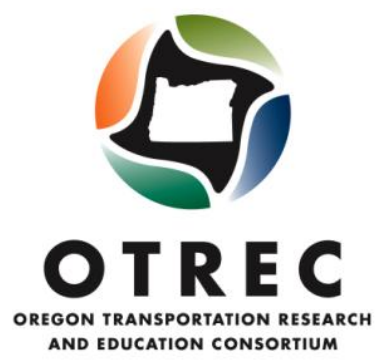

and

The Oregon Department of Transportation

ITS Unit

Transportation Building

355 Capitol St NE, $5^{\text {th }}$ Floor

Salem, OR 97301-3871

\section{October 2008}





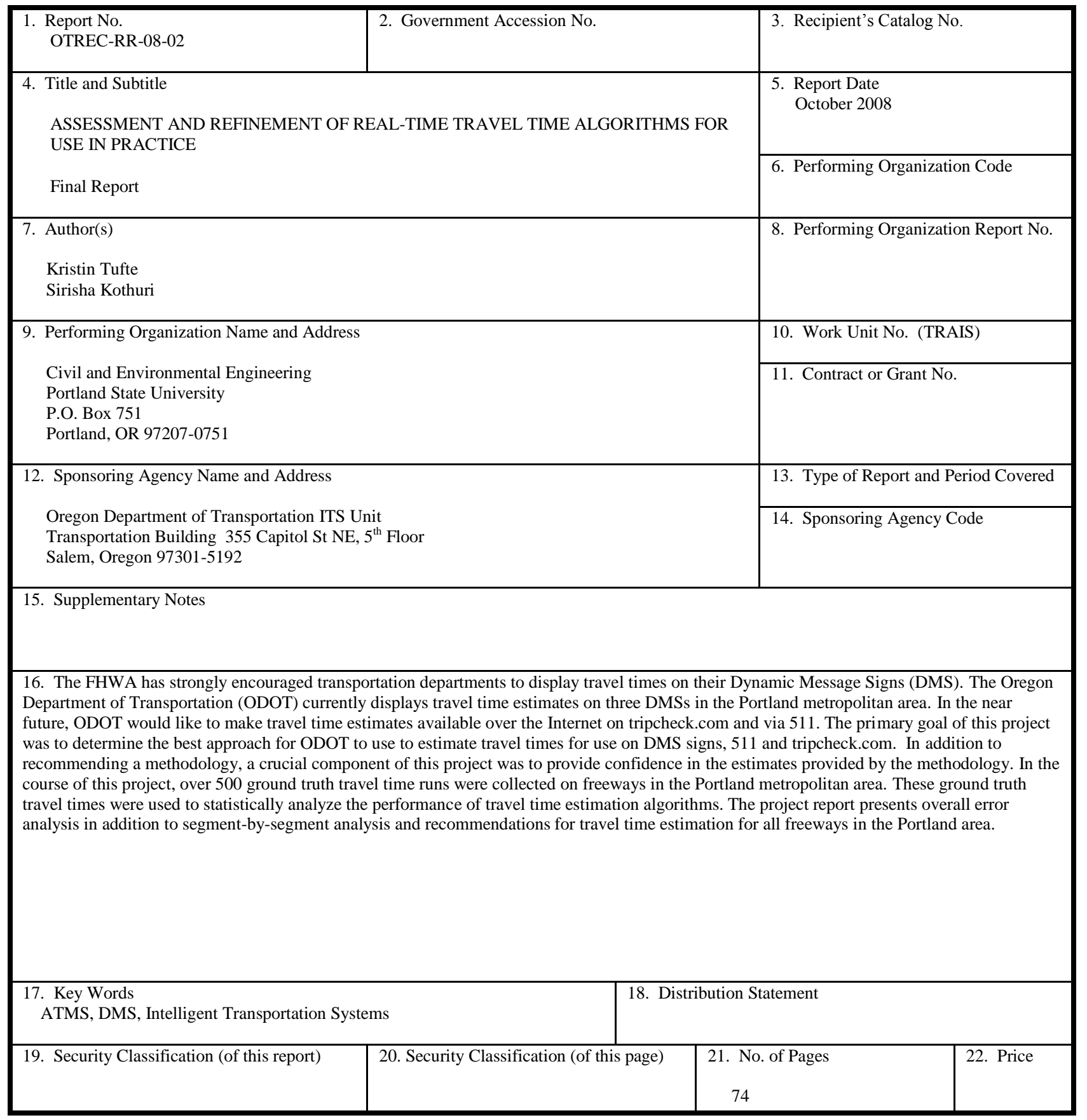




\section{Acknowledgements}

The authors would like to thank the members of the Oregon Department of Transportation (ODOT) Research Unit and the Technical Advisory Committee for their sage advice and assistance in the preparation of this report.

This project was funded by the Oregon Transportation Research and Education Consortium (OTREC).

\section{Disclaimer}

The contents of this report reflect the views of the authors who are solely responsible for the facts and accuracy of the material presented herein. This document is disseminated under the sponsorship of the U.S. Department of Transportation University Transportation Centers Program and ODOT in the interest of information exchange. The U.S. Government and the state of Oregon assume no liability for the contents or use thereof. The contents do not necessarily reflect the official views of the U.S. Government and the State of Oregon. This report does not constitute a standard specification, or regulation. 


\section{Table of Contents}

EXECUTIVE SUMMARY ........................................................................................................ 1

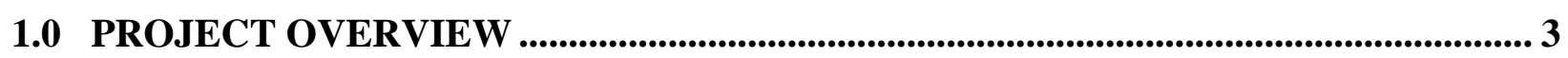

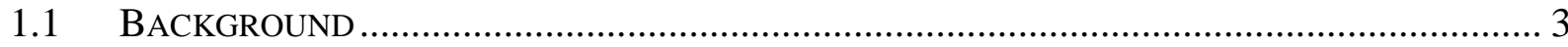

2.0 INVESTIGATION OF OTHER PRACTICES ACROSS NORTH AMERICA ............. 5

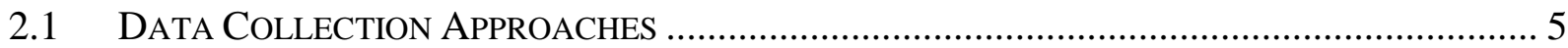

2.2 METHODOLOGIES FOR THE PROVISION OF TRAVEL TIMES................................................. 5

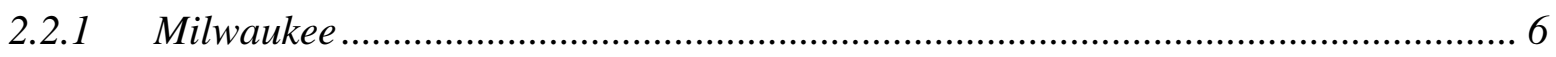

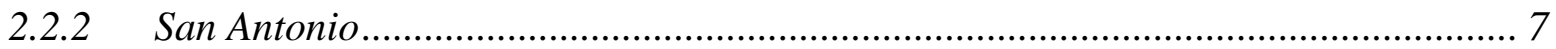

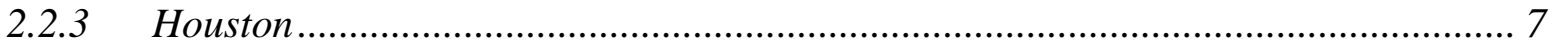

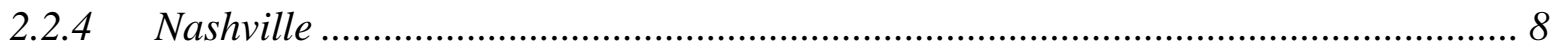

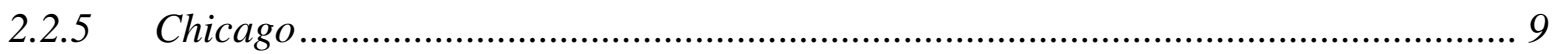

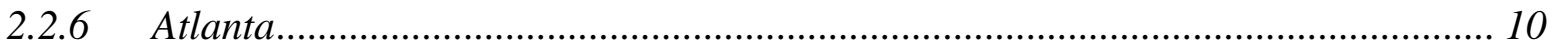

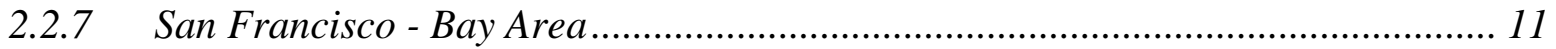

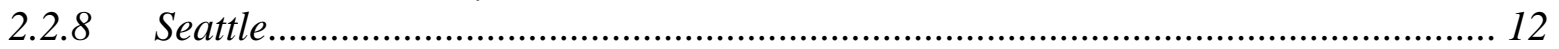

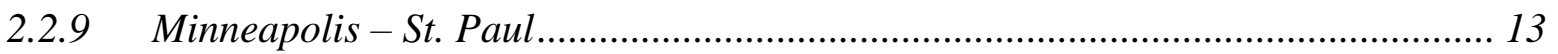

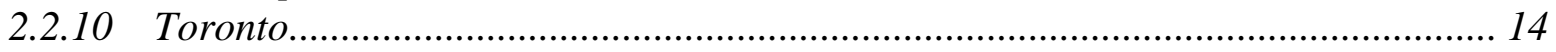

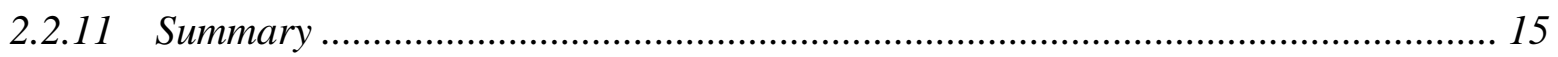

3.0 DATA COLLECTION .................................................................................................... 17

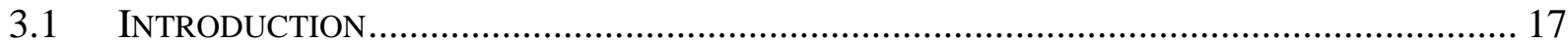

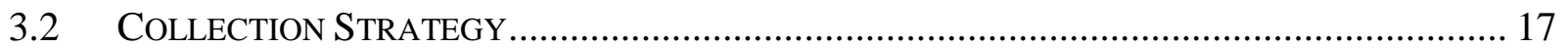

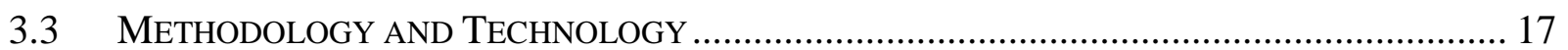

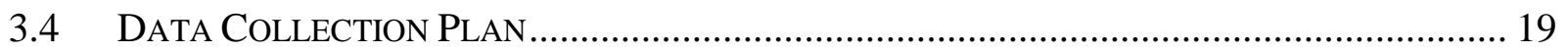

3.4.1 Corridor Selection and Priority..................................................................... 19

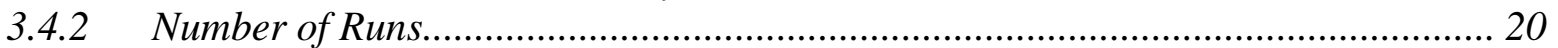

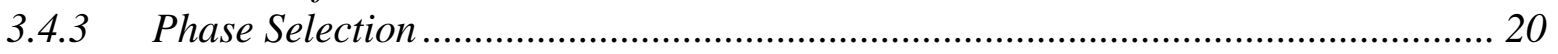

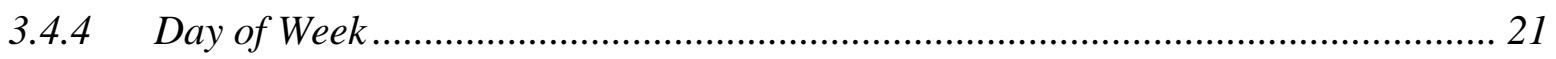

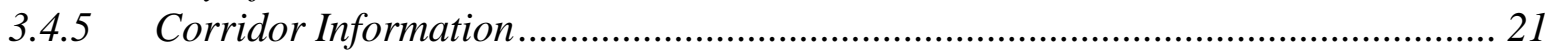

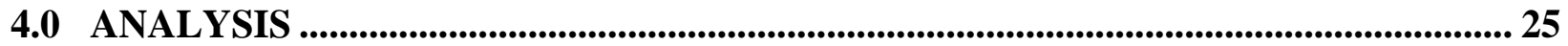

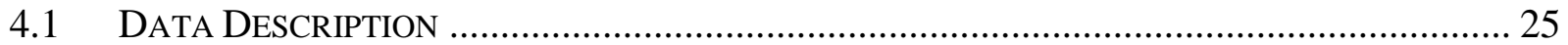

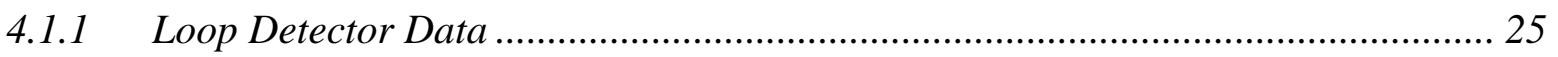

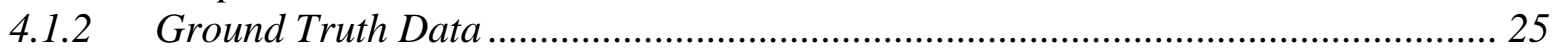

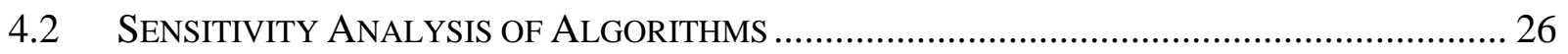

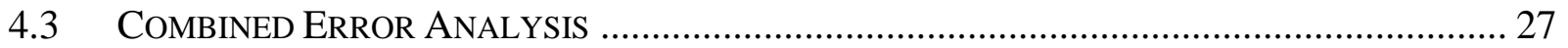

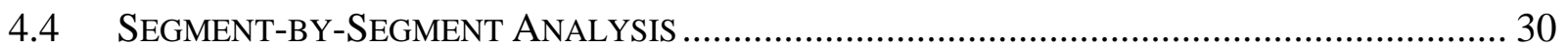

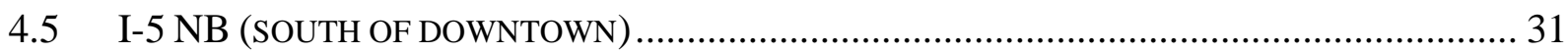

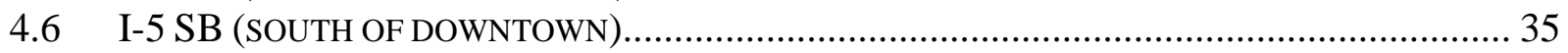

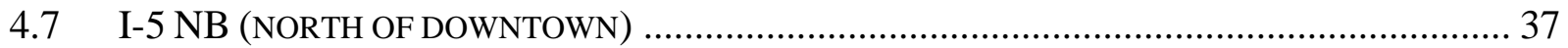

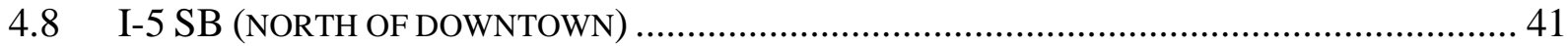

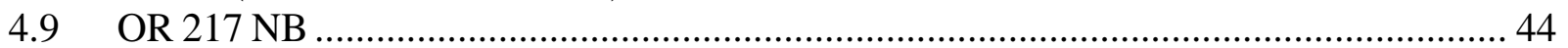

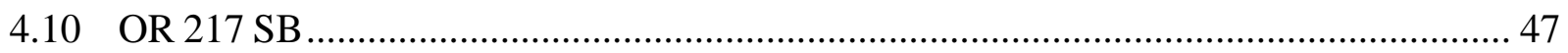

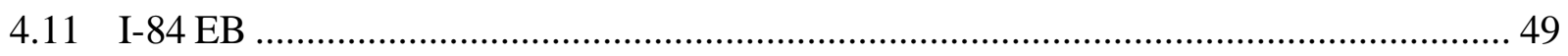




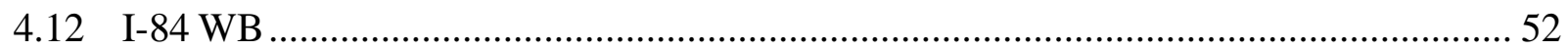

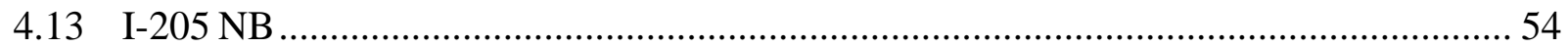

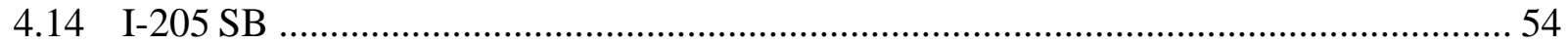

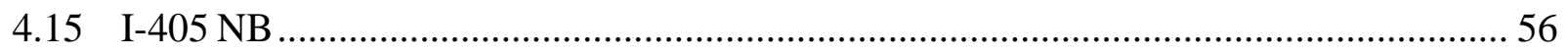

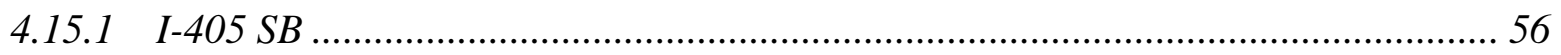

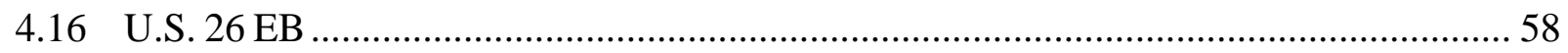

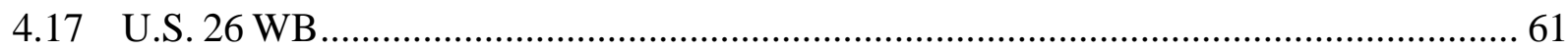

5.0 ALGORITHM REFINEMENT.......................................................................................... 63

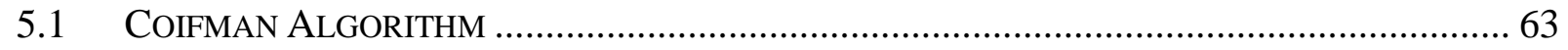

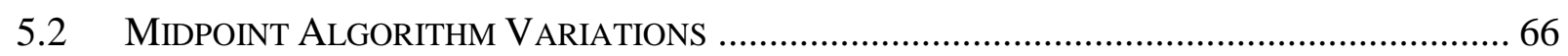

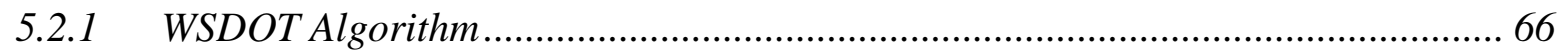

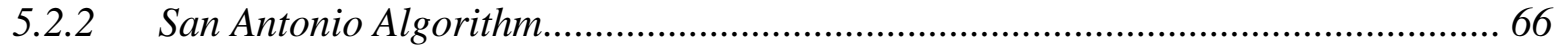

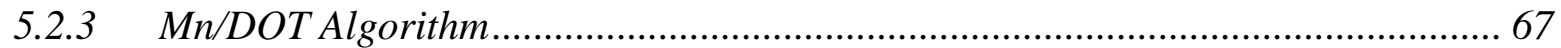

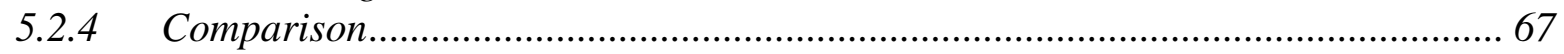

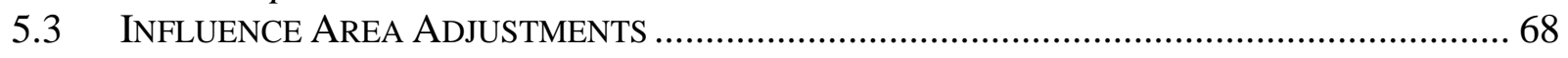

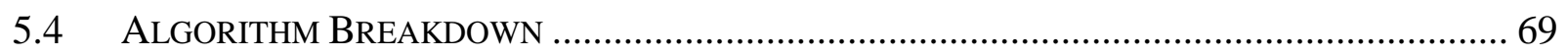

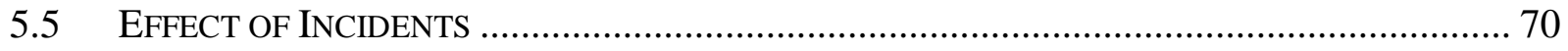

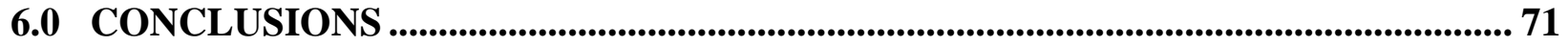

7.0 REFERENCES..................................................................................................................... 73 


\section{List of Figures}

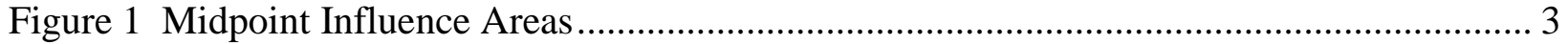

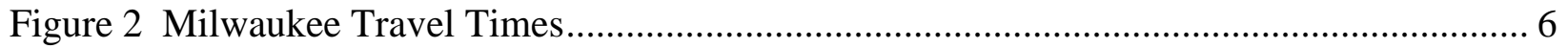

Figure 3 San Antonio Travel Times.............................................................................. 7

Figure 4 Automatic Vehicle Identification (AVI) Readers................................................ 8

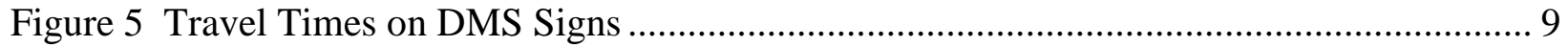

Figure 6 Map showing estimated travel times for Chicago .............................................. 10

Figure 7 Atlanta Travel Times on the Web ....................................................................... 11

Figure 8 San Francisco - Bay Area Travel Times........................................................... 12

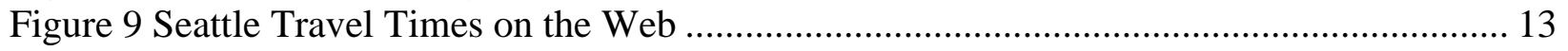

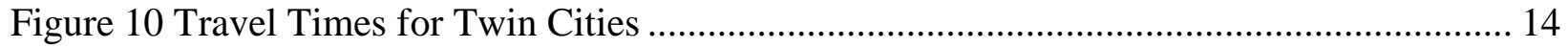

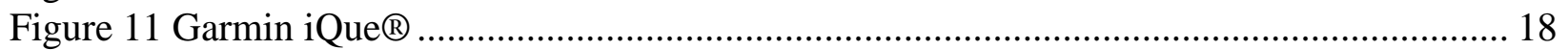

Figure 12 Raw Data from Garmin iQue ${ }^{\circledR}$....................................................................... 19

Figure 13 I-205 Probe Run ................................................................................................. 26

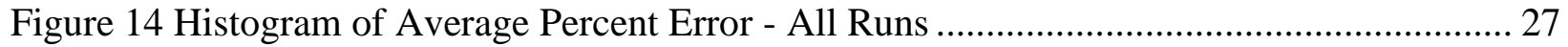

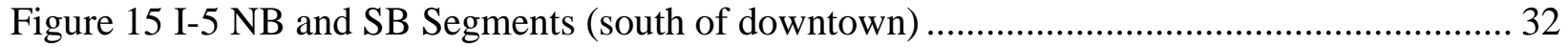

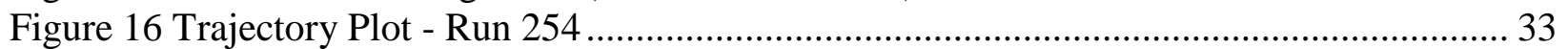

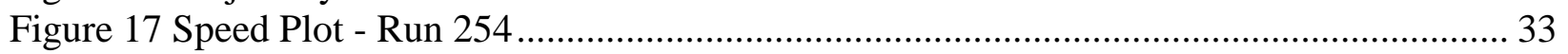

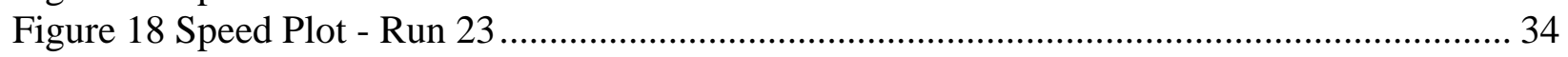

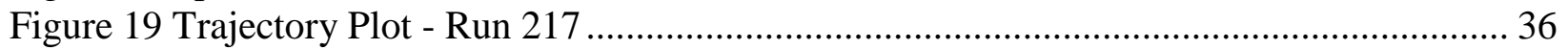

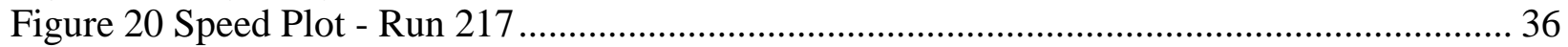

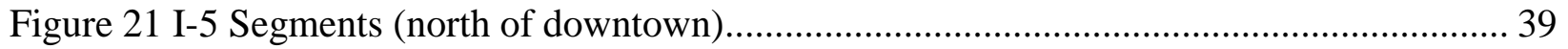

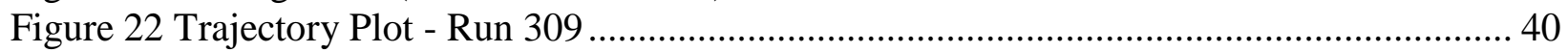

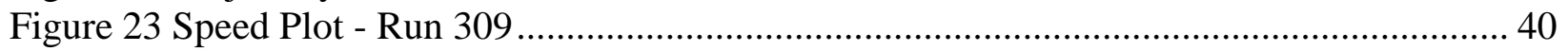

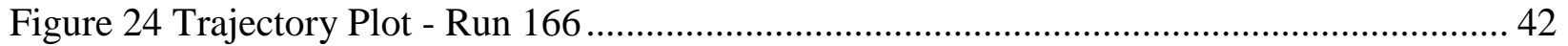

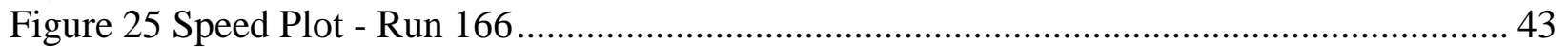

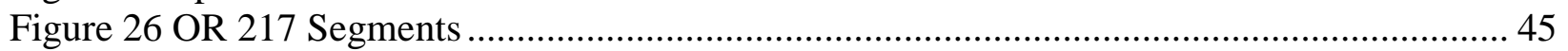

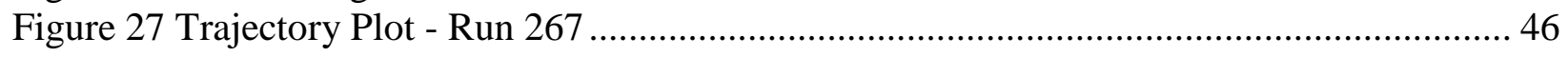

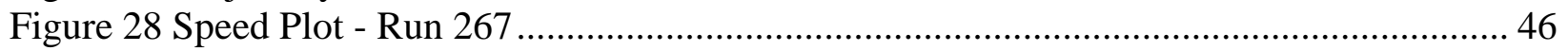

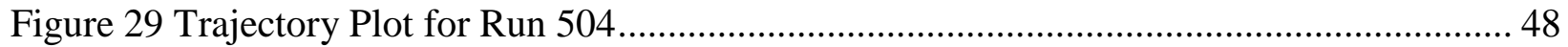

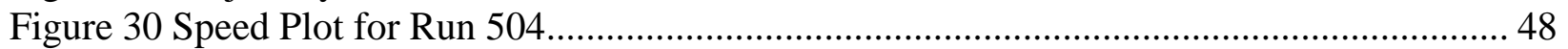

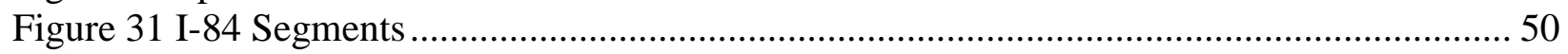

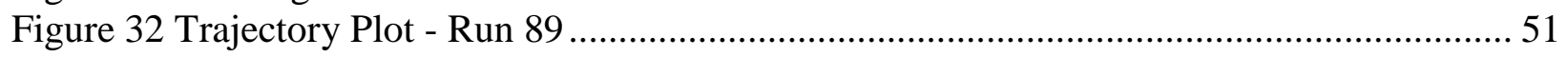

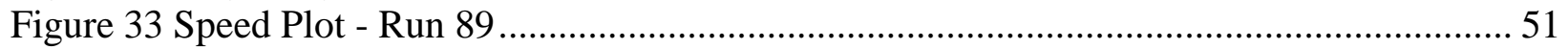

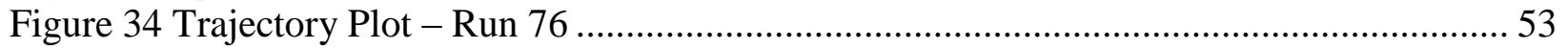

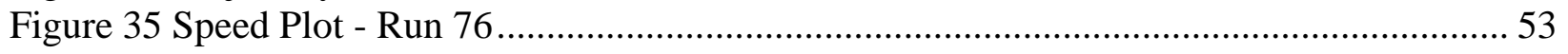

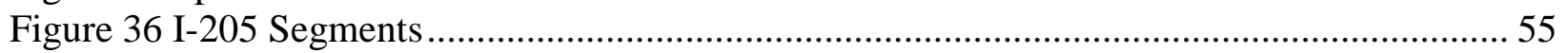

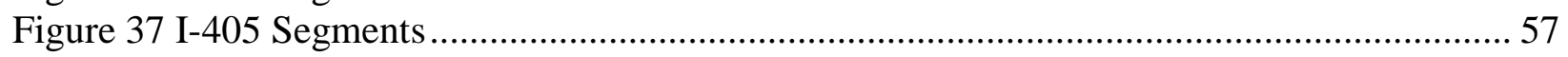

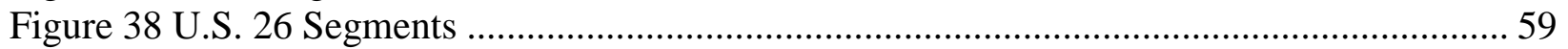

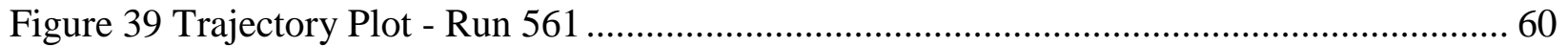

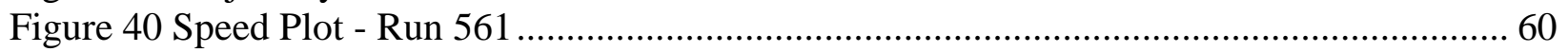

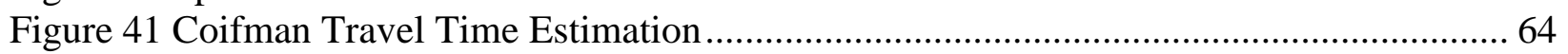

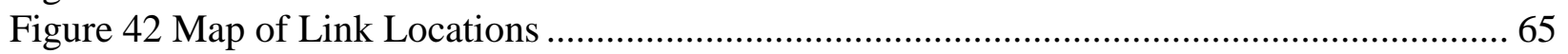

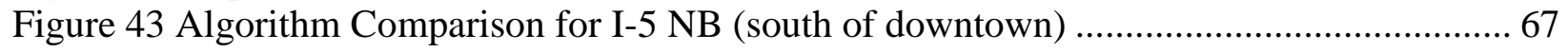

Figure 44 Correlation Between Estimated Travel Time and Estimation Error ......................... 69

Figure 45 Correlation Between Average Probe Speed and Estimation Error............................ 69 


\section{List of Tables}

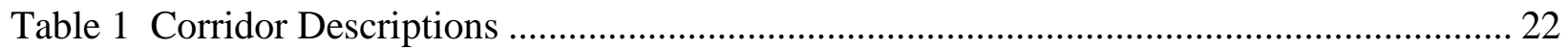

Table 2 Peak Times, Level of Congestion, Estimated Round-Trip Times .............................. 23

Table 3 Collected and Desired Runs by Corridor ............................................................... 24

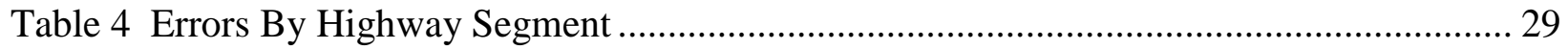

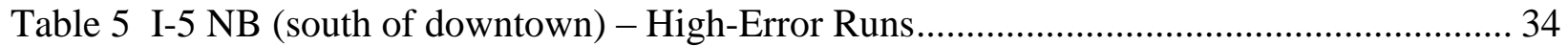

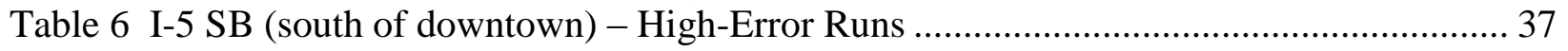

Table 7 I-5 NB (north of downtown) - High-Error Runs .................................................. 41

Table 8 I-5 SB (north of downtown) - High-Error Runs.................................................. 43

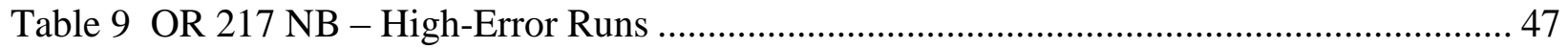

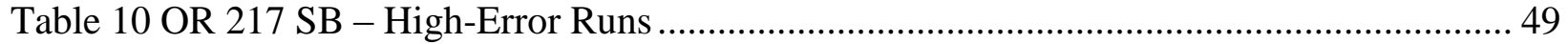

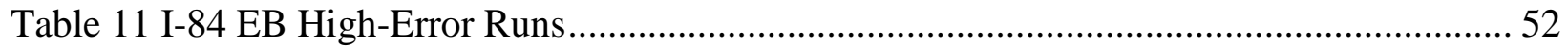

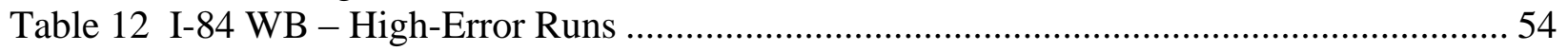

Table 13 U.S. 26 EB - High-Error Runs ....................................................................... 61

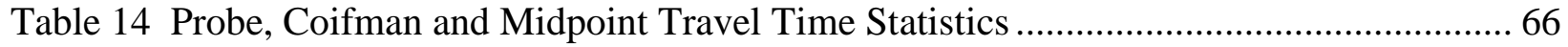

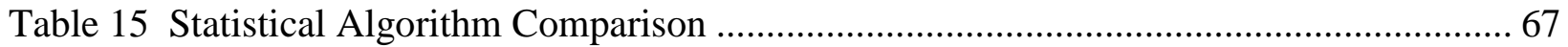

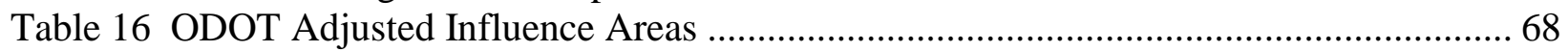

Table 17 Effect of Incidents on Error Rates .................................................................... 70 


\section{EXECUTIVE SUMMARY}

As part of the Advanced Traveler Information Systems (ATIS), ODOT provides travel times on three dynamic message signs (DMS) in the Portland, Oregon, metropolitan area. These travel times are estimated using speeds obtained from loop detectors. In the near future, ODOT wants to expand the coverage for travel time information by providing estimates through different media (e.g., DMS, Web, 511, etc.). Therefore, the goal of this project was to assess the accuracy of the algorithm in use, identify situations where the algorithm fails and propose refinements where applicable.

The methodology followed to assess the algorithm's accuracy involved comparing the travel time estimates from loop detector data with the ground truth travel times over selected freeway segments. The ground truth travel times were collected by probe vehicles during morning and afternoon peak periods on various days from December 21, 2006, through May 1, 2007. A total of 544 runs, representing approximately 160 hours of driving, were collected and analyzed. The data is stored in the PORTAL database [3] and is available to other researchers. This report provides a combined error analysis of all runs as well as detailed segment-by-segment analysis with specific conclusions and recommendations for each segment. The analysis includes statistical analysis as well as graphical analysis of high-error runs.

The project has reached the following conclusions and results:

- The overall average absolute error is relatively good; $11.4 \%$ over all runs combined. Standard deviation of percent error, another common metric of travel time accuracy, is $17.8 \%$. In addition, there is not a statistically significant over- or underestimation bias in the estimates for all runs combined (some individual segments did show biases).

- Detector infrastructure is an important issue in the Portland metropolitan region. The loop detectors in the Portland-area freeway system were installed for the purpose of ramp metering and placed just upstream of on-ramps. This placement leads to high detector spacing on certain freeway sections. Detector failures exacerbated the detector spacing issues; $50 \%$ of the ground truth travel time runs collected had at least one station not functioning during the run. This number does not indicate that $50 \%$ of the detectors were not functioning during the ground truth runs.

- Specific recommendations are provided on a segment-by-segment basis of freeway sections wherein additional detection should be considered. In addition, ODOT may wish to consider some type of portable low-cost detection to address medium-term detector outages such as those due to construction.

- Freeway geometry should be taken into account when implementing travel time estimation. A "one-size-fits-all" definition of influence areas may not be appropriate; incorporating knowledge of the physical characteristics of the freeways into influence area definition appears promising in improving travel time accuracy. 
Several travel time estimation algorithms have been compared, with limited differences observed between the accuracy of the algorithms.

- Analysis demonstrates that there is not a specific level of congestion at which travel time estimation breaks down; however, understanding the conditions in which travel time algorithms are less accurate is important. This project has received additional funding from the Oregon Transportation Research and Education Consortium (OTREC) and will use that funding to study this issue in depth.

The segment-by-segment analysis shows that error rates as well as detector infrastructure vary significantly from freeway segment to freeway segment. The analysis identified several areas of high detector spacing and high congestion that contributed to significant estimation error. These areas included the Terwilliger Curves on Interstate 5 NB and the OR 217 - I-5 SB merge section of I-5 SB. Additionally, several freeways in the Portland area, including U.S. 26 and I-84, have very large (greater than two-mile) detector spacing in areas of high and complex congestion. Provision of travel times on these highways is not recommended without additional detection and analysis.

In summary, the project has produced a large collection of ground truth travel time data which was critical to the conclusions reached by this project and which will be valuable to other researchers studying traffic in the Portland metropolitan region. The project has analyzed the ground truth data for several algorithms and algorithmic adjustments and has begun to investigate the breakdown of travel time estimation accuracy. While the ODOT-funded portion of this project is complete, the project will continue over the next several months with funding from OTREC, building on this project's data collection and analysis efforts.

The rest of this report is organized as follows: Section 2 provides a project overview; Section 3 describes our investigation into other jurisdictions' practices for travel time estimation; Section 4 describes the data collection process; Section 5 provides combined and segment-by-segment analysis of the current algorithm; Section 6 discusses alternative algorithms, algorithmic adjustments and break down of travel time estimation accuracy; and Section 7 provides the conclusion. 


\subsection{PROJECT OVERVIEW}

In recent years, state transportation agencies have tried to provide travel time estimates to the public as a part of Advanced Traveler Information Systems (ATIS) so the public can make informed choices about travel. By providing relevant travel information, including current traffic conditions, ATIS seeks to improve the transportation system's quality and efficiency. The Federal Highway Administration (FHWA) issued a memorandum in 2004 recommending that states utilize their existing DMS infrastructure to provide travel time information to the public [2]. ODOT currently displays travel time estimates on three DMS in the Portland metropolitan area. In the near future, ODOT would like to make travel time estimates available over the Internet on tripcheck.com and via 511.

The primary goal of this project was to determine the best approach for ODOT to estimate travel times for use on DMS signs, 511 and tripcheck.com. In addition to recommending a methodology, a crucial component of this project was to provide confidence in the estimates provided by the methodology. To that end, travel time estimates were verified using ground truth data. In addition, the project aimed to provide statistical analysis so that algorithm performance is understood under different conditions (e.g., free-flow, congestion, incidents); and to develop a method for determining when travel times are accurate enough to be posted.

\subsection{BACKGROUND}

Currently, there are 18 variable message signs present along the various highways in the Portland area. Three of these signs are configured to display travel times. ODOT wants to provide travel time estimates on additional DMS as well as through the Web (www.tripcheck.com) and 511. Currently, ODOT uses the standard midpoint algorithm to generate travel time estimates from loop detector data. There are about 600 double-loop detectors embedded under the freeways in the Portland area. These loop detectors report count, occupancy and speed every 20 seconds. This data is received in real time by the ODOT Traffic Management Operations Center (TMOC). The TMOC processes this data to generate travel time estimates. The midpoint algorithm that generates travel time estimates is a simple algorithm that uses speeds measured at the detectors and the spacing between the detectors. A key feature of the midpoint algorithm is the use of influence areas. An influence area is an area around each detector station both upstream and downstream over which the detector's influence is present. An example of influence areas is shown in Figure 1.

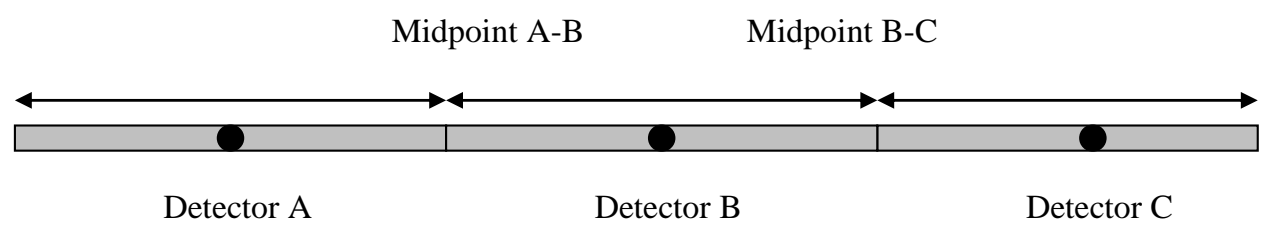

Figure 1 Midpoint Influence Areas

Each link is divided into a number of small segments based on influence areas; travel time for each segment is obtained by dividing distance by speed. Past research has indicated that the midpoint algorithm works well under free-flow conditions but tends to underestimate travel time 
under congested conditions. Travel time estimates provided to the public need to be accurate and reliable. Therefore, the aim of this project was to evaluate and identify an optimal algorithm that can generate accurate real-time travel time estimates under all traffic conditions. 


\subsection{INVESTIGATION OF OTHER PRACTICES ACROSS NORTH AMERICA}

As a part of the ITS infrastructure, most states have invested in Advanced Traveler Information Systems (ATIS). These systems aim to provide commuters, shippers and travelers with reliable travel time estimates so that highway congestion is alleviated and unexpected variation in travel times are reduced. Current traffic conditions and travel times are provided through the Internet, via phone (511) and through DMS. A review of literature indicates that not all states provide real-time travel time estimates. The provision of travel time estimates seems to be currently confined to medium and large metropolitan areas. The following sections present a brief overview of the data collection approaches and methodologies different cities use to generate travel times.

\subsection{DATA COLLECTION APPROACHES}

How to collect data is one of the important decisions jurisdictions face before they start providing travel times. A review of the data collection approaches nationwide and in Toronto, Ontario, Canada, reveals four main options. These include fixed detection of volume and occupancy, fixed detection of speed, direct travel times and other proprietary approaches (3). The fixed detection of volume and occupancy requires a vast network of sensors, which in turn require a lot of capital investment as well as regular maintenance. The volume and occupancy measurements are generally provided by loop detectors or radar sensors. The fixed detection of speed allows for gathering of speed data, which can be used for travel time calculations. This data is also often collected through loop detectors or radar sensors. A third approach to collecting travel times directly includes automatic toll tag readers, which record the passage time of a vehicle carrying a toll tag. This method is employed in areas that have toll facilities and an automatic toll collection program. The main feature in this approach is the need for toll readers, which are generally placed on the side of the highway. This approach enables the direct collection of travel times; accuracy increases with greater toll reader density. Finally, another approach is to fuse the data derived from different sources such as fixed sensors, probe vehicles, cellular phones, etc., to derive travel times. This approach is generally followed by private vendors who often use proprietary algorithms and data fusion techniques to derive travel times. Some areas have outsourced the generation of travel times to these private vendors (e.g., Inrix, Traffic.com).

\subsection{METHODOLOGIES FOR THE PROVISION OF TRAVEL TIMES}

Several areas provide travel time information or plan to provide such information. For those that seek to provide such information, a review of other jurisdictions' practices will be beneficial when deploying their systems. 


\subsubsection{Milwaukee}

The Wisconsin Department of Transportation (WisDOT) maintains and operates a traffic operations center in Milwaukee. As of 2005, the infrastructure consisted of 36 DMS and 100 cameras on freeways and major arterials and 125 ramp meters. WisDOT began generating travel time estimates in 1995 using existing loop detectors. Over the years, WisDOT has consistently tested these estimates for reliability and accuracy. Travel times are calculated using speeds from loop detectors embedded in the pavement. The urban areas are characterized by high detector density ( 0.25 mile spacing), whereas the rural areas have lower density ( 2 miles). Speeds from the embedded loop detectors are transmitted to the traffic operations center where the freeway traffic management system (FTMS) calculates travel times as a ratio of distance to speed. These travel time estimates are then posted to the DMS and are also available through the Internet. A snapshot of the travel times posted on the Web is shown in Figure 2.

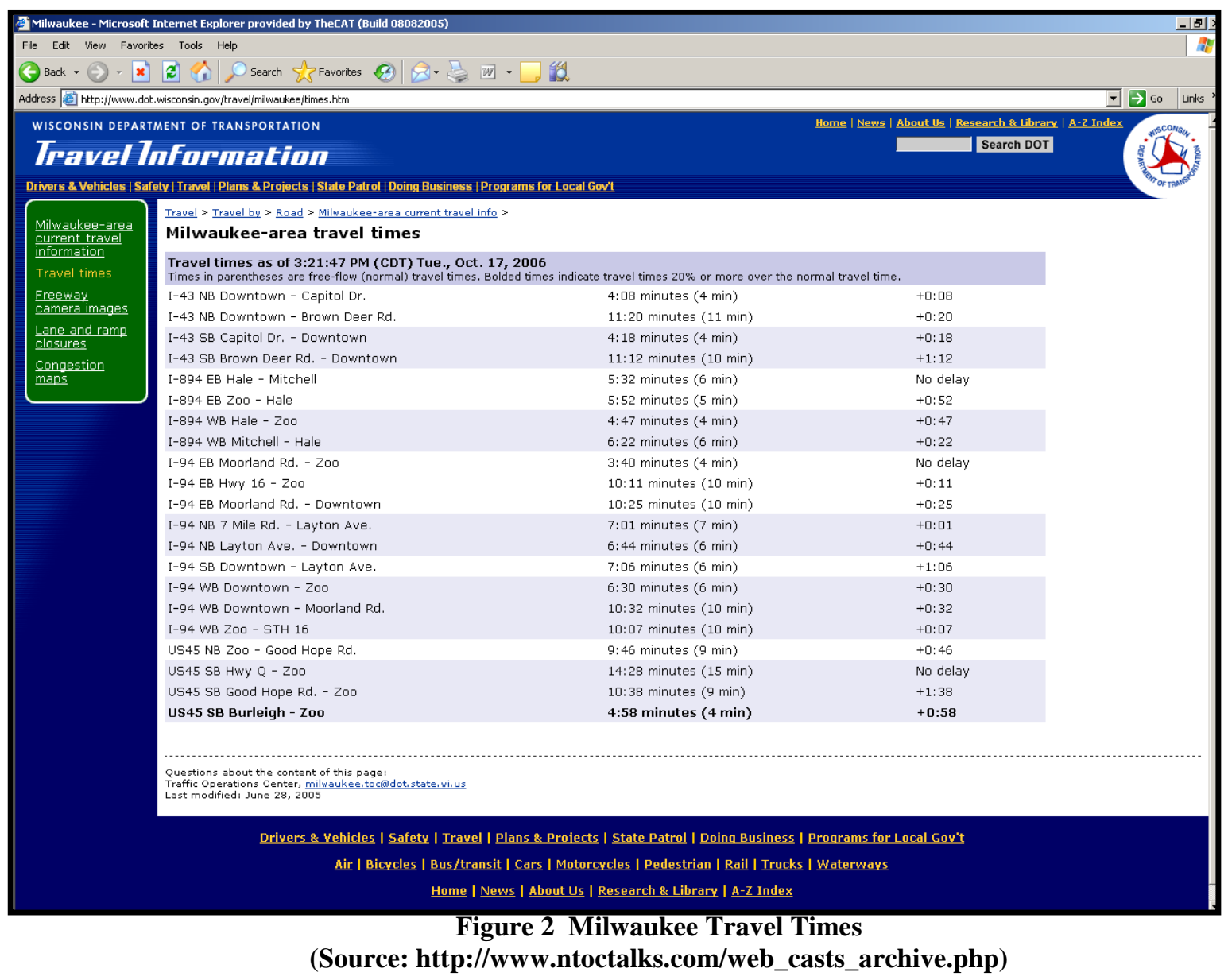

The DMS are updated every minute, whereas the Website is updated every 3 minutes. To maintain accuracy, if more than $33 \%$ of the segments for a link are invalid, travel times for that link are not displayed. Additionally, if the FTMS server is not working properly, the software removes online and DMS travel time estimates within 10 minutes. 


\subsubsection{San Antonio}

Between 1997 and 1999, the TransGuide program in San Antonio started creating a database of travel speeds that were obtained in real time from the freeway system. The automated display of travel times on the DMS was implemented in 1999. These travel times are generally calculated from the DMS signs to major intersections/interchanges. Travel times are displayed on the DMS signs from 6 a.m. - 10 p.m., seven days a week. A snapshot of travel times as displayed on the Web is shown in Figure 3.

\begin{tabular}{|c|c|c|c|c|c|}
\hline 7) & \begin{tabular}{l|l|l|l|l|l|} 
Tratilic Conditions & Travel Times \\
Common Travel Times & Pers \\
Dynamic Route Builder & Indiv \\
Current Sign Display
\end{tabular} & \multirow[t]{2}{*}{$\begin{array}{l}\text { te Selector } \\
\text { Wway Pages }\end{array}$} & & & \\
\hline Highway & Starting Point & & Distance & $\begin{array}{c}\text { Segment } \\
\text { Travel Time }\end{array}$ & $\begin{array}{c}\text { Average } \\
\text { Speed (MPH) }\end{array}$ \\
\hline \multirow{4}{*}{ IH 10 Eastbound } & Loop 1604 & Loop 410 & $7.0 \mathrm{mi}$ & $6^{1 / 2} \min$. & $>60$ \\
\hline & Loop 1604 & I 35 Interchange North of Downtown & $13.2 \mathrm{mi}$ & $13 \min$. & $>60$ \\
\hline & Loop 410 & I 35 Interchange North of Downtown & $6.2 \mathrm{mi}$ & No data & No data \\
\hline & Huebner & Hildebrand & $6.7 \mathrm{mi}$. & $6^{1 / 2} \min$. & $>60$ \\
\hline & IH 35 Interchange North of Downtown & Loop 410 & $6.2 \mathrm{mi}$ & $6^{1 / 2} \min$. & $>60$ \\
\hline & Loop 410 & Wurzbach & $2.3 \mathrm{mi}$. & $2 \min$. & $>60$ \\
\hline H 10 Westbound & Loop 410 & Loop 1604 & $7.0 \mathrm{mi}$ & $6^{1 / 2} \min$. & $>60$ \\
\hline & Hildebrand & Huebner & $6.9 \mathrm{mi}$. & $6 \min$. & $>60$ \\
\hline & IH 35 Interchange North of Downtown & Loop 1604 & $13.2 \mathrm{mi}$. & $13 \mathrm{~min}$. & $>60$ \\
\hline & Perrin Beitel & US 281 & $4.5 \mathrm{mi}$. & $4 \frac{4}{\min }$. & $>60$ \\
\hline P 410 Westhound & US 281 & IH 10 & $4.5 \mathrm{mi}$. & Construction & No data \\
\hline 410 vestovemin & IH 10 & Bandera & $3.6 \mathrm{mi}$. & $3^{1 / 2} \min$. & $>60$ \\
\hline & Perrin Beitel & Bandera & $8.1 \mathrm{mi}$ & Construction & No data \\
\hline & Bandera & IH 10 & $3.6 \mathrm{mi}$. & $4 \min$. & $>60$ \\
\hline & IH 10 & US 281 & $4.5 \mathrm{mi}$. & Construction & No data \\
\hline LP 410 Eastbound & US 281 & Perrin Beitel & $4.5 \mathrm{mi}$. & $4 \frac{4}{\min }$. & $>60$ \\
\hline & Bandera & Perrin Beitel & $9.0 \mathrm{mi}$ & Construction & No data \\
\hline & IH 10 & Perrin Beitel & $9.0 \mathrm{mi}$ & Construction & No data \\
\hline & US 181 & LP 410 South & $1.5 \mathrm{mi}$. & $1 \frac{1}{2} \min$. & $>60$ \\
\hline & LP 410 South & IH 10 & $6.3 \mathrm{mi}$. & $6 \min$. & $>60$ \\
\hline 37 / US 281 North & LP 410 South & IH 35 & $9.4 \mathrm{mi}$ & $9 \min$. & $>60$ \\
\hline 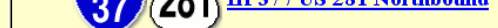 & SE Military & IH 10 & $4.5 \mathrm{mi}$. & $4 \frac{4}{\min }$. & $>60$ \\
\hline & IH 10 & IH 35 & $3.2 \mathrm{mi}$ & $3 \frac{1}{2} \min$. & $>60$ \\
\hline & IH 35 & Basse & $3.2 \mathrm{mi}$ & No data & No data \\
\hline & Basse & IH 35 & $4.1 \mathrm{mi}$ & No data & No data \\
\hline & IH 35 & IH 10 & $3.1 \mathrm{mi}$ & $3 \min$. & $>60$ \\
\hline $1<0$ & IH 35 & LP 410 South & $9.1 \mathrm{mi}$. & $8^{1 / 2} / 2 \min$. & $>60$ \\
\hline
\end{tabular}

Figure 3 San Antonio Travel Times

(Source: http://www.transguide.dot.state.tx.us/TravelTimes/commontimes.php)

Travel speeds are obtained from loop detectors and video detectors. These speeds are used to calculate travel times based on the ratio of distance between the detectors to the speeds obtained from the detectors. These travel time estimates are verified for accuracy and the test runs indicate that $85 \%$ of drivers arrive within the predicted time range.

\subsubsection{Houston}

Traveler information in Houston is disseminated through the Internet, DMS, HAR and the local media by Transtar, a partnership of the stakeholders involved with ITS in Houston. Transtar began posting travel times onto the DMS in 1996 and currently posts travel times on approximately 81 DMS located throughout Houston's freeways. Travel times are posted on the DMS between 5:30 a.m. and 7:30 p.m. every day and are updated approximately every 10 minutes. Travel times are collected by vehicles equipped with transponder tags as part of the automatic toll collection system. Transponder tag readers are placed along freeways and are spaced one to five miles apart. These readers are shown in Figure 4. 


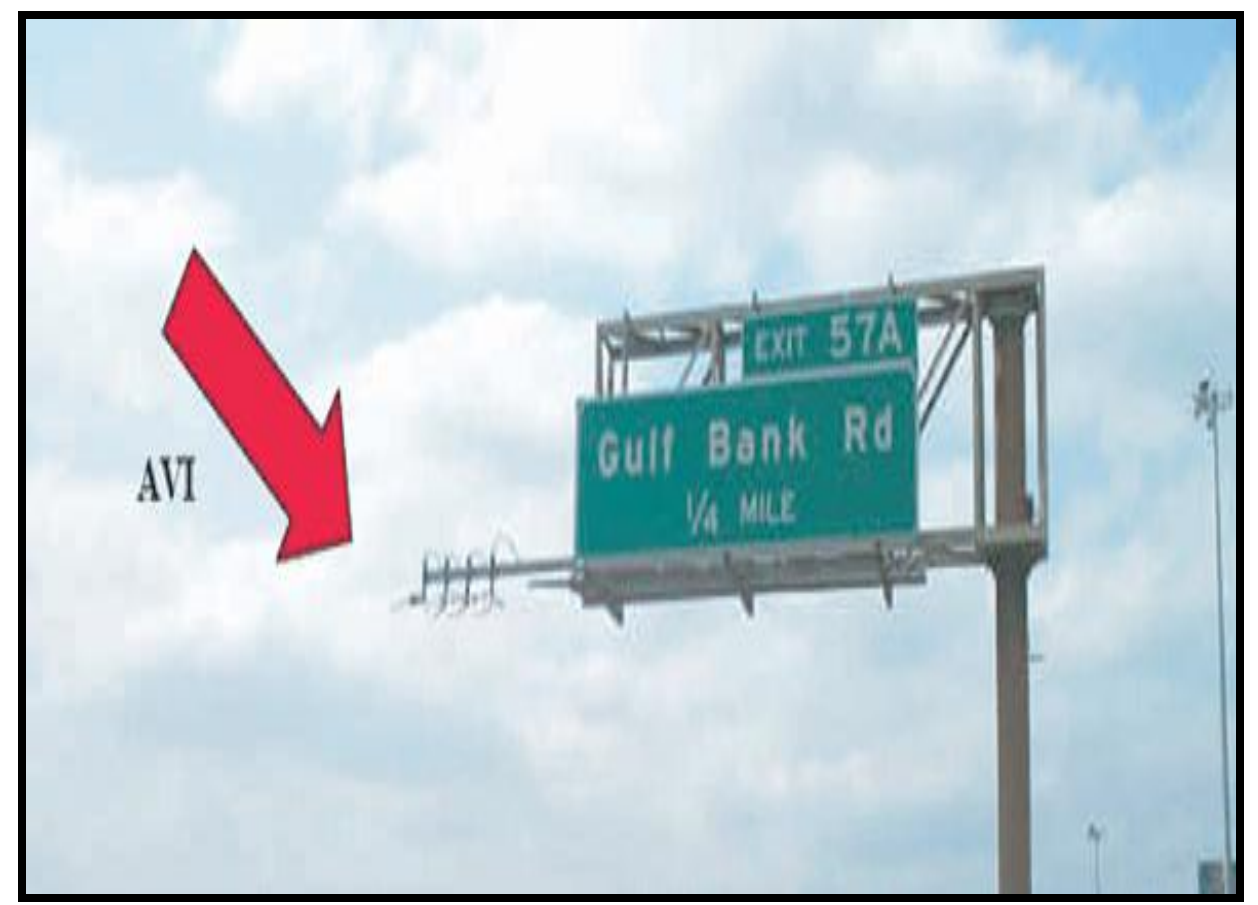

Figure 4 Automatic Vehicle Identification (AVI) Readers

(Source: http://www.ops.fhwa.dot.gov/publications/travel_time_study/houston/houston_ttm.htm)

Each Automatic Vehicle Identification (AVI) reader records the time and location of the probe vehicles as they pass and transmits this information to a central computer. Average travel times and speeds are calculated by the software and automatically updated on the Internet and the DMS. The travel time software used by Transtar enables a vehicle to be tracked as it passes along the freeways, but removes all personal information so that vehicles cannot be identified.

\subsubsection{Nashville}

As of 2005, travel times are posted on two of the 20 DMS in the Nashville area. Travel time messages are posted at all times on the DMS unless incidents need to be reported. Radar-based speed sensors (RTMS) are used to collect speeds. These sensors are placed every quarter mile and transmit average speeds to the traffic management center (TMC) every 2 minutes. Travel times are calculated based on the ratio of distance between the sensors to the speed obtained from the sensor. These times are calculated by the software at the TMC and are automatically posted to the DMS. 


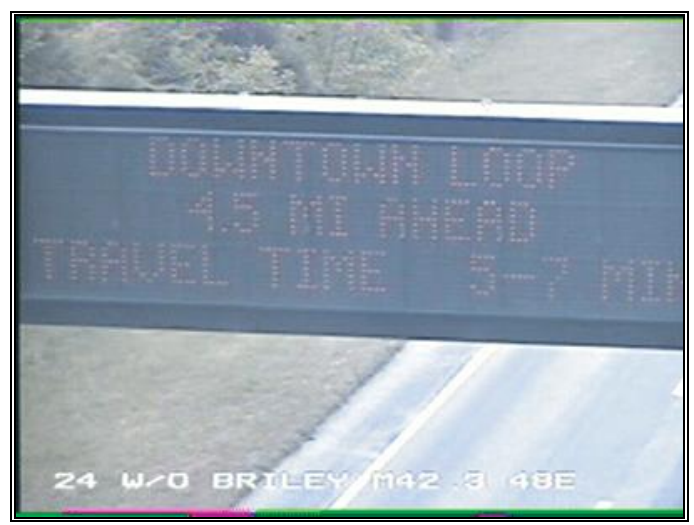

Figure 5 Travel Times on DMS Signs

(Source: http://www.ops.fhwa.dot.gov/publications/travel_time_study/nashville/nashville_ttm.htm)

Travel time estimates provided by the Tennessee Department of Transportation (TDOT) are in ranges of 2-3 minutes. Closed circuit television (CCTV) cameras are used by TDOT to verify the accuracy of the travel time estimates.

\subsubsection{Chicago}

The Illinois State Highway Toll Authority (ISTHA) provides real-time information to commuters in the northern Illinois area. Travel time estimates are available on the Web and also posted on DMS located on the freeways. The Traffic and Incident Management System (TIMS) traffic operations center manages the software that automatically posts the travel times onto the DMS. The travel time system used by ISTHA divides the freeway into segments. Three sources of data are used by the travel time software to generate travel time estimates - I-PASS readers at toll plazas, RTMS data and loop detector data. Average travel times are provided from one toll plaza to the next based on I-PASS toll transponder data. The electronic toll collection system has more than one million users and therefore the large numbers of users provide the tollway authority with probe-based average travel times. Additionally, RTMS sensors are present along the tollway, providing additional data that aid in travel time calculations. The Illinois Department of Transportation also maintains a loop detector network, and speeds from the loop detectors are used to calculate travel time estimates for links that connect to the toll facilities. Depending on the link, some or all of the data sources are used to estimate travel times. A map showing estimated travel times is shown in Figure 6. 


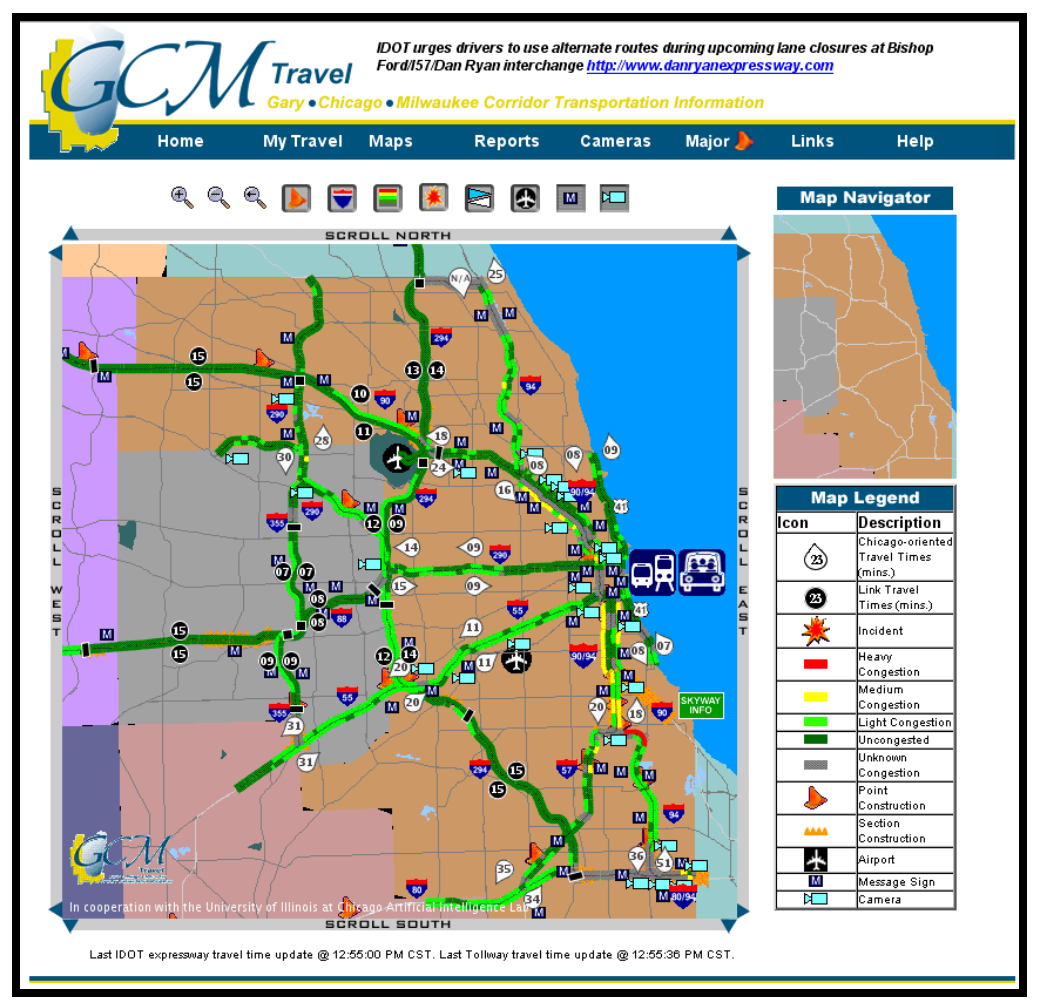

Figure 6 Map showing estimated travel times for Chicago

(Source: http://www.gcmtravel.com/gcm/maps_chicago.jsp)

There is a slight difference in the travel times provided online and those posted on DMS. For toll roads, owing to restrictions, only travel times calculated from I-PASS transponder data are available online, whereas the DMS contains travel times calculated from transponder data as well as RTMS data.

\subsubsection{Atlanta}

The TMC in Atlanta generates travel time estimates. The monitoring and Video Detection System (VDS) cameras are the main sources of real-time traffic conditions data. VDS is comprised of fixed black-and-white cameras placed along major freeways. These cameras report speeds and volumes to the TMC and the software at the TMC generates travel time estimates from this data. These travel time estimates are provided on DMS as well as on the Web. Figure 7 shows a snapshot of travel times as reported online. 


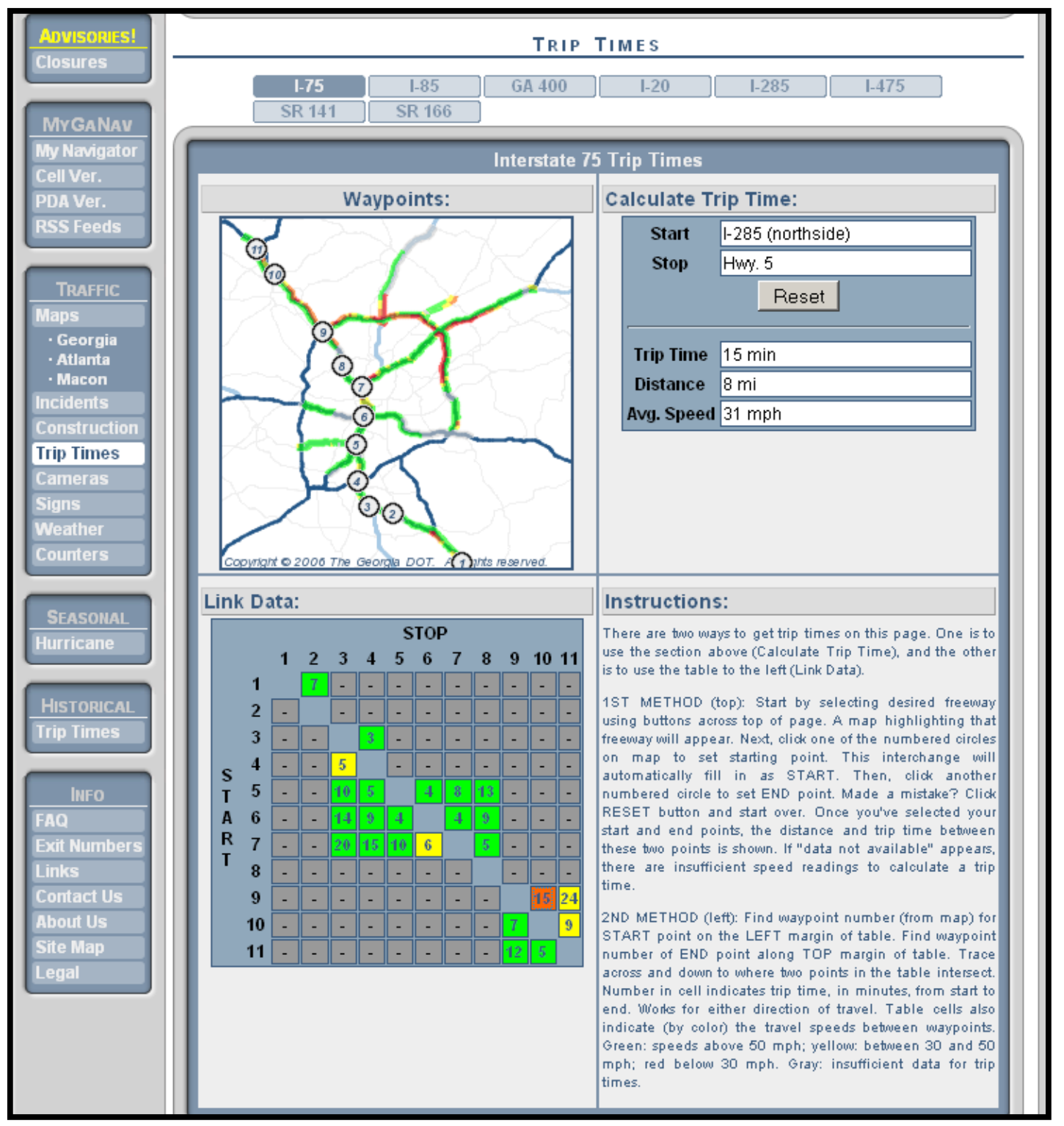

Figure 7 Atlanta Travel Times on the Web (Source: http://www.georgia-navigator.com/trips)

Travel time estimates for a link are calculated from average speeds over that link recorded by the cameras. The DMS report travel times between major points along the freeway system. These travel time estimates on the DMS are provided between 6 a.m. and 9 p.m.

\subsubsection{San Francisco - Bay Area}

Travel times in the San Francisco-Bay Area are available online or via phone through the 511 system. These travel times are estimated using the existing Caltrans data collection system along with the new data collection system with FasTrak ${ }^{\mathrm{TM}}$. Figure 8 shows the travel times as available on the Web. 


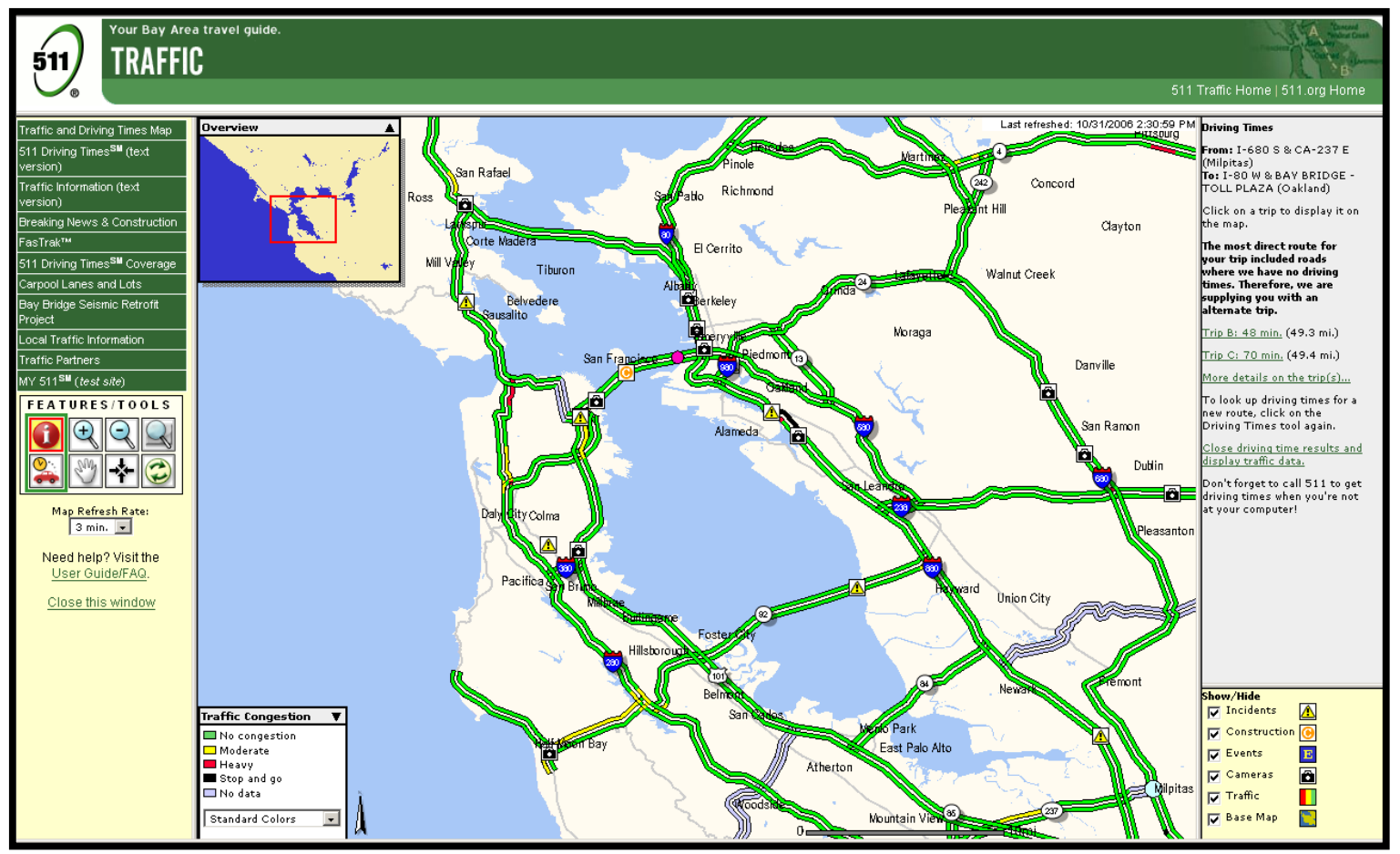

Figure 8 San Francisco - Bay Area Travel Times

(Source: traffic.511.org)

The Caltrans data collection system consists of loop detectors that report speeds. The new data collection system consists of antennas placed over the freeways to read FasTrak ${ }^{\mathrm{TM}}$ toll tags. The system tracks vehicles with toll tags as they pass over the freeways and records a travel time for each vehicle. The travel times and speeds are averaged across all vehicles to obtain average travel times and speeds.

\subsubsection{Seattle}

Travel times in Seattle are estimated using occupancy measurements from single loop detectors spaced $0.25-0.5$ miles apart. The speeds and segment lengths are used to estimate travel times for different links. These current status travel times are compared to the historical travel times and are adjusted if the historical travel times report a higher value. Figure 9 shows Seattle travel times posted on the Web. 


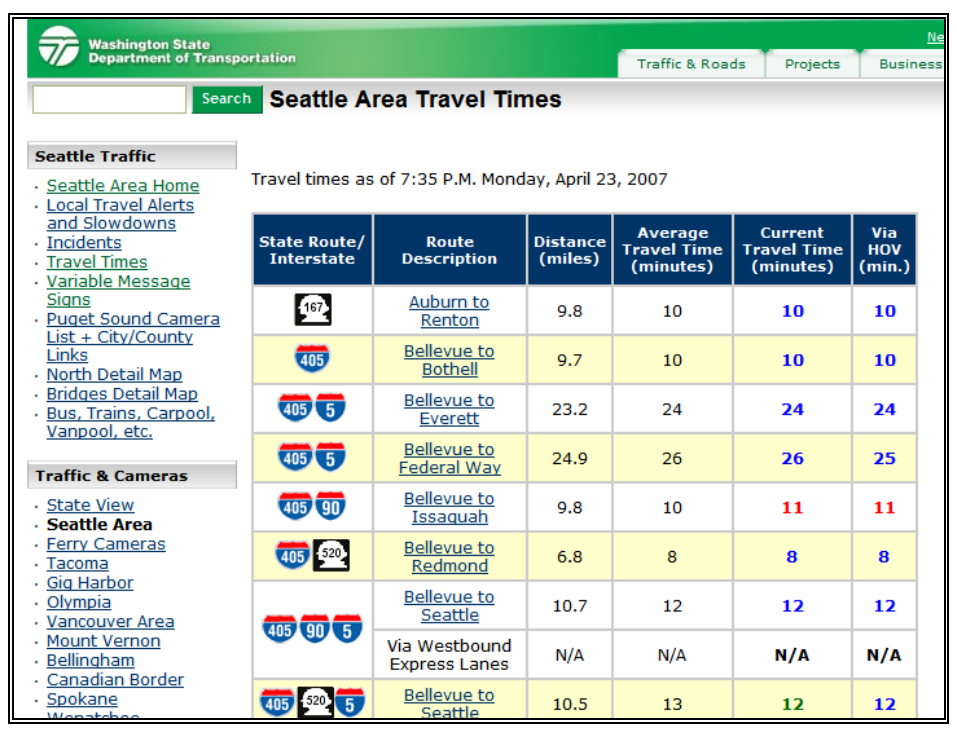

Figure 9 Seattle Travel Times on the Web

(Source: http://www.wsdot.wa.gov/traffic/seattle/traveltimes)

These travel times are disseminated through DMS as well as the Web and are updated approximately every 2 minutes. The performance of the algorithm is checked through cameras as well as customer feedback. Tests show accuracy greater than $90 \%$.

\subsubsection{Minneapolis - St. Paul}

Travel times in the Twin Cities are estimated based on speeds, which are calculated from volume and occupancy measurements from single loop detectors spaced approximately 0.5 miles apart. A modified midpoint algorithm is used to estimate travel times based on calculated speeds. These travel times are reported on DMS, and software developed by the Minnesota DOT's TMC is used to control the signs and post messages. Figure 10 shows the sample travel times for the Twin Cities. 


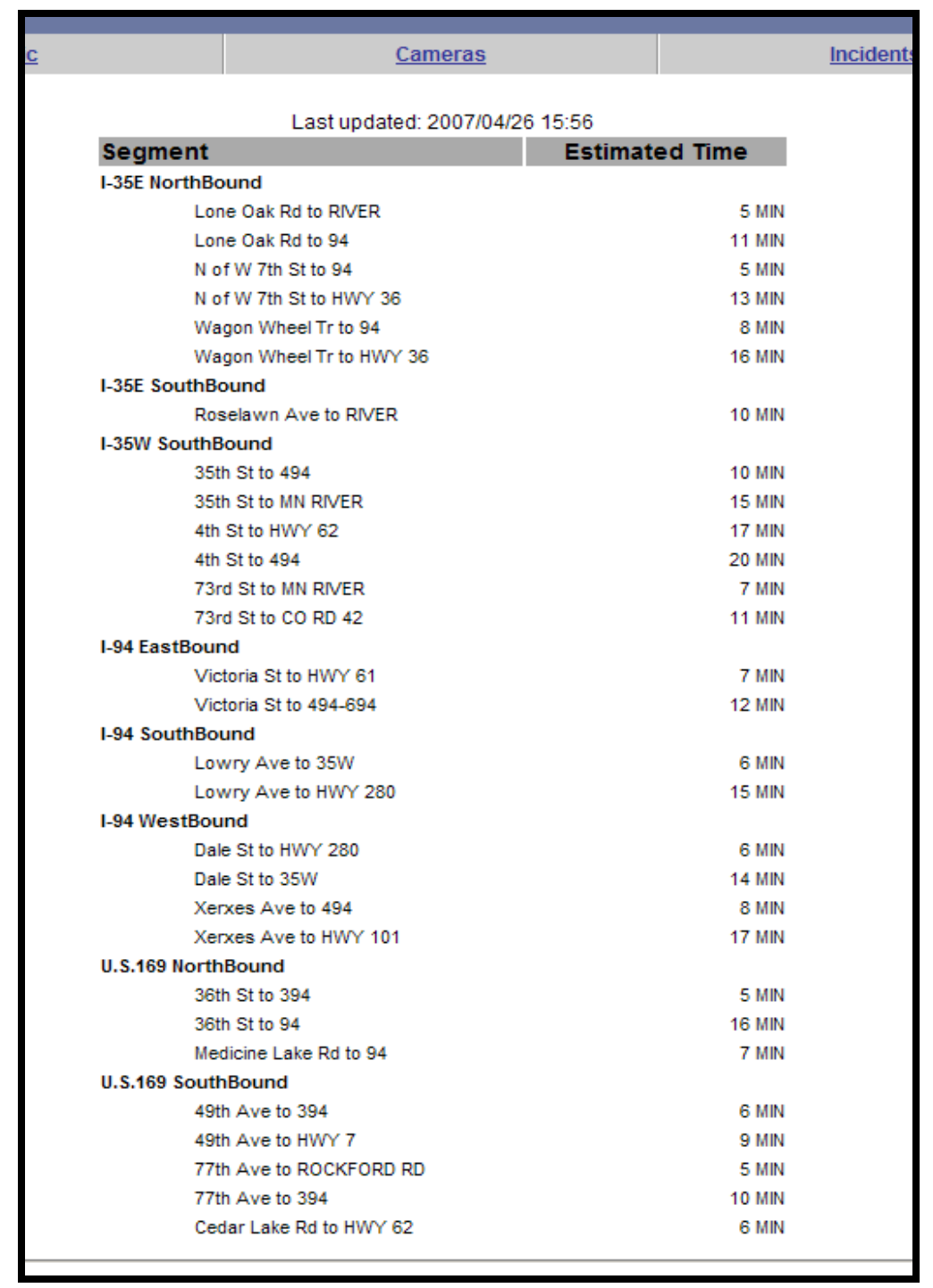

Figure 10 Travel Times for Twin Cities

(Source: http://www.dot.state.mn.us/tmc/trafficinfo/traveltime.html)

Estimated travel times have been found accurate most of the time, except when traffic conditions change. The DOT has encountered favorable public and media response to the posting of travel times.

\subsubsection{Toronto}

Loop detectors placed every one-third mile in Toronto provide speeds that are used to calculate travel times. The initial travel time algorithm employed to generate times used distance over speed to compute time. Due to large errors in estimation, a more complex algorithm was developed which incorporated queue formation and dissipation and time of day. Travel times are displayed on the DMS in ranges of times. When travel times exceed 40 minutes, the DMS does not display travel times; instead, the message "stop and go conditions" is displayed. Public reaction has been positive to the display of travel times, which have been accurate. More research is being conducted to display travel times on arterials. 


\subsubsection{Summary}

The increase in congestion has made the provision of traveler information and, in particular, travel times essential. A review of the methodologies followed by different jurisdictions around the North America indicates that they use two main approaches to generate travel times: in-house or outsourced to a private vendor. Different data collection approaches are followed by different jurisdictions - loop detectors, RTMS and AVI toll tag transponders/readers. Most areas that calculate travel time in-house use the midpoint algorithm. Areas that outsource the generation of travel times to private contractors use contractor-developed proprietary algorithms.

In general, the provision of travel times has evoked an almost universal positive public response. Most jurisdictions that provide travel times maintain high standards of data quality by periodic accuracy checks. Therefore, areas that have not yet provided travel times to the public should be encouraged to provide them, while placing special emphasis on accuracy. 


\subsection{DATA COLLECTION}

\subsection{INTRODUCTION}

The focus of this study was to evaluate and attempt to improve travel time estimation algorithms for the freeway network in the Portland metropolitan region. Evaluating the accuracy of travel time estimation algorithms requires ground truth data, which is compared with travel time estimates to determine the accuracy of those estimates. While some ground truth data was available from a previous Portland State University (PSU) project 7.0, the technical advisory committee and the research team felt that additional data was required to validate travel time estimates for Portland freeways. This analysis used the data collected during this project and, when feasible, applicable data from the previous project.

\subsection{COLLECTION STRATEGY}

Data collection was conducted in three phases. The first was designed to be a very short investigatory phase to assess the viability of the collection process and the hardware and software to be used. The second phase focused on two or three freeway corridors. By focusing on a limited number of corridors, the goal was to ensure that an adequate number of runs were available on those corridors. It was anticipated that collecting enough runs for statistically significant analysis of the entire freeway network may be difficult due to budget constraints. Also, initially focusing on a few corridors allowed the research team to fine-tune the data collection and analysis procedures. Lessons learned from the initial collection and analysis were applied to the final phase.

\subsection{METHODOLOGY AND TECHNOLOGY}

Ground truth data was collected by local firms. For the first phase of data collection, data was collected using Garmin iQue units owned by PSU's Intelligent Transportation Systems (ITS) Lab. The Garmin iQues are PDA devices with embedded GPS support. The ITS Lab has developed software for such PDA units that is specifically designed for travel time data collection. This software is publicly available from the ITS Lab. 


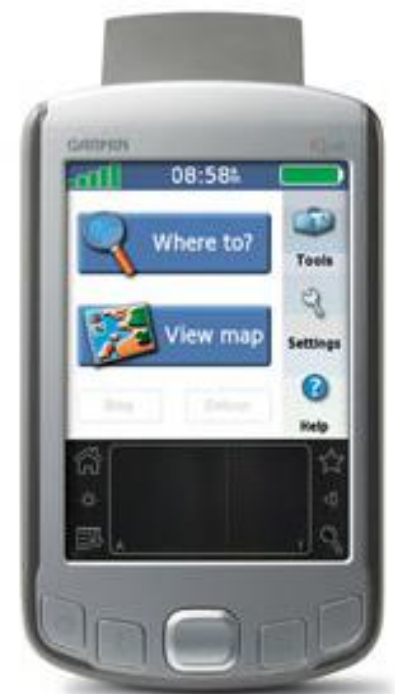

Figure 11 Garmin iQue®

The probe data collected by the iQues and PSU software provides a variety of information useful for travel time analysis. Every 3 seconds, the iQue software records the date, time, elapsed time, location (latitude, longitude) and speed of the probe vehicle. This data is provided in a comma-separated-value file that can be used for analysis or easily converted into GIS files readable by programs such as ArcGIS. A sample file is

\begin{tabular}{|c|c|c|c|c|c|c|c|c|c|c|}
\hline \multicolumn{11}{|c|}{ I Microsoft Excel - 01-04-07kwork01.itsg } \\
\hline \multicolumn{11}{|c|}{ 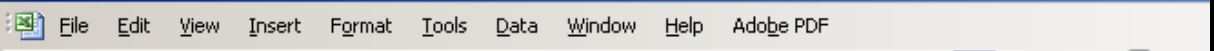 } \\
\hline \multirow{2}{*}{\multicolumn{11}{|c|}{ 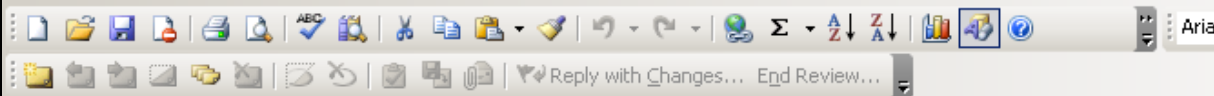 }} \\
\hline & & & & & & & & & & \\
\hline \multicolumn{11}{|c|}{ N52 $\rightarrow \quad f_{x} 0$} \\
\hline & $\mathrm{A}$ & $\mathrm{B}$ & $\mathrm{C}$ & $\mathrm{D}$ & $E$ & $\mathrm{~F}$ & G & $\mathrm{H}$ & 1 & $J$ \\
\hline 1 & date & time & elapsedTii & latitude & longitude & error & speed & alt & $\operatorname{cont} A$ & contB \\
\hline 2 & $1 / 4 / 2007$ & $09: 18: 54$ & 0 & 45.50393 & -122.674 & 27.05 & 0 & none & none & none \\
\hline 3 & $1 / 4 / 2007$ & $09: 26: 06$ & 432 & 45.39263 & -122.689 & 33.92894 & 0 & none & none & none \\
\hline 4 & $1 / 4 / 2007$ & $09: 26: 08$ & 434 & 45.39268 & -122.689 & 17.27733 & 11.96214 & none & none & none \\
\hline 5 & $1 / 4 / 2007$ & $09: 26: 11$ & 437 & 45.39275 & -122.69 & 16.16839 & 6.560515 & none & none & none \\
\hline 6 & $1 / 4 / 2007$ & $09: 26: 14$ & 440 & 45.39279 & -122.69 & 16.16849 & 3.674484 & none & none & none \\
\hline 7 & $1 / 4 / 2007$ & $09: 26: 17$ & 443 & 45.39284 & -122.69 & 16.28199 & 3.851036 & none & none & none \\
\hline 8 & $1 / 4 / 2007$ & $09: 26: 20$ & 446 & 45.39288 & -122.69 & 16.28199 & 3.851036 & none & none & none \\
\hline 9 & $1 / 4 / 2007$ & $09: 26: 23$ & 449 & 45.39305 & -122.69 & 16.17323 & 7.350757 & none & none & none \\
\hline 10 & $1 / 4 / 2007$ & $09: 26: 26$ & 452 & 45.39309 & -122.69 & 16.63563 & 7.649557 & none & none & none \\
\hline 11 & $1 / 4 / 2007$ & $09: 26: 29$ & 455 & 45.39293 & -122.69 & 17.30137 & 7.056112 & none & none & none \\
\hline 12 & $1 / 4 / 2007$ & $09: 26: 32$ & 458 & 45.39274 & -122.691 & 17.30137 & 7.056112 & none & none & none \\
\hline 13 & $1 / 4 / 2007$ & $09: 26: 35$ & 461 & 45.39253 & -122.691 & 20.74569 & 9.556489 & none & none & none \\
\hline 14 & $1 / 4 / 2007$ & $09: 26: 38$ & 464 & 45.39228 & -122.691 & 20.74569 & 9.556489 & none & none & none \\
\hline 15 & $1 / 4 / 2007$ & $09: 26: 41$ & 467 & 45.39202 & -122.691 & 20.74569 & 9.556489 & none & none & none \\
\hline 16 & $1 / 4 / 2007$ & $09: 26: 44$ & 470 & 45.39164 & -122.691 & 22.90032 & 20.19727 & none & none & none \\
\hline 17 & $1 / 4 / 2007$ & $09: 26: 47$ & 473 & 45.39111 & -122.691 & 17.32081 & 19.07734 & none & none & none \\
\hline 18 & $1 / 4 / 2007$ & $09: 26: 50$ & 476 & 45.3905 & -122.691 & 19.75206 & 19.59858 & none & none & none \\
\hline 19 & $1 / 4 / 2007$ & $09: 26: 53$ & 479 & 45.38998 & -122.691 & 19.74913 & 19.12151 & none & none & none \\
\hline 20 & $1 / 4 / 2007$ & $09: 26: 56$ & 482 & 45.38948 & -122.691 & 19.74913 & 19.12151 & none & none & none \\
\hline 21 & $1 / 4 / 2007$ & $09: 26: 59$ & 485 & 45.38898 & -122.691 & 19.74913 & 19.12151 & none & none & none \\
\hline 22 & $1 / 4 / 2007$ & $09: 27: 02$ & 488 & 45.38856 & -122.692 & 28.01889 & 18.39938 & none & none & none \\
\hline 23 & $1 / 4 / 2007$ & $09: 27: 05$ & 491 & 45.38822 & -122.692 & 30.23302 & 18.71399 & none & none & none \\
\hline
\end{tabular}

12. 


\begin{tabular}{|c|c|c|c|c|c|c|c|c|c|c|}
\hline \multicolumn{11}{|c|}{$\mathbb{Z}$ Microsoft Excel-01-04-07kwork01.itsg } \\
\hline 国 & File Édit & View Ins & Format & Iools & Wind & Help & be PL & & & \\
\hline \multicolumn{11}{|c|}{ 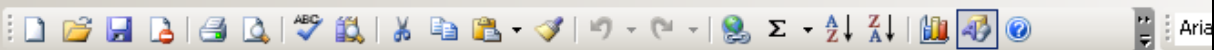 } \\
\hline \multirow{2}{*}{\multicolumn{11}{|c|}{ 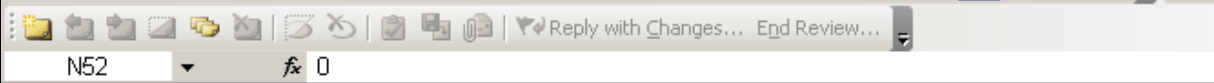 }} \\
\hline & & & & & & & & & & \\
\hline & A & $\mathrm{B}$ & C & D & $E$ & $\mathrm{~F}$ & G & $\mathrm{H}$ & I & $\mathrm{J}$ \\
\hline 1 & date & time & elapsedTil & latitude & longitude & error & speed & alt & $\operatorname{cont} \mathrm{A}$ & contB \\
\hline 2 & $1 / 4 / 2007$ & $09: 18: 54$ & 0 & 45.50393 & -122.674 & 27.05 & 0 & none & none & none \\
\hline 3 & $1 / 4 / 2007$ & $09: 26: 06$ & 432 & 45.39263 & -122.689 & 33.92894 & 0 & none & none & none \\
\hline 4 & $1 / 4 / 2007$ & $09: 26: 08$ & 434 & 45.39268 & -122.689 & 17.27733 & 11.96214 & none & none & none \\
\hline 5 & $1 / 4 / 2007$ & $09: 26: 11$ & 437 & 45.39275 & -122.69 & 16.16839 & 6.560515 & none & none & none \\
\hline 6 & $1 / 4 / 2007$ & $09: 26: 14$ & 440 & 45.39279 & -122.69 & 16.16849 & 3.674484 & none & none & none \\
\hline 7 & $1 / 4 / 2007$ & $09: 26: 17$ & 443 & 45.39284 & -122.69 & 16.28199 & 3.851036 & none & none & none \\
\hline 8 & $1 / 4 / 2007$ & $09: 26: 20$ & 446 & 45.39288 & -122.69 & 16.28199 & 3.851036 & none & none & none \\
\hline 9 & $1 / 4 / 2007$ & $09: 26: 23$ & 449 & 45.39305 & -122.69 & 16.17323 & 7.350757 & none & none & none \\
\hline 10 & $1 / 4 / 2007$ & $09: 26: 26$ & 452 & 45.39309 & -122.69 & 16.63563 & 7.649557 & none & none & none \\
\hline 11 & $1 / 4 / 2007$ & $09: 26: 29$ & 455 & 45.39293 & -122.69 & 17.30137 & 7.056112 & none & none & none \\
\hline 12 & $1 / 4 / 2007$ & $09: 26: 32$ & 458 & 45.39274 & -122.691 & 17.30137 & 7.056112 & none & none & none \\
\hline 13 & $1 / 4 / 2007$ & $09: 26: 35$ & 461 & 45.39253 & -122.691 & 20.74569 & 9.556489 & none & none & none \\
\hline 14 & $1 / 4 / 2007$ & $09: 26: 38$ & 464 & 45.39228 & -122.691 & 20.74569 & 9.556489 & none & none & none \\
\hline 15 & $1 / 4 / 2007$ & $09: 26: 41$ & 467 & 45.39202 & -122.691 & 20.74569 & 9.556489 & none & none & none \\
\hline 16 & $1 / 4 / 2007$ & $09: 26: 44$ & 470 & 45.39164 & -122.691 & 22.90032 & 20.19727 & none & none & none \\
\hline 17 & $1 / 4 / 2007$ & $09: 26: 47$ & 473 & 45.39111 & -122.691 & 17.32081 & 19.07734 & none & none & none \\
\hline 18 & $1 / 4 / 2007$ & $09: 26: 50$ & 476 & 45.3905 & -122.691 & 19.75206 & 19.59858 & none & none & none \\
\hline 19 & $1 / 4 / 2007$ & $09: 26: 53$ & 479 & 45.38998 & -122.691 & 19.74913 & 19.12151 & none & none & none \\
\hline 20 & $1 / 4 / 2007$ & $09: 26: 56$ & 482 & 45.38948 & -122.691 & 19.74913 & 19.12151 & none & none & none \\
\hline 21 & $1 / 4 / 2007$ & $09: 26: 59$ & 485 & 45.38898 & -122.691 & 19.74913 & 19.12151 & none & none & none \\
\hline 22 & $1 / 4 / 2007$ & $09: 27: 02$ & 488 & 45.38856 & -122.692 & 28.01889 & 18.39938 & none & none & none \\
\hline 23 & $1 / 4 / 2007$ & $09: 27: 05$ & 491 & 45.38822 & -122.692 & 30.23302 & 18.71399 & none & none & none \\
\hline
\end{tabular}

Figure 12 Raw Data from Garmin iQue ${ }^{\circledR}$

\subsection{DATA COLLECTION PLAN}

Collecting sufficient ground truth data was crucial to understanding algorithm performance. A plan was developed that helped to organize the collection effort. This included the number of runs desired on each corridor and the appropriate times to collect data on each corridor.

\subsubsection{Corridor Selection and Priority}

Corridor selection involved selecting which corridors to collect data during which phases and how many runs to collect on each corridor. Corridor selection was based on several considerations:

Level of interest: Level of interest in the corridor as indicated by the Technical Advisory Committee (TAC).

Location of existing DMS signs: Corridors with existing DMS signs were considered higher priority.

Detector coverage: Since detector density was suspected to affect algorithm accuracy, highway segments were prioritized based on the level of detector coverage. Highways with moderately spaced detectors were given priority, whereas highways with insufficiently spaced detectors were given lower priority. Insufficiently spaced detection was considered to be high (2-3 mile) spacing, particularly when such spacing occurred in areas of high congestion. 
Level of congestion: As travel time estimation in free flow is trivial, data collection was appropriate only in congested conditions and on congested freeway segments. Corridors with particularly high congestion were prioritized.

Construction: Data was not collected on freeway segments under construction.

\subsubsection{Number of Runs}

The Travel Time Data Collection Handbook [10] produced by the Federal Highway Administration (FHWA) and the Texas Transportation Institute provides a methodology for determining the required sample size for travel time evaluations. This methodology, outlined below, was used to determine the number of runs required on each corridor.

The uncorrected sample size, $\mathrm{n}^{\prime}$, can be estimated as follows:

$$
\begin{aligned}
n^{\prime}=\left(c . v .^{2} \times z^{2}\right) /\left(e^{2}\right) & \\
\text { where: } & z=\text { Z-statistic based on confidence level } \\
& e=\text { relative permitted error level }(\%)
\end{aligned}
$$

The Travel Time Data Collection Handbook indicates that the coefficient of variation on freeways ranges from 15 to $25 \%$, depending on traffic volume. For this study, $20 \%$ was chosen as an initial estimate. The handbook provides a set of Z-statistics for various confidence levels; for this study a Z-statistic of 1.960 for a desired confidence level of $95 \%$ was selected. Finally, the handbook recommends a relative permitted error of $\pm 5 \%$ for design and operational analyses. Using these values, an uncorrected sample size was determined as:

$n^{\prime}=\left((.20)^{2} \times(1.960)^{2}\right) /(.05)^{2} \cong 61.46$

\subsubsection{Phase Selection}

A phased data collection plan was used so that lessons learned in early phases could be applied to future phases, and so that analysis of data collected in earlier phases could be used to help determine which corridors to prioritize in later phases.

Phase 1: For Phase 1, the I-5 corridor south of downtown, extending from the junction of I-5 with Tualatin-Sherwood Road to the junction of I-5 and I-405 just south of downtown Portland, was selected. This corridor was chosen because it had an existing DMS, was of high interest to the TAC and had reasonable detector coverage.

Phase 2: For Phase 2, the I-5 corridor south of downtown (as described above) and the Highway 217 corridor initially were considered. The I-5 corridor was selected for reasons specified above; 217 was selected because it was of interest to the TAC and had good detector coverage (average detector spacing is 0.8 miles). However, due to construction on 217, it was eliminated from Phase 2 and collection on I-205 and I-84 was substituted.

Phase 3: For Phase 3, the study was expanded to all freeways in the metropolitan area and added additional coverage on the I-5 corridor south of downtown. Limited amounts of data were collected on U.S. 26 and I-405 because of poor detector coverage in the highly congested areas. 


\subsubsection{Day of Week}

The Travel Time Data Collection Handbook indicates that data should be collected on all days of the week, but if data cannot be collected on all days, Tuesday-Thursday should be prioritized. For this study, data was collected on weekdays; the exact days of the week varied by corridor.

\subsubsection{Corridor Information}

For each corridor, a driving route, including turnaround points, and information in terms of level, time and location of congestion and average estimated driving times were specified. This data allowed the research staff to estimate the time required to collect the desired number of runs on that corridor which, in turn, helped organize and prioritize travel time collection. Table 1 provides corridor descriptions and turnarounds, and Table 2 provides congestion and driving time information. The data in the tables was collected using the PORTAL database and the PORTAL Website (portal.its.pdx.edu) [3]. 
Table 1 Corridor Descriptions

\begin{tabular}{|c|c|c|c|}
\hline Corridor & Route Description & $\begin{array}{l}\text { North/West } \\
\text { Turnaround }\end{array}$ & $\begin{array}{l}\text { South/East } \\
\text { Turnaround }\end{array}$ \\
\hline $\begin{array}{l}\text { I-5 S of } \\
\text { Downtown }\end{array}$ & $\begin{array}{l}\text { I-5 from Tualatin- } \\
\text { Sherwood to downtown }\end{array}$ & $\begin{array}{l}\text { Exit into downtown } \\
\text { (Naito Prkwy), turn } \\
\text { around and re-enter } \\
\text { freeway }\end{array}$ & $\begin{array}{l}\text { Turn around at } \\
\text { Tualatin-Sherwood } \\
\text { Road }\end{array}$ \\
\hline $\begin{array}{l}\mathrm{I}-5 \mathrm{~N} \text { of } \\
\text { Downtown }\end{array}$ & $\begin{array}{l}\text { I-5 from south of } \\
\text { Marquam Bridge } \\
\text { Marine Drive }\end{array}$ & $\begin{array}{l}\text { Turn around at the } \\
\text { Marine } \\
\text { intersection }\end{array}$ & $\begin{array}{l}\text { Cross over Marquam } \\
\text { Bridge - exit towards } \\
\text { Lake Oswego/43, } \\
\text { cross under I-5 and } \\
\text { follow signs back to } \\
\text { I-5 NB. }\end{array}$ \\
\hline Hwy 217 & Entire highway & $\begin{array}{l}\text { Barnes Road exit - go } \\
\text { under U.S. 26, turn } \\
\text { around near hospital }\end{array}$ & $\begin{array}{l}\text { Exit off } 217 \text { onto I-5 } \\
\text { SB, exit at Carmen, } \\
\text { cross bridge over I-5 } \\
\text { and get on I-5 NB at } \\
\text { Carmen. }\end{array}$ \\
\hline $\mathrm{I}-84$ & $\begin{array}{l}\text { I- } 84 \text { from downtown (I- } \\
5 \text { junction) to the I- } 205 \\
\text { junction }\end{array}$ & $\begin{array}{l}\text { Exit (north) onto NE } 1^{\text {st }} \\
\text { Ave, go north to } \\
\text { Broadway and enter I- } \\
\text { 84E via Wheeler St. }\end{array}$ & $\begin{array}{l}\text { Exit onto Halsey, } \\
\text { right on } 102^{\text {nd }} \text {, right } \\
\text { on Glisan, then right } \\
\text { onto an on-ramp that } \\
\text { leads to I-84W }\end{array}$ \\
\hline $\mathrm{I}-205$ & $\begin{array}{l}\text { Initially from I-5 } \\
\text { junction to Airport } \\
\text { Way. Updated to be } \\
\text { from Highway } 212 / 224 \\
\text { to I- } 84 \text { due to } \\
\text { construction and lack } \\
\text { of detectors N of I- } 84\end{array}$ & $\begin{array}{l}\text { Exit at Glisan and turn } \\
\text { around and re-enter I-5 } \\
\text { SB (original turnaround } \\
\text { was Airport Way) }\end{array}$ & $\begin{array}{l}\text { Exit and turn around } \\
\text { at } 212 / 224 \\
\text { Clackamas Highway } \\
\text { (original turnaround } \\
\text { was on I-5 at Nyberg) }\end{array}$ \\
\hline $\mathrm{I}-405$ & Entire highway & & \\
\hline U.S. 26 & $\begin{array}{l}\text { U.S. } 26 \quad \text { from } \\
\text { downtown to Murray }\end{array}$ & $\begin{array}{l}\text { Turn around at Murray } \\
\text { exit }\end{array}$ & $\begin{array}{l}\text { Take Market St exit, } \\
\text { re-enter } 26 \text { off of } \\
\text { Clay St }\end{array}$ \\
\hline
\end{tabular}


Table 2 Peak Times, Level of Congestion, Estimated Round-Trip Times

\begin{tabular}{|c|c|c|c|c|c|}
\hline Corridor & $\begin{array}{l}\mathbf{A M} / \\
\mathbf{P M}\end{array}$ & $\begin{array}{l}\mathrm{NB} / \\
\mathrm{SB}\end{array}$ & Peak Times & $\begin{array}{l}\text { Level of } \\
\text { Congestion } \\
\text { (approx min } \\
\text { observed speed) }\end{array}$ & $\begin{array}{l}\text { Estimated } \\
\text { Round-Trip Time } \\
\text { (minutes) }\end{array}$ \\
\hline \multirow{4}{*}{$\begin{array}{l}\mathrm{I}-5 \quad \mathrm{~S} \text { of } \\
\text { Downtown }\end{array}$} & \multirow[t]{2}{*}{$\mathrm{AM}$} & NB & $6: 30-9: 00$ & $30 \mathrm{mph}$ & \multirow[t]{2}{*}{32.4} \\
\hline & & SB & & N/A & \\
\hline & \multirow[t]{2}{*}{$\mathrm{PM}$} & NB & $3: 00-6: 30$ & $30-35 \mathrm{mph}$ & \multirow[t]{2}{*}{37.1} \\
\hline & & SB & & $35-40 \mathrm{mph}$ & \\
\hline \multirow[t]{4}{*}{$\begin{array}{l}\mathrm{I}-5 \mathrm{~N} \text { of } \\
\text { Downtown }\end{array}$} & \multirow[t]{2}{*}{$\mathrm{AM}$} & NB & $\begin{array}{l}\text { Limited } \\
\text { congestion }\end{array}$ & N/A & \multirow[t]{2}{*}{30} \\
\hline & & SB & $7-9$ & $40-50 \mathrm{mph}$ & \\
\hline & \multirow[t]{2}{*}{$\mathrm{PM}$} & NB & $3-6$ & $25-30 \mathrm{mph}$ & \multirow[t]{2}{*}{44.9} \\
\hline & & SB & $3-5: 30$ & $25-30 \mathrm{mph}$ & \\
\hline \multirow[t]{4}{*}{$\mathrm{I}-84$} & \multirow[t]{2}{*}{$\mathrm{AM}$} & EB & & N/A & \multirow[t]{2}{*}{13.4} \\
\hline & & WB & $7-9$ & $25 \mathrm{mph}$ & \\
\hline & \multirow[t]{2}{*}{$\mathrm{PM}$} & EB & $3-6: 30$ & 20-30 mph & \multirow[t]{2}{*}{13.1} \\
\hline & & WB & $4: 30-6$ & $45 \mathrm{mph}$ & \\
\hline \multirow[t]{4}{*}{$\mathrm{I}-205$} & \multirow[t]{2}{*}{ AM } & NB & $7: 30-8: 30$ & $25-35 \mathrm{mph}$ & \multirow[t]{2}{*}{50.2 (full length) } \\
\hline & & SB & $6: 30-8$ & $35-40 \mathrm{mph}$ & \\
\hline & \multirow[t]{2}{*}{$\mathrm{PM}$} & NB & $4-6$ & $40 \mathrm{mph}$ & \multirow[t]{2}{*}{57.4 (full length) } \\
\hline & & SB & $4-6$ & $35-40 \mathrm{mph}$ & \\
\hline \multirow[t]{4}{*}{ U.S. 26} & \multirow[t]{2}{*}{$\mathrm{AM}$} & EB & $6: 15-9$ & $35 \mathrm{mph}$ & \multirow[t]{2}{*}{ Not calculated } \\
\hline & & WB & $7: 45-8$ & & \\
\hline & \multirow[t]{2}{*}{ PM } & EB & $5: 30-6: 30$ & $40 \mathrm{mph}$ & \multirow[t]{2}{*}{ Not calculated } \\
\hline & & WB & $4-6: 30$ & & \\
\hline \multirow[t]{4}{*}{ HWY 217} & \multirow[t]{2}{*}{ AM } & NB & $7: 30-8: 30$ & $40 \mathrm{mph}$ & \multirow[t]{2}{*}{17.9} \\
\hline & & SB & $7-8: 30$ & $35 \mathrm{mph}$ & \\
\hline & \multirow[t]{2}{*}{$\mathrm{PM}$} & NB & $2: 30-6: 15$ & $20-40 \mathrm{mph}$ & \multirow[t]{2}{*}{21.3} \\
\hline & & SB & $3-6$ & $30-35 \mathrm{mph}$ & \\
\hline \multirow[t]{4}{*}{$\mathrm{I}-405^{*}$} & \multirow[t]{2}{*}{$\mathrm{AM}$} & $\mathrm{NB}$ & Few detectors & & 15.6 \\
\hline & & SB & $\begin{array}{l}\text { Limited } \\
\text { congestion }\end{array}$ & & \\
\hline & $\mathrm{PM}$ & NB & Few detectors & & 5.6 \\
\hline & & SB & $3: 30-6$ & $35-40 \mathrm{mph}$ & \\
\hline
\end{tabular}

(* The estimates for I-405 are very rough due to lack of detectors.) 
Table 3 shows the number of runs collected for each corridor. The I-5 corridor, both north and south of downtown Portland, was given high priority due to high interest from the TAC, high congestion and reasonable detector spacing. I-84 was given lower priority due to poor detector spacing. While some runs were collected on I-205, this corridor also had slightly lower priority due to construction and lack of detectors in high congestion areas. In particular, construction on I-205 near the I-5 junction and the lack of functioning detectors on I-205 north of I-84 restricted the data collection effort. A limited amount of data was collected on U.S. 26 due to poor detector coverage in highly congested areas. Finally, I-405 was given lower priority due to less congestion and poor detector spacing.

Table 3 Collected and Desired Runs by Corridor

\begin{tabular}{|l|l|}
\hline Segment & Runs Collected \\
\hline I-5 NB Carmen DMS to Downtown & 67 \\
\hline $\begin{array}{l}\text { I-5 SB Terwilliger DMS to Tualatin- } \\
\text { Sherwood }\end{array}$ & 60 \\
\hline I-5 NB Downtown to River & 77 \\
\hline I-5 SB River to Downtown & 76 \\
\hline OR 217 NB & 45 \\
\hline OR 217 SB & 45 \\
\hline I-84 EB Downtown to I-205 & 14 \\
\hline I-84 WB I-205 to Downtown & 15 \\
\hline I-205 NB 212/224 to Glisan & 32 \\
\hline I-205 SB Glisan to 212/224 & 31 \\
\hline I-405 NB & 21 \\
\hline I-405 SB & 21 \\
\hline U.S. 26 EB Murray to Downtown & 20 \\
\hline U.S. 26 WB Downtown to Murray & 20 \\
\hline
\end{tabular}




\subsection{ANALYSIS}

This section focuses on the accuracy of the existing travel time estimation algorithm used by ODOT; the following section addresses analysis of other algorithms, algorithm refinements and conditions under which the midpoint algorithm breaks down. The section begins with a brief description of the data used for this study, which included loop detector data from the PORTAL system as well as probe-vehicle data used as ground truth. Next, an overall analysis of the algorithm's estimation error is presented. Finally, a summary of errors and recommendations by segments is provided.

\subsection{DATA DESCRIPTION}

This study used two primary types of data: loop detector data collected from inductive loop detectors on freeways in the Portland metropolitan area and ground truth data collected using probe vehicles equipped with GPS units.

\subsubsection{Loop Detector Data}

The loop detector data was obtained from the PORTAL database. PORTAL (Portland Regional Transportation Archive Listing; http://portal.its.pdx.edu) is the transportation data archive for the Portland metropolitan region and has been archiving loop detector data at 20-second granularity for area freeways since July 2004 [3]. ODOT provides this loop detector data. The estimation of travel times from loop data for segments corresponding to the probe vehicle runs was automated using a series of scripts. The estimated travel times, along with the probe vehicle travel times and associated estimation errors, were stored in the database for further analysis. In addition, PORTAL also was used to automatically generate midpoint and probe vehicle trajectories as well as speed plots. These graphs identified error patterns as well as high-error locations.

\subsubsection{Ground Truth Data}

Ground truth data was collected using GPS-enabled Garmin iQues. The iQues record the location (in latitude and longitude) and speed of the probe vehicle every 3 seconds as described previously in Section 3.0. One raw data file is produced for each vehicle for each peak-time driving session; thus, each data file contains information about multiple runs up and down a freeway corridor. The raw data files must be processed to make the information they contain useful for analysis. This processing contains two primary steps: using GIS to divide each raw data file into a set of runs; and inserting the resulting run data into the PORTAL database so it is available for further processing.

ArcGIS was employed to separate the raw data files into individual runs for analysis. The raw run data was imported into ArcGIS as a database (.dbf) file and overlaid on the highway network for the Portland region. Individual directional segments were created based on location of the VMS signs and major freeway interchanges. For example, one directional segment represents I-5 NB from the Carmen VMS to downtown Portland. The probe data was clipped to the length of each segment, and the travel time for each probe run was computed from the difference in time at the destination and the origin. Figure 13 shows a probe run in ArcGIS for I-205. The extraction 
procedure was the same as was used for the previous travel time project and is described in the report for that project 7.0 .

\subsection{SENSITIVITY ANALYSIS OF ALGORITHMS}

The midpoint algorithm employed by ODOT to generate travel time estimates uses speeds from the loop detectors to estimate travel times. The only input to the algorithm is speed; however, there are travel time algorithms that use count and occupancy as inputs. Travel time is defined as distance/speed; therefore travel time estimation requires speed as an input. There are two possible methods for obtaining speed; speed can be measured directly using dual loop detectors

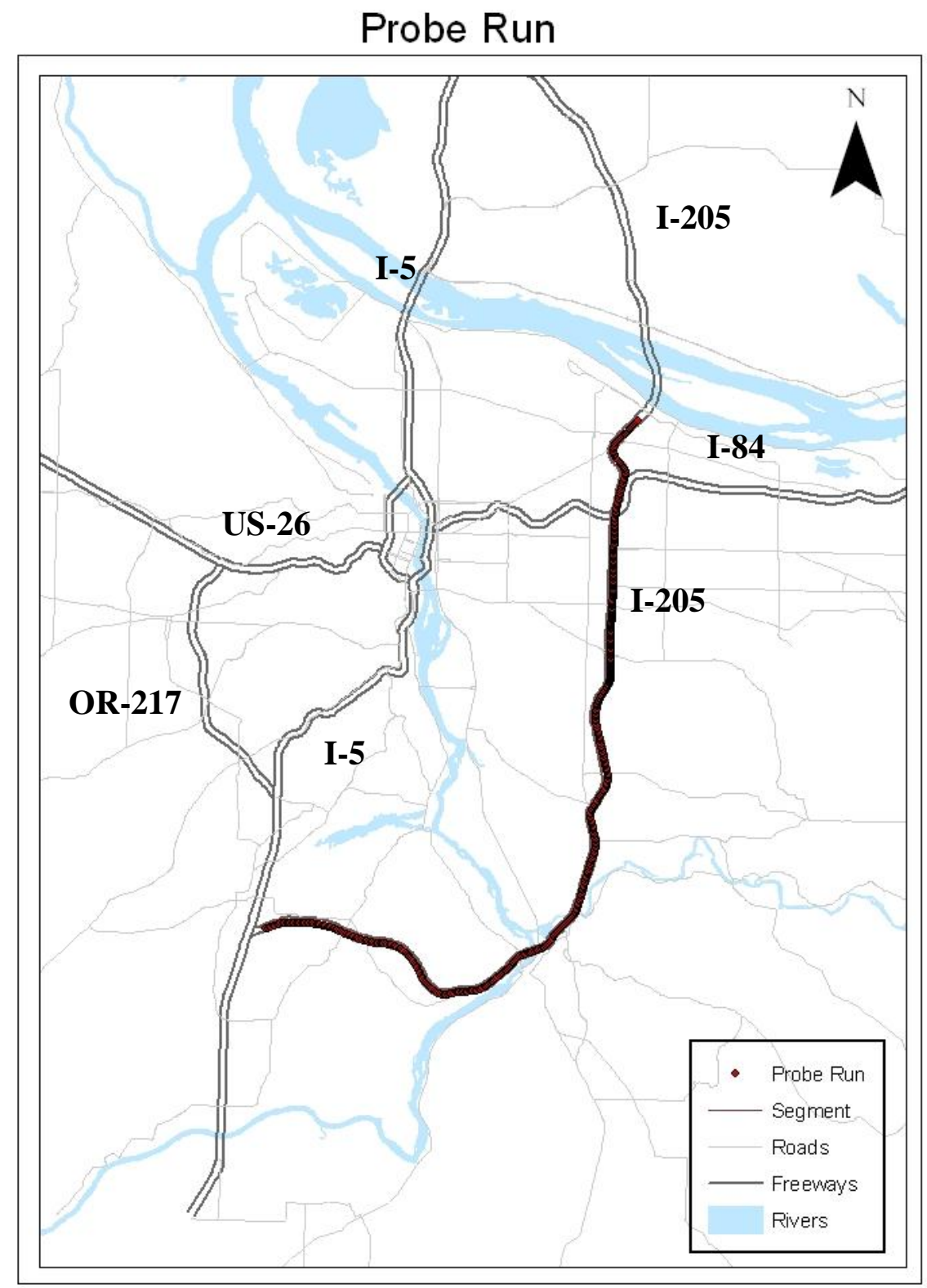

Figure 13 I-205 Probe Run 
or speed can be calculated from measured occupancy and count values as well as an assumed average vehicle length. Proposals for using travel time based on speeds calculated from measured occupancy and count have been made [4][10]. The research team's current understanding is that the ODOT Region 1 speeds are obtained by measuring the speed of cars using the installed dual-loop detectors; those measured speeds are then aggregated to 20 -second intervals.

The ODOT 20-second data was manually inspected and it was observed that in general the speed values appear more reliable than the occupancy values. Sets of detectors have been observed where the speed values appear reasonable, but for which the occupancy values are significantly off (i.e., detectors on I-5 NB around Delta Park and Denver Avenue). In addition, the research team attempted to calculate speeds using the reported count and occupancy values, but this back calculation was not successful. The calculated speeds did not match the reported speeds and appeared to be incorrect; this is potentially due to errors in occupancy measurement and the fact that occupancies are rounded to the nearest integer when they are reported. For these reasons, the research team did not feel that calculating speeds from occupancy is a viable alternative to using the reported ODOT speeds.

\subsection{COMBINED ERROR ANALYSIS}

This section presents error analysis for all the runs combined to provide an overall picture of travel time estimation error using the current algorithm. Section 4.4 provides detailed analysis for each segment.

Error Threshold: For this project, we have selected an error threshold of 20\%. That threshold is based on FHWA direction and research [3][9]; it is believed that errors above $20 \%$ are unacceptable and are potentially detrimental to drivers.

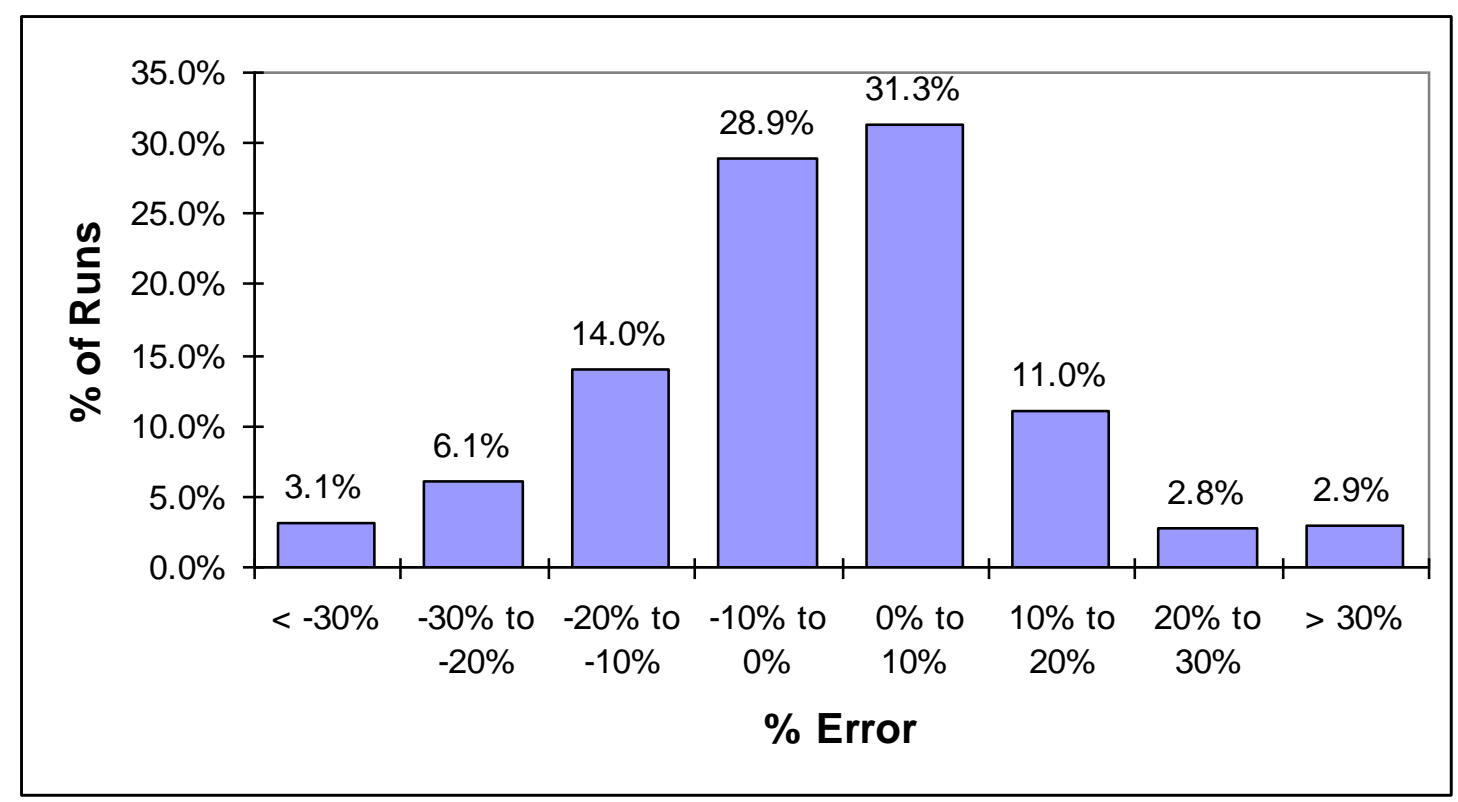

Figure 14 Histogram of Average Percent Error - All Runs 
A total of 544 travel time runs have been analyzed for this study. Figure 14 shows a histogram of the error percentages for those runs. We see that approximately $60 \%$ of runs have errors of less than $10 \%$; an additional $25 \%$ of runs have errors less than our threshold of $20 \%$. In total, $85 \%$ of runs have errors less than our $20 \%$ threshold. This leaves $15 \%$ of the runs where improvement is needed in travel time accuracy. Alternatively, if we could detect in real-time the situations where estimation was expected to be inaccurate, then that would at least enable us to minimize reporting of travel times with high errors. Extensions of this project will perform additional work on both improvement of accuracy of estimation and on real-time error estimation.

Table 4 shows a breakdown of error rates by highway segment and provides the estimated accuracy of travel time given the current instrumentation and using the standard midpoint algorithm. For each segment, the following are provided:

Average absolute percent error: Percent error is calculated as: ((estimated travel time - ground truth travel time)/ground truth travel time)*100. Taking the absolute value prevents positive and negative values from canceling each other out.

Standard Deviation of Percent Error (SDPE): This number is a representation of the error in an individual travel time estimate for a particular segment. It, along with the average absolute percent error, provide an overall picture of estimation error for the segment. SDPE is a recommended error metric for travel time [10] estimation, but has the disadvantage of highly weighting outliers.

Average percent error: When calculating average percent error, the positive and negative errors cancel out; thus, this number provides a measure of the bias of the estimates.

Standard error (SDPE divided by the square root of the number of runs): This number provides a representation of error in the average percent error. If the absolute value of average percent error is greater than the standard error, this indicates a statistically significant estimation bias. For example, I-5 NB Carmen VMS to Downtown has a statistically significant positive estimation bias, while I-5 SB Terwilliger VMS to Tualatin-Sherwood has a statistically significant negative estimation bias.

Percent of estimates with absolute error $<20 \%$ : The percentage of estimates for this segment with absolute percent error less than $20 \%$.

Percent of estimates with absolute error $<30 \%$ : The percentage of estimates for this segment with absolute percent error less than $30 \%$.

An in-depth study would be required to determine exactly what accuracies are required for dissemination of travel times via VMS, the Web and telephone applications. However, as stated below, the acceptable estimation error threshold chosen for this study is $20 \%$. The percent of estimates with errors less than $20 \%$ and $30 \%$ may provide useful in determining if travel time estimates are accurate enough to be provided on a particular segment. 
Table 4 Errors By Highway Segment

\begin{tabular}{|c|c|c|c|c|c|c|c|}
\hline $\begin{array}{l}\text { Segment } \\
\text { Description }\end{array}$ & $\begin{array}{l}\text { Avg } \\
\text { Abs } \\
\text { Pct } \\
\text { Error }\end{array}$ & $\begin{array}{l}\text { Std } \\
\text { Dev } \\
\text { Pct } \\
\text { Error } \\
\text { (SDPE) }\end{array}$ & $\begin{array}{l}\text { Avg } \\
\text { Pct } \\
\text { Error }\end{array}$ & $\begin{array}{l}\text { Std } \\
\text { Error }\end{array}$ & $\begin{array}{l}\text { Num } \\
\text { Runs }\end{array}$ & $\begin{array}{l}\text { Percent } \\
\text { Estimates } \\
\text { with Error } \\
<20 \%\end{array}$ & $\begin{array}{l}\text { Percent } \\
\text { Estimates } \\
\text { with Error } \\
<\mathbf{3 0 \%}\end{array}$ \\
\hline $\begin{array}{l}\text { I-5 NB Carmen } \\
\text { VMS to } \\
\text { Downtown }\end{array}$ & 7.7 & 10.8 & 1.9 & 1.3 & 67 & 91.0 & 97.0 \\
\hline $\begin{array}{l}\text { I-5 SB } \\
\text { Terwilliger VMS } \\
\text { to Tualatin- } \\
\text { Sherwood }\end{array}$ & 11.0 & 14.4 & -2.4 & 1.9 & 60 & 86.7 & 95.0 \\
\hline $\begin{array}{l}\text { I-5 NB } \\
\text { Downtown to } \\
\text { Columbia River }\end{array}$ & 16.9 & 31.5 & 7.9 & 3.59 & 77 & 82.0 & 87.0 \\
\hline $\begin{array}{l}\text { I-5 SB Columbia } \\
\text { River to } \\
\text { Downtown }\end{array}$ & 13.5 & 16.5 & -2.0 & 1.9 & 76 & 76.3 & 94.7 \\
\hline OR $217 \mathrm{NB}$ & 11.8 & 11.9 & -8.2 & 1.8 & 45 & 82.2 & 96.0 \\
\hline OR $217 \mathrm{SB}$ & 12.6 & 15.1 & -6.1 & 2.2 & 45 & 82.2 & 88.9 \\
\hline $\begin{array}{l}\text { I-84 EB } \\
\text { Downtown to I- } \\
205\end{array}$ & 11.5 & 20.0 & 3.7 & 5.4 & 14 & 85.7 & 85.7 \\
\hline $\begin{array}{l}\text { I-84 WB I-205 to } \\
\text { Downtown }\end{array}$ & 17.1 & 19.6 & -6.2 & 5.0 & 15 & 46.7 & 80.0 \\
\hline $\begin{array}{l}\text { I-205 NB } \\
212 / 224 \text { to Glisan }\end{array}$ & 7.8 & 10.0 & 2.1 & 1.77 & 32 & 96.9 & 100.0 \\
\hline $\begin{array}{l}\text { I-205 SB Glisan } \\
\text { to } 212 / 224\end{array}$ & 9.0 & 15.2 & 0.06 & 2.73 & 31 & 90.3 & 96.8 \\
\hline I-405 NB & 4.3 & 4.8 & -2.1 & 1.0 & 21 & 100.0 & 100.0 \\
\hline I-405 SB & 8.3 & 10.6 & -4.2 & 2.3 & 21 & 95.2 & 100.0 \\
\hline $\begin{array}{l}\text { U.S. } 26 \text { EB } \\
\text { Murray to } \\
\text { Downtown }\end{array}$ & 12.6 & 13.5 & -7.1 & 3.0 & 20 & 80.0 & 100.0 \\
\hline $\begin{array}{l}\text { U.S. } 26 \mathrm{WB} \\
\text { Downtown to } \\
\text { Murray }\end{array}$ & 7.6 & 8.5 & 3.9 & 1.9 & 20 & 100.0 & 100.0 \\
\hline
\end{tabular}




\subsection{SEGMENT-BY-SEGMENT ANALYSIS}

In this study, data was collected for six highways: I-5, OR-217, I-205, I-84, I-405 and U.S. 26. Each highway was divided into directional segments. For each segment, a set of analyses was run. For each probe run, the ground truth travel time and an estimated travel time using the midpoint algorithm and archived loop detector data from the PORTAL database was computed. An estimation error was computed based on the difference between the probe (ground truth) travel times and the estimated travel times. For all segments, trajectory and speed plots were visually analyzed for all runs with absolute errors greater than $20 \%$ to attempt to understand the source of the errors.

In this section, we provide a discussion of error levels, infrastructure, travel time provision and recommendations for each segment. Additional detection is recommended for many segments. Determining the amount and spacing of additional detection will be addressed in future phases of this project. Segment descriptions, discussion, conclusions, and trajectory and speed plots for selected high-error runs are provided. A summary table with details for each probe run as well as the complete set of trajectory and speed plots is available from the PSU research team. A description of the trajectory and speed plots and the run summary table is below:

Trajectory plot: The trajectory plot provides a comparison of the actual trajectory of the probe vehicle to a calculated trajectory for the travel time estimation. In trajectory plots, the probe vehicle trajectory is shown with small purple dots, and the midpoint trajectory is shown with a blue line. The red dots and horizontal dashed lines represent detector locations.

Speed plot: The speed plot shows a plot of probe vehicle speeds, detector speeds used in the midpoint travel time estimation and real-time detector speeds at the time the probe passed the detector. The latter speeds are useful in determining whether traffic conditions have changed since the probe started its run. Since the midpoint algorithm uses static speeds at the instant when the probe vehicle starts its run, large estimation errors can be expected when conditions change during the course of the run. Probe speeds are shown as small purple dots, static detector speeds are shown as large blue dots and real-time detector speeds are shown as large red dots. Note, the detector speeds are the speeds reported when the probe vehicle entered the segment since those were the speeds available to calculate travel times.

Run summary table: The table includes runid, date, start time, ground truth travel time, average probe speed, estimated travel times, and travel time estimation error in seconds and percentage. The error in travel time estimation was computed as estimated (midpoint) travel time less the probe vehicle travel time; a negative error indicates that the travel time was underestimated and a positive error indicates an overestimate. The error was computed as the ratio of the error to the probe vehicle travel time and expressed as a percentage. 


\subsection{I-5 NB (SOUTH OF DOWNTOWN)}

Segment description: The I-5 NB (south of downtown) segment begins at the Carmen DMS (milepost 290.9) and extends to the junction of I-5 and I-405 (milepost 299.8). Figure 15 shows this segment as well as the SB segment on this corridor.

Discussion: A total of 67 runs have been collected on the I-5 NB (south of downtown) segment. As seen in Table 4, 91\% of the runs exhibit errors under the $20 \%$ threshold. In addition, all of the errors greater than $20 \%$ were overestimation errors.

In this segment, there is large detector spacing (2.37 miles) between the stations at Terwilliger Boulevard (milepost 297.33) and Macadam Avenue (milepost 299.7). Further, this section of freeway is curvy ("Terwilliger Curves") and is known to be congested. Large detector spacing in an area with congestion and complex geometry is likely to be problematic.

Run 254 is an example of estimation error in the region of the Terwilliger Curves, with an overestimation error of $28.7 \%$. Run 254 has a start time of 3:55 p.m. and travel time was estimated using speeds available at that time. Figure 16 shows a plot of the probe vehicle's actual trajectory (small purple dots) and the estimated trajectory (blue line). The actual and estimated trajectories diverge significantly between mileposts 297 and 299. Figure 17 shows the speed plot for run 254; small purple dots are the recorded probe vehicle speeds, large blue dots are the speeds at 3:55 p.m. and the large red dots are the speeds the detectors recorded at approximately the time the probe passed the detectors. Figure 17 quite clearly shows that the Macadam Ave. detector (milepost 299.7) records a low speed. Due to the use of the midpoint algorithm that speed is extrapolated upstream, resulting in overestimation; an additional detector would help resolve this issue.

A second source of error present in all travel time estimation is that travel time must be estimated at the time the vehicle enters the segment; however, conditions may change after the vehicle has entered the segment. Run 23 exhibits this type of error; Figure 18 shows a speed plot from run 23. The difference in the blue dots and red dots between mileposts 296 and 298 shows that conditions improved in this region between the time the probe entered the segment and when it arrived at this section of freeway. Advanced algorithms based on traffic theory and/or historical data could be employed to address changing conditions. Table 5 (shown after the plots) shows the high-error runs on this segment.

Conclusion: The overall estimation error for this segment was reasonable with $91 \%$ of the runs within the $20 \%$ threshold; providing travel time on this segment may be practical. The analysis indicates that estimation error occurred in the Terwilliger Curves area between stations at Terwilliger Boulevard (milepost 297.33) and Macadam Avenue (milepost 299.7). Based on this result and the fact that this section has complex geometry and high congestion, the research team recommends adding a detector in this section of highway. 


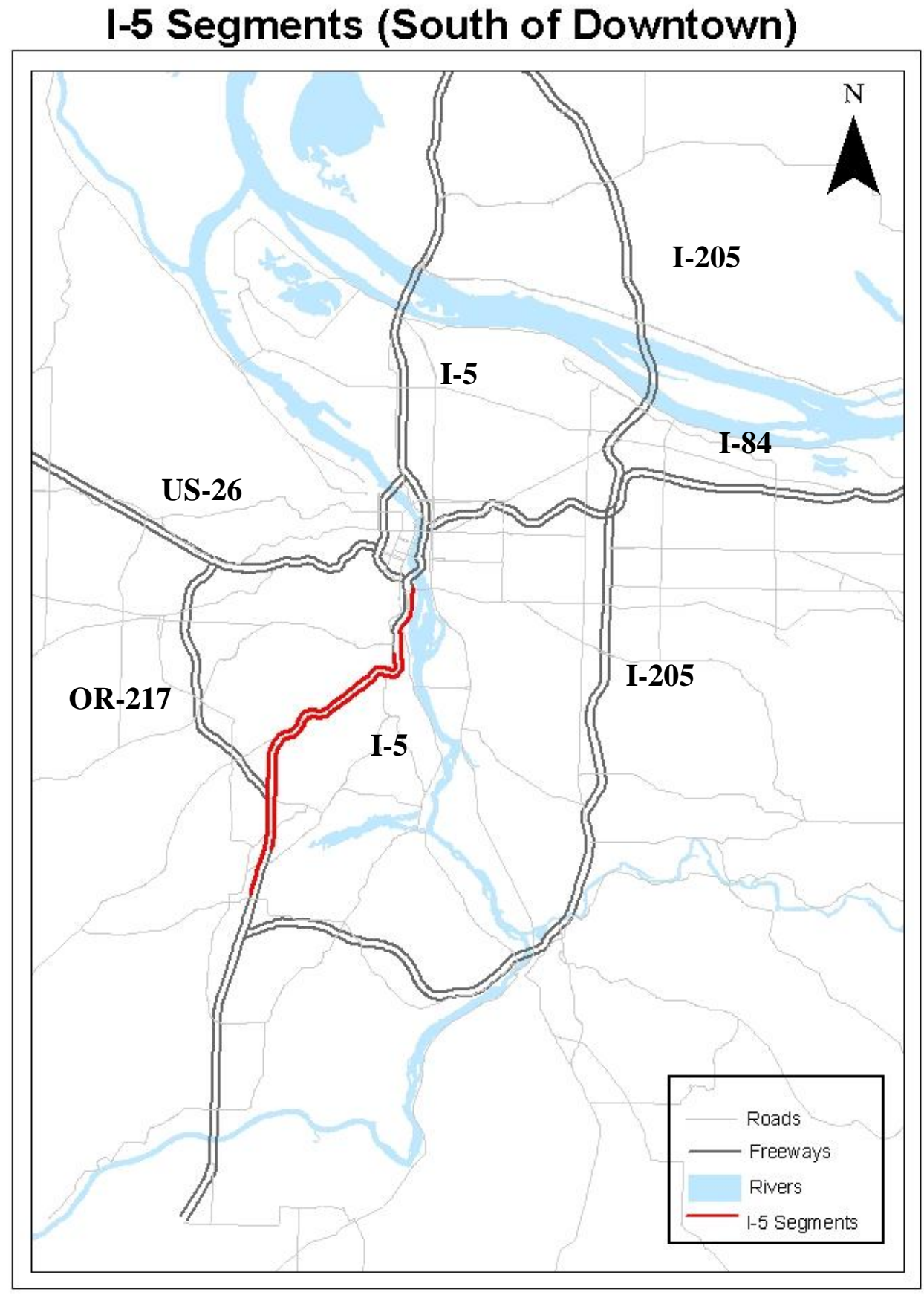

Figure 15 I-5 NB and SB Segments (south of downtown) 
Trajectories for run 254

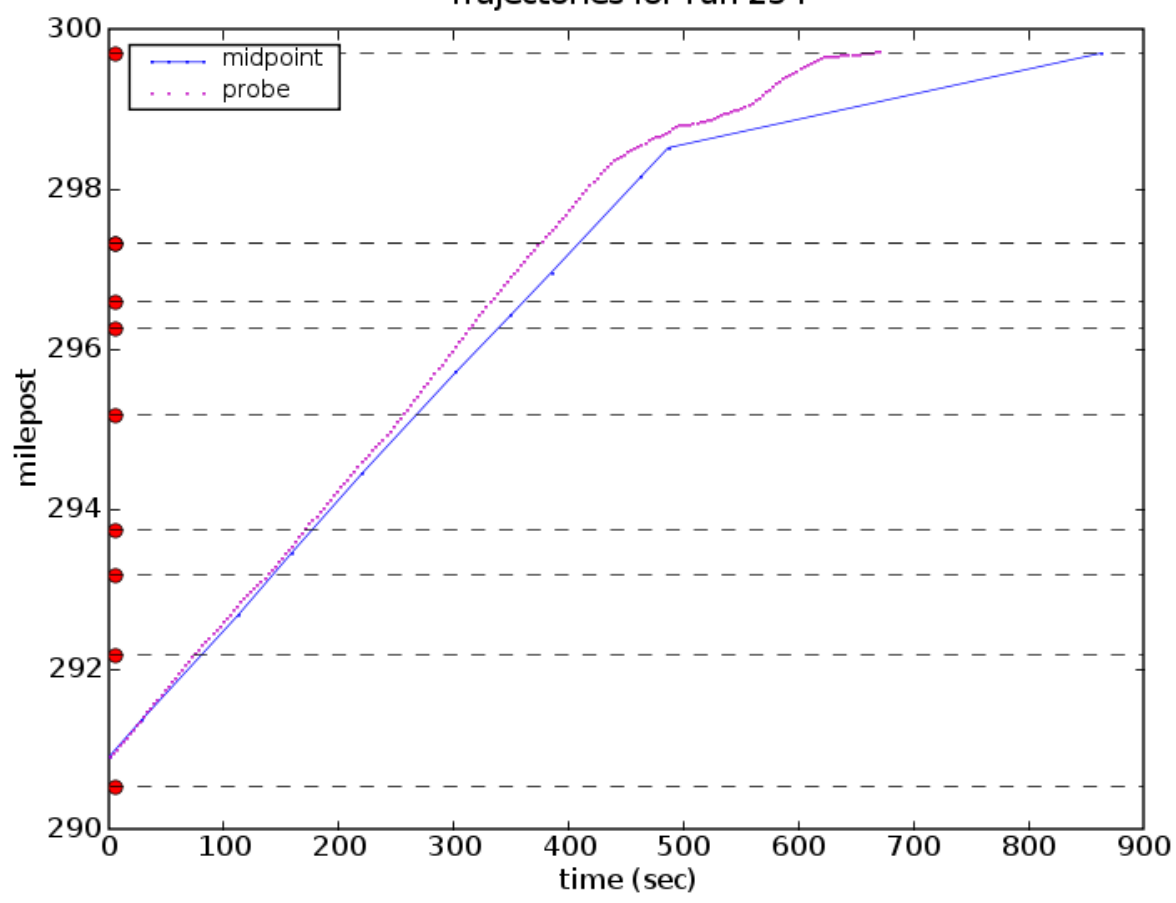

Figure 16 Trajectory Plot - Run 254

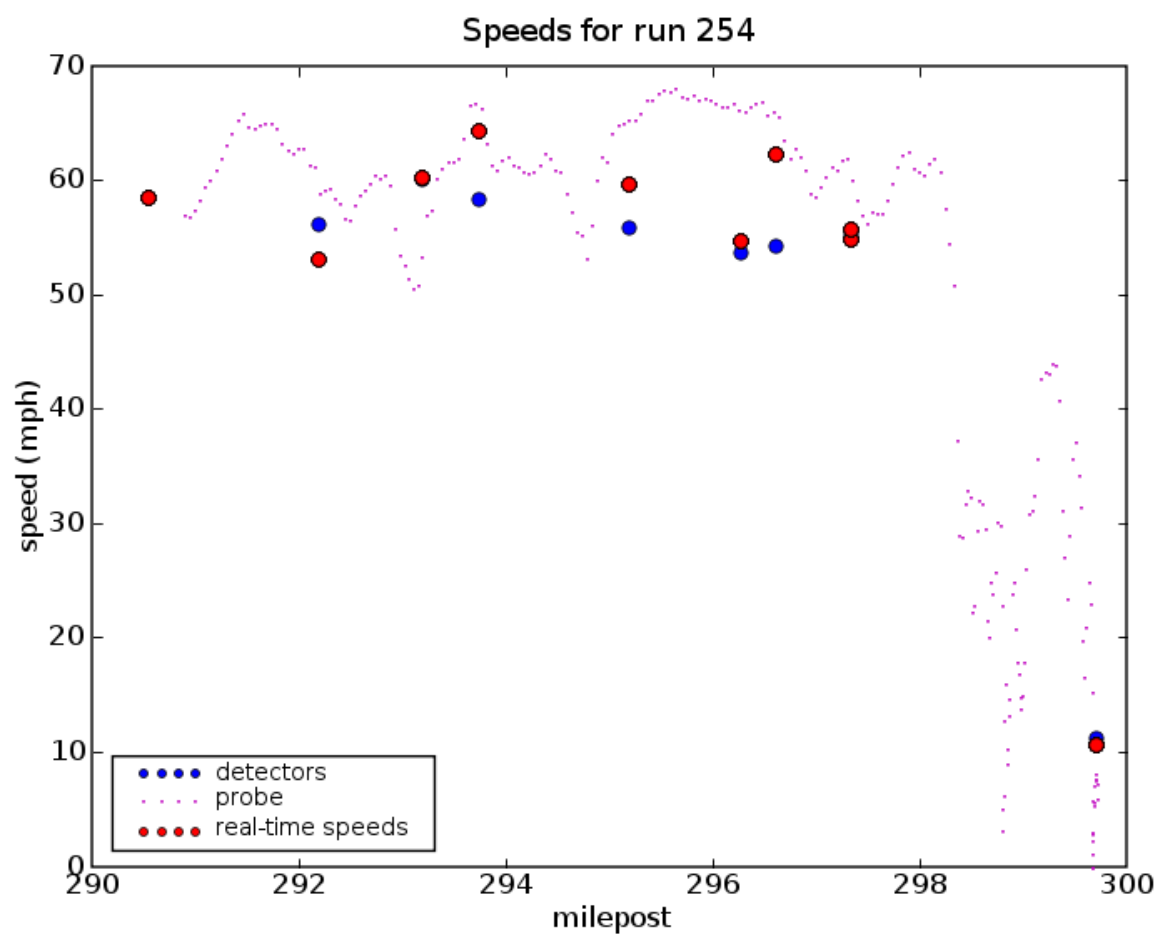

Figure 17 Speed Plot - Run 254 


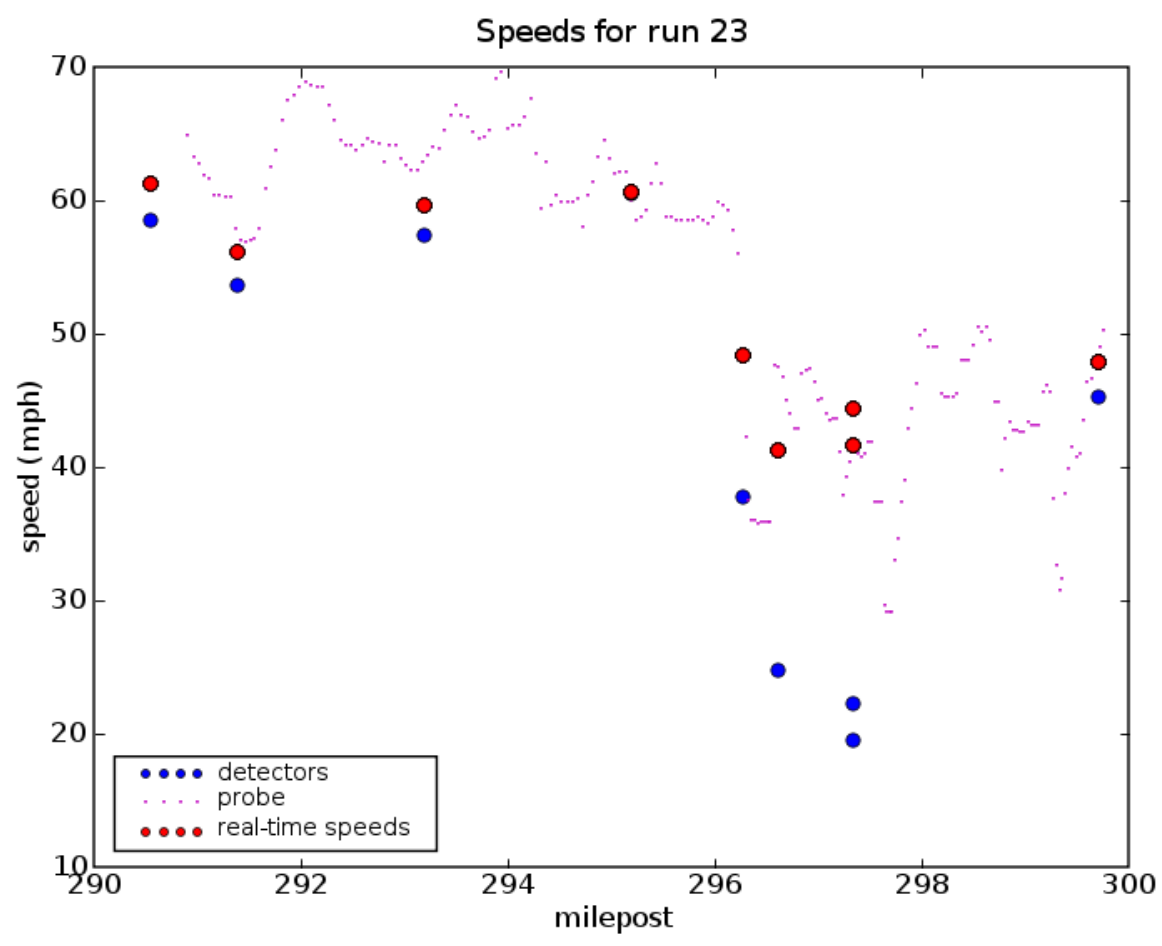

Figure 18 Speed Plot - Run 23

Table 5 I-5 NB (south of downtown) - High-Error Runs

\begin{tabular}{|c|c|c|c|c|c|c|}
\hline Runid & Start time & $\begin{array}{l}\text { Ground } \\
\text { Truth } \\
\text { Travel } \\
\text { Time } \\
\text { (hh:mm:ss) }\end{array}$ & $\begin{array}{l}\text { Average } \\
\text { Probe } \\
\text { Speed } \\
\text { (mi/hr) }\end{array}$ & $\begin{array}{l}\text { Midpoint } \\
\text { Travel } \\
\text { Time } \\
\text { (hh:mm:ss) }\end{array}$ & $\begin{array}{l}\text { Error } \\
\text { (min) }\end{array}$ & $\begin{array}{l}\text { Error } \\
(\%)\end{array}$ \\
\hline 23 & $1 / 9 / 20078: 49$ & $0: 10: 06$ & 52.67 & $0: 13: 20$ & 3.23 & 32.01 \\
\hline 33 & 4/8/2005 16:05 & $0: 09: 51$ & 53.89 & $0: 12: 21$ & 2.5 & 25.38 \\
\hline 254 & 4/19/2007 15:55 & $0: 11: 10$ & 47.41 & $0: 14: 22$ & 3.2 & 28.66 \\
\hline 273 & 4/19/2007 16:16 & $0: 15: 15$ & 34.95 & $0: 21: 03$ & 5.8 & 38.03 \\
\hline 405 & 4/17/2007 8:08 & $0: 13: 33$ & 39.22 & $0: 16: 22$ & 2.82 & 20.79 \\
\hline 433 & 4/18/2007 8:47 & $0: 10: 48$ & 49.11 & $0: 13: 07$ & 2.32 & 21.45 \\
\hline
\end{tabular}




\subsection{I-5 SB (SOUTH OF DOWNTOWN)}

Segment description: The I-5 SB (south of downtown) segment stretches from the VMS at milepost 298 (north of Terwilliger Boulevard) to the intersection of I-5 with Tualatin/Sherwood Road (milepost 289.4). This segment is shown in Figure 15.

Discussion: A total of 60 probe runs have been conducted on the I-5 SB (south of downtown) segment; of those runs, $87 \%$ had error less than the $20 \%$ threshold. Further, the statistics show an underestimation bias on this segment. The problematic section of this segment is the areas between mileposts 293 and 291. There is a large space of almost two miles between the detector at Haines Street (milepost 293.1) and the detector at Upper Boones Ferry Road (milepost 291.25). In addition, Highway 217 merges into I-5 SB in between these two detectors; the merge causes traffic to back up on I-5 SB north of the merge, but there is no detector until the one at Haines St. to capture that congestion. All runs with absolute error greater than $20 \%$ are underestimates and exhibit problems in this region from Haines Street to Upper Boones Ferry Rodd. Table 6 lists the high-error runs on this segment.

Run 217 is an example of a high-error run on this segment. Figures 19 and 20 show the trajectory and speed plots for run 217, respectively. As seen from the figures, the probe vehicle and midpoint trajectories diverge significantly between mileposts 293 and 291.In addition, the speed plot also indicates a large speed drop between mileposts 293 and 291.

Conclusion: In this segment, the merge of SB 217 onto I-5 SB in the area between the stations at Haines Street (milepost 293.3) and Upper Boones Ferry Road (milepost 291.25) is problematic. The research team recommends adding detection between these two stations to capture congestion data in the area. 
Trajectories for run 217

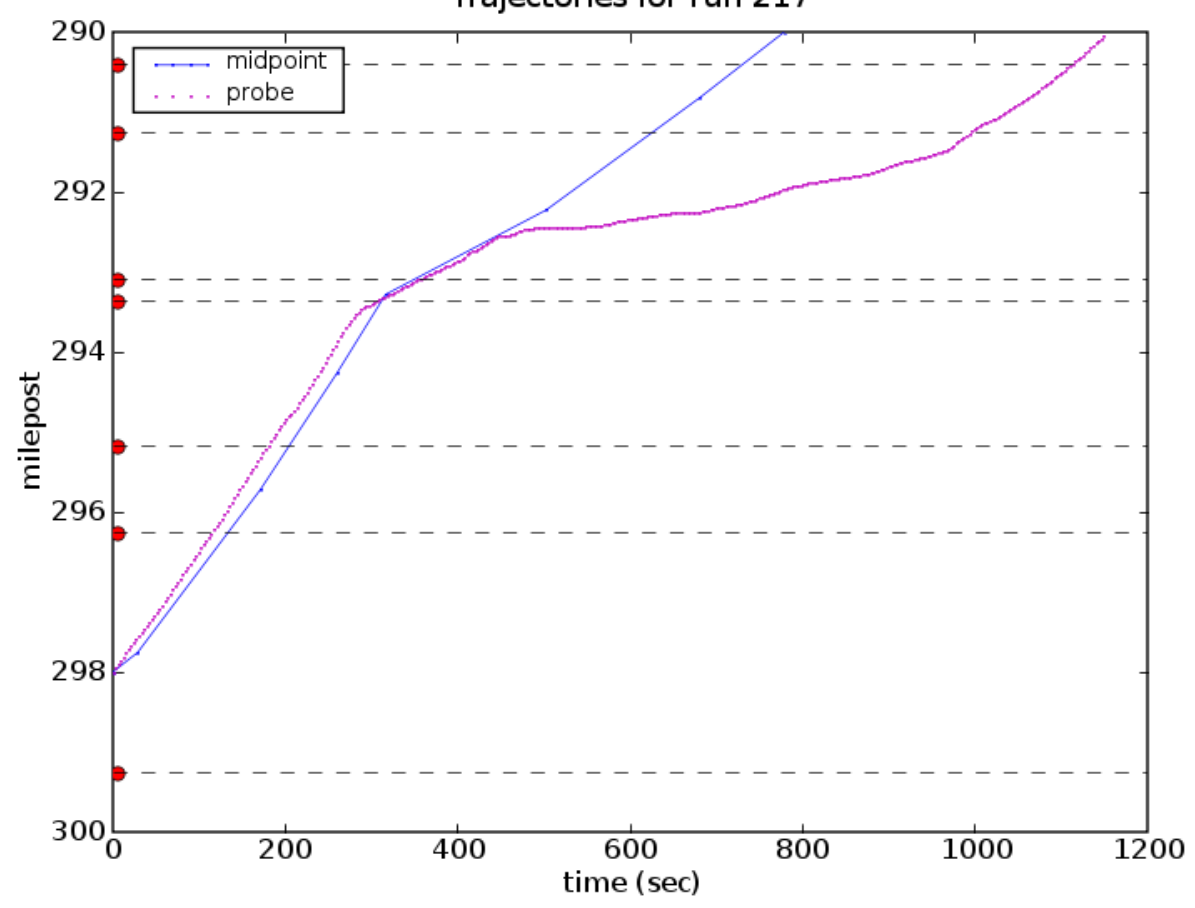

Figure 19 Trajectory Plot - Run 217

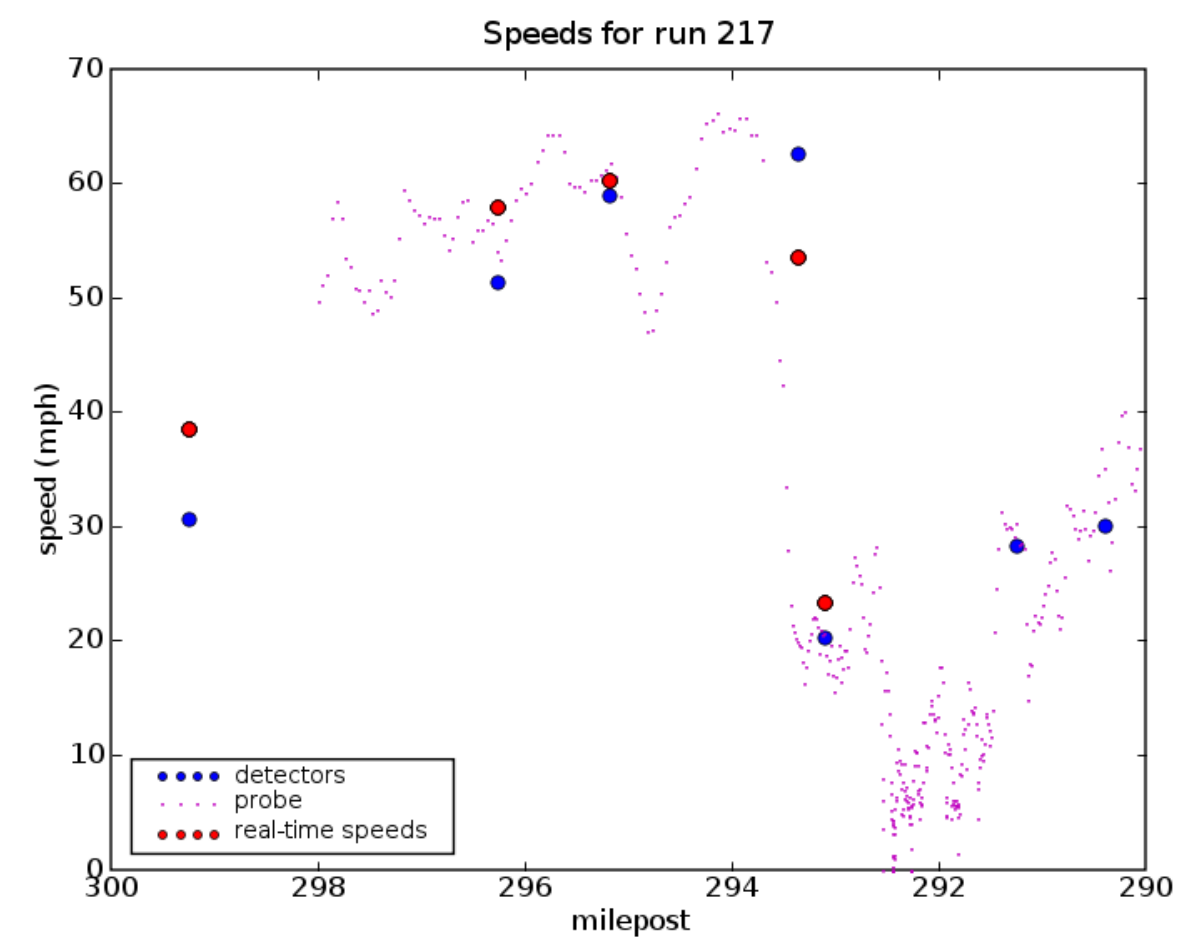

Figure 20 Speed Plot - Run 217 
Table 6 I-5 SB (south of downtown) - High-Error Runs

\begin{tabular}{|c|c|c|c|c|c|c|}
\hline Runid & Start time & $\begin{array}{l}\text { Ground } \\
\text { Truth } \\
\text { Travel } \\
\text { Time } \\
\text { (hh:mm:ss) }\end{array}$ & $\begin{array}{l}\text { Average } \\
\text { Probe } \\
\text { Speed } \\
\text { (mi/hr) }\end{array}$ & $\begin{array}{l}\text { Midpoint } \\
\text { Travel } \\
\text { Time } \\
\text { (hh:mm:ss) }\end{array}$ & $\begin{array}{l}\text { Error } \\
\text { (min) }\end{array}$ & $\begin{array}{l}\text { Error } \\
(\%)\end{array}$ \\
\hline 14 & $\begin{array}{r}12 / 21 / 2006 \\
16: 13\end{array}$ & $0: 16: 24$ & 29.18 & $0: 11: 39$ & -4.75 & -28.96 \\
\hline 28 & 1/9/2007 16:42 & $0: 15: 42$ & 30.31 & $0: 12: 17$ & -3.42 & -21.76 \\
\hline 416 & 4/17/2007 17:32 & $0: 33: 27$ & 14.31 & $0: 19: 14$ & -14.22 & -42.5 \\
\hline 437 & 4/18/2007 17:13 & 0:25:06 & 18.99 & $0: 16: 15$ & -8.85 & -35.26 \\
\hline 449 & 4/18/2007 16:18 & $0: 30: 03$ & 15.87 & $0: 21: 47$ & -8.27 & -27.51 \\
\hline 451 & 4/18/2007 17:18 & $0: 29: 15$ & 16.33 & $0: 18: 34$ & -10.68 & -36.52 \\
\hline
\end{tabular}

\subsection{I-5 NB (NORTH OF DOWNTOWN)}

Segment Description: The north segment of I-5 starts near downtown Portland and extends to the Columbia River, between mileposts 299.99 and 307.46. Figure 21 illustrates this segment.

Discussion: A total of 77 probe vehicle runs were conducted on this segment; of those, $28 \%$ had errors of greater than $20 \%$ and $13 \%$ had errors greater than $30 \%$. The vast majority of these high errors were overestimation errors; only $4 \%$ of the runs had underestimations of less than $-20 \%$. Some of the overestimations were very large, with three runs having overestimation error of greater than $100 \%$. As would be expected with these numbers, the statistics show a significant overestimation bias for this segment. Table 7 (shown at the end of this subsection) provides a run summary table for this segment's high-error runs.

This segment's issues are somewhat complex. First, a significant number of overestimations were due to conditions changing near the end of the segment (by the Columbia River Crossing) after the probe entered the segment. These problems were exacerbated by the Marine Drive detector being non-functional for some runs.

A second issue was detector failure. The three runs with errors of greater than $100 \%$ were due to the extrapolation of a low speed due to detector failure. This segment extends from just south of the Marquam Bridge to the Columbia River. The first three detectors on this segment occur at: Macadam Avenue (milepost 299.7), the Morrison Bridge (milepost 301.09) and Broadway (milepost 302.5). During several runs, the detectors at the Morrison Bridge were out, causing the slow speed from Macadam Avenue to be extrapolated downstream, which caused a significant underestimation. Figures 22 and 23 show trajectory and speed plots, respectively, from run 309 that demonstrate this phenomenon.

A third potential issue was slowing around milepost 301. This slowing may be caused by the exit from I-5 NB to I-84 EB and the weave before that exit. As this slowing appeared on only three high-error runs, it is not clear if this is a consistent problem.

Conclusion: The analysis of this segment shows issues with detector failure and changing conditions. To detect and address errors caused by changing conditions, more complex algorithms must be investigated. The issue of detecting when such error conditions occur in real time will be addressed in an extension of this project. Algorithms such as those tested in Section 
5.2.1 through Section 5.2.3 are unlikely to address such issues. Finally, adjustment of influence areas based on physical freeway geometry is strongly recommended for this section. The influence of the Macadam Avenue detector needs to be considered, particularly when the Morrison Bridge detector drops out. The exact influence area of the Macadam detector should be determined by the particular segment for which ODOT wishes to provide travel time estimates. 


\section{I-5 Segments (North of Downtown)}

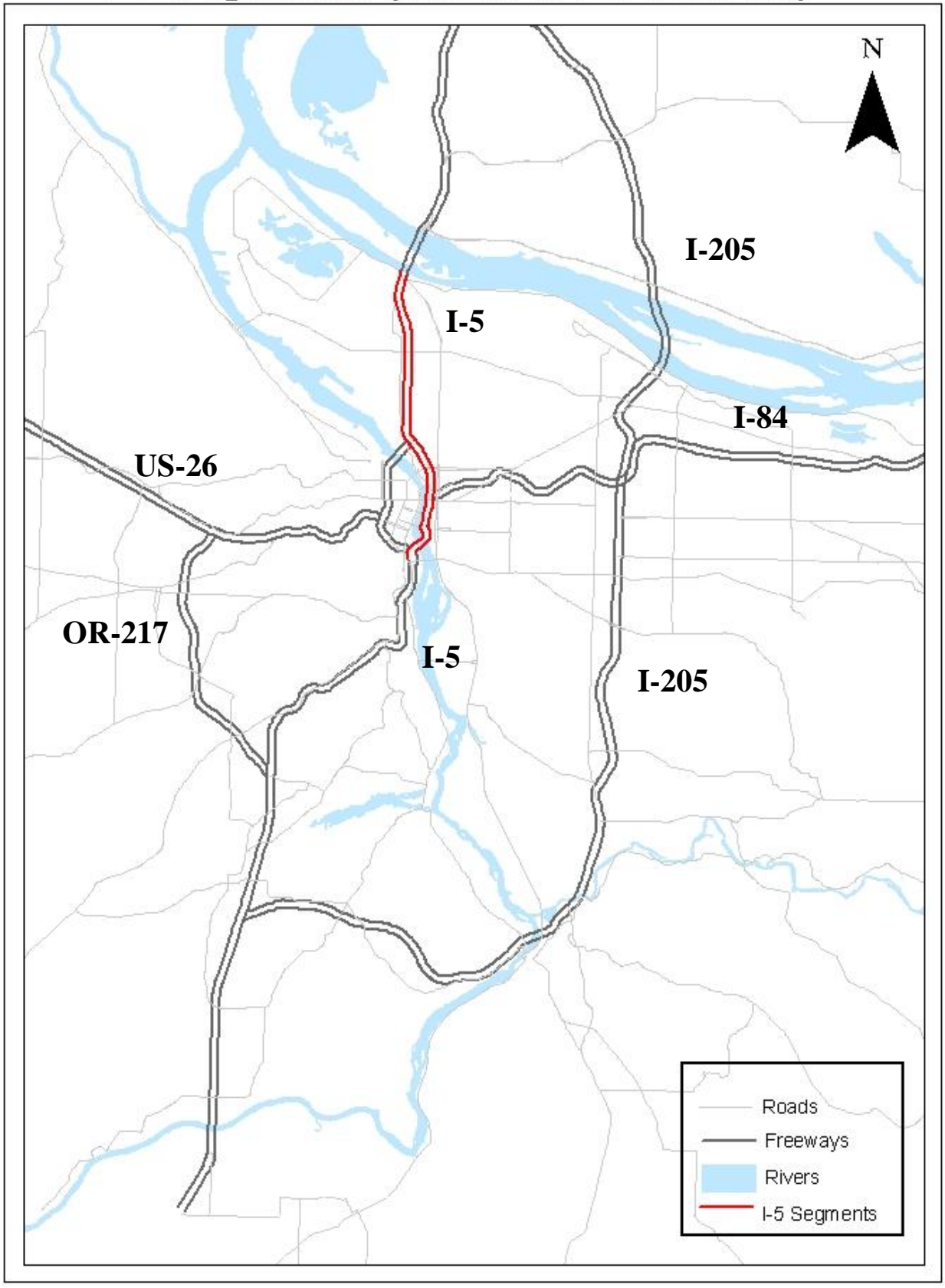

Figure 21 I-5 Segments (north of downtown) 


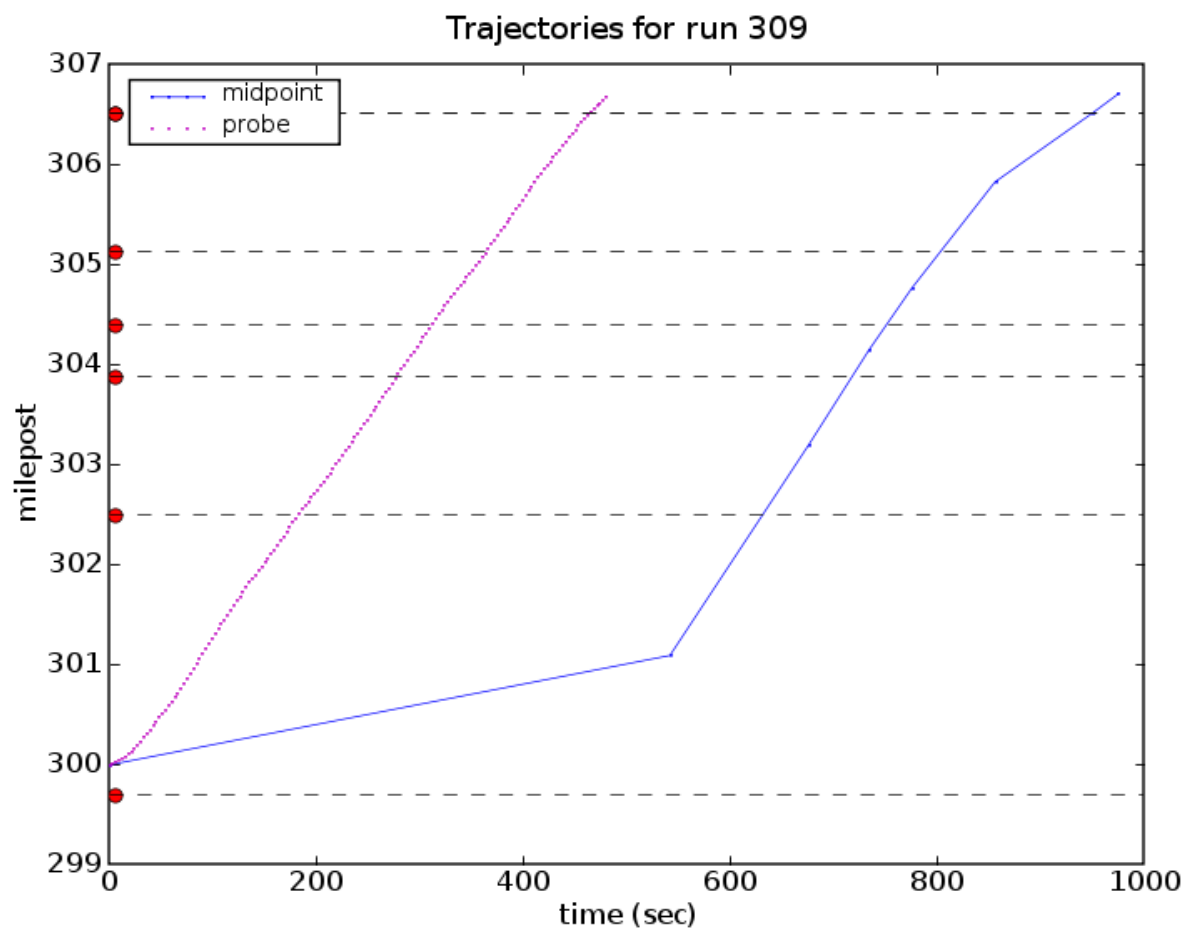

Figure 22 Trajectory Plot - Run 309

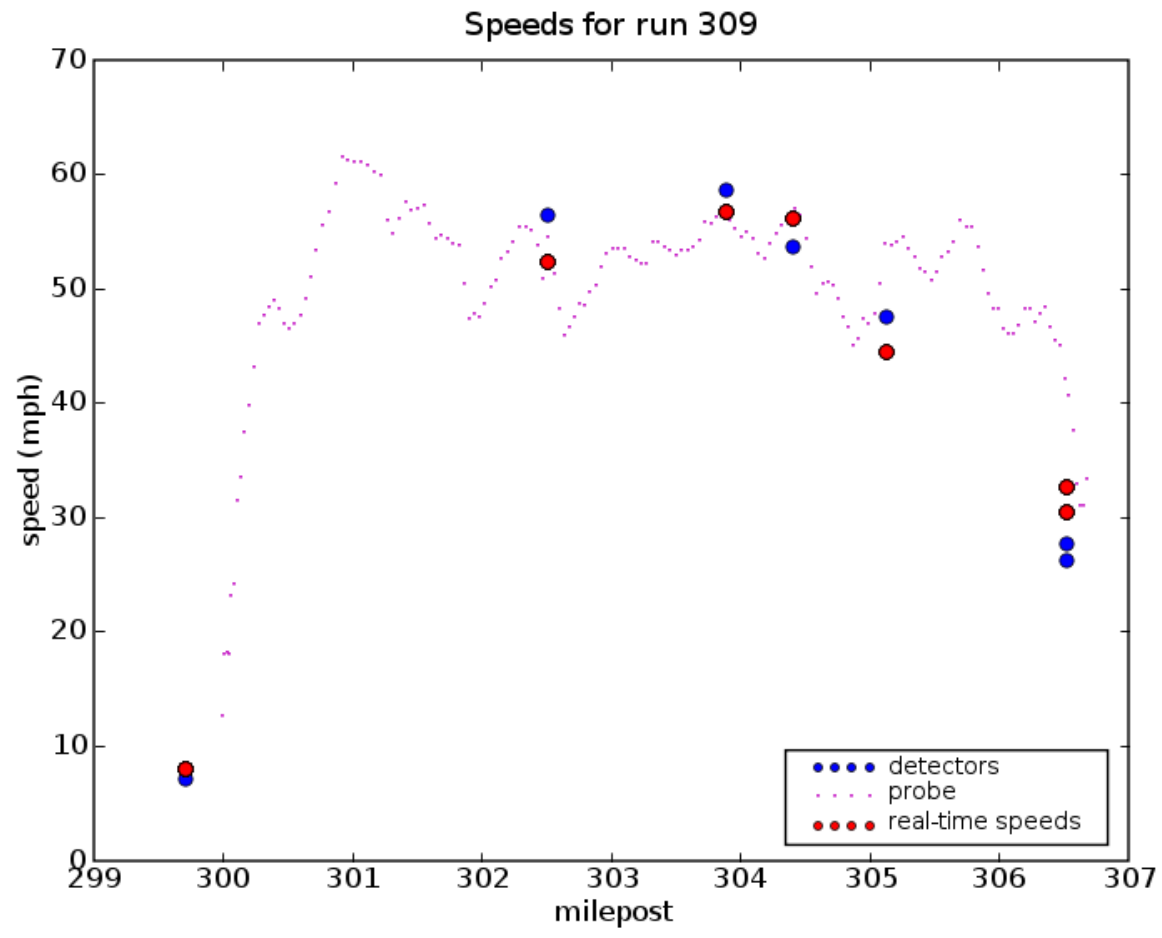

Figure 23 Speed Plot - Run 309 
Table 7 I-5 NB (north of downtown) - High-Error Runs

\begin{tabular}{|c|c|c|c|c|c|c|}
\hline Runid & Start time & $\begin{array}{l}\text { Ground } \\
\text { Truth } \\
\text { Travel } \\
\text { Time } \\
\text { (hh:mm:ss) }\end{array}$ & $\begin{array}{l}\text { Average } \\
\text { Probe } \\
\text { Speed } \\
\text { (mi/hr) }\end{array}$ & $\begin{array}{l}\text { Midpoint } \\
\text { Travel } \\
\text { Time } \\
\text { (hh:mm:ss) }\end{array}$ & $\begin{array}{l}\text { Error } \\
\text { (min) }\end{array}$ & $\begin{array}{l}\text { Error } \\
(\%)\end{array}$ \\
\hline 110 & 2/12/2007 17:32 & 0:08:27 & 47.08 & $0: 10: 41$ & 2.23 & 26.43 \\
\hline 114 & 2/12/2007 17:47 & 0:07:03 & 56.61 & 0:09:21 & 2.3 & 32.62 \\
\hline 156 & 2/15/2007 17:58 & $0: 10: 45$ & 37.29 & $0: 18: 05$ & 7.33 & 68.22 \\
\hline 277 & 4/26/2007 16:02 & $0: 17: 45$ & 22.53 & $0: 27: 59$ & 10.23 & 57.65 \\
\hline 293 & 4/26/2007 16:03 & $0: 18: 42$ & 21.55 & 0:29:09 & 10.45 & 55.88 \\
\hline 299 & 4/26/2007 17:57 & 0:07:27 & 53.53 & $0: 12: 53$ & 5.43 & 72.93 \\
\hline 301 & 4/24/2007 16:09 & 0:08:00 & 49.73 & 0:19:10 & 11.17 & 139.58 \\
\hline 303 & 4/24/2007 16:39 & $0: 11: 21$ & 35.24 & 0:08:00 & -3.35 & -29.52 \\
\hline 307 & 4/24/2007 17:47 & 0:07:15 & 54.97 & 0:09:13 & 1.97 & 27.13 \\
\hline 309 & 4/24/2007 16:05 & 0:08:00 & 49.87 & $0: 16: 15$ & 8.25 & 103.13 \\
\hline 321 & 4/24/2007 16:08 & 0:08:00 & 49.87 & 0:19:32 & 11.53 & 144.17 \\
\hline 338 & 4/25/2007 16:57 & 0:42:59 & 9.39 & $0: 17: 21$ & -25.63 & -59.64 \\
\hline
\end{tabular}

Note: Runs 277 and 293 were subject to an incident.

\subsection{I-5 SB (NORTH OF DOWNTOWN)}

Segment Description: The I-5 SB (north of downtown) segment extends from the Columbia River to downtown Portland (over the Marquam Bridge) between mileposts 307.47 and 299.83. This segment is illustrated in Figure 21.

Discussion: The study collected 76 runs for this segment; of those runs, $76.3 \%$ had absolute estimation errors under the $20 \%$ threshold and $94.7 \%$ had errors under $30 \%$. Of the absolute errors greater than $20 \%, 75 \%$ were underestimation errors. The underestimation errors occurred predominantly in the afternoon and appear to be the result of large detector spacing as described below. In addition, the Marine Drive-Columbia section is potentially problematic during the AM peak. Table 8 (at the end of this subsection) shows this segment's high-error runs.

The high-error runs in the PM peak consistently showed problems in the areas between mileposts 304 and 299; this is from Greely Avenue to the south side of the Marquam Bridge.

Greely-Wheeler: There are three detectors in the north end of this region: Going Street (milepost 303.9), Greely Avenue and Wheeler (milepost 302.17). I-405 SB exits off of I-5 SB around the Greely Avenue station, and the exit from I-5 to I-84 is just south of the Wheeler Street stations; thus, this is an area of high congestion and complex traffic. A majority of the high-error PM peak runs showed that the existing detectors are not capturing the congestion in this area of freeway. The trajectory and speed plot for run 166 demonstrate this issue (Figures 24 and 25).

Wheeler-Hood: Another problem area is between the Wheeler (milepost 302.17) and Hood Avenue (milepost 299.25) detectors. A 2.92-mile spacing exists between these two detectors; further, this region of freeway goes through downtown and over the Marquam Bridge, which may cause traffic variations. 
Marine-Columbia: At the north end of this segment, there is a space of 1.25 miles between the detectors at Marine Drive (milepost 307.35) and Columbia Boulevard (305.97); further, there is a lane drop between these two detectors. Several runs showed problems in this area. Additional detection may be needed in this area; however, additional analysis is required.

Conclusion: The current error level on this segment is concerning; almost $25 \%$ of runs were above the error threshold of $20 \%$. The problematic section of this segment is from around Greely to Macadam Avenue just south of the Marquam Bridge. If ODOT wishes to provide travel times for a segment that includes this section, additional detection is recommended. However, it may be possible to provide travel time from the Columbia River to the I-5 and I- 84 junction with acceptable error.

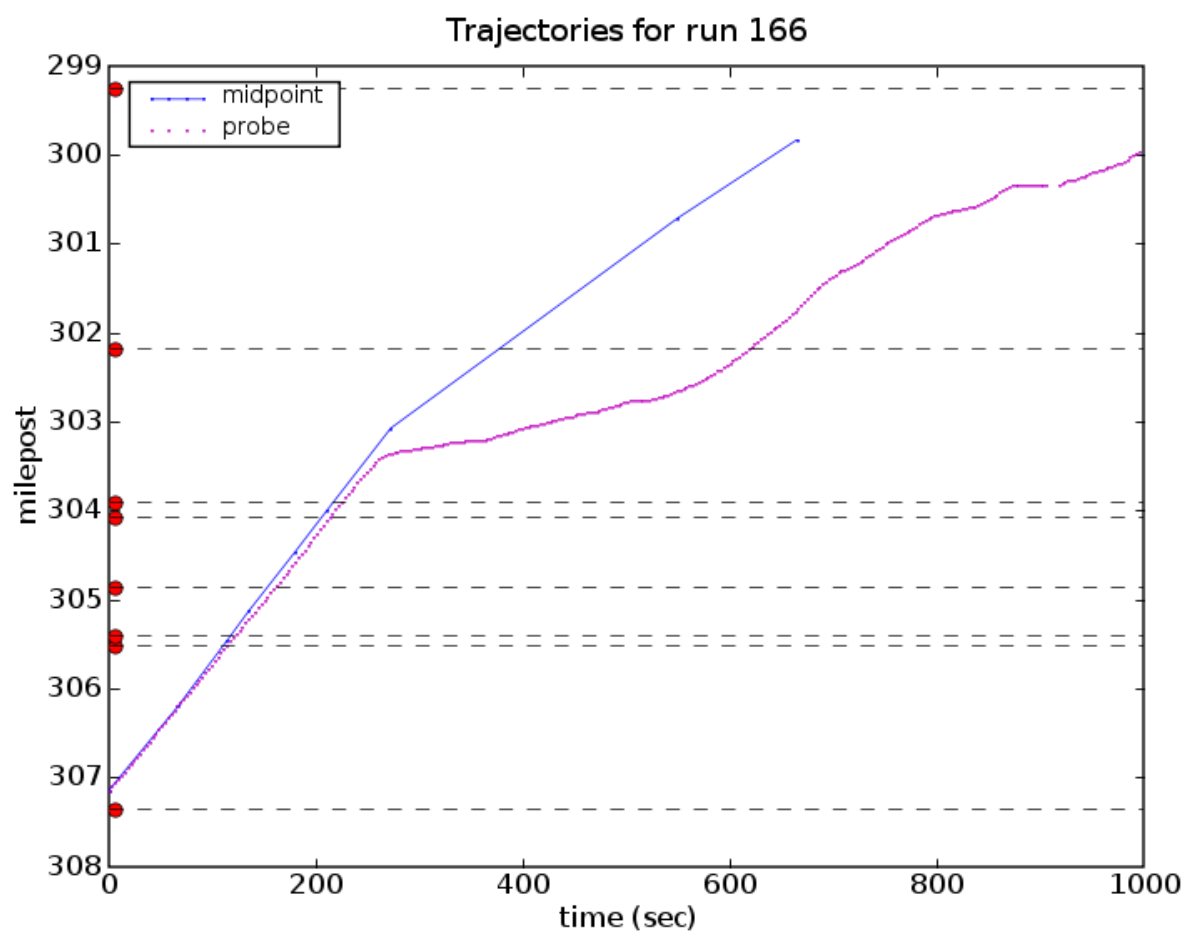

Figure 24 Trajectory Plot - Run 166 


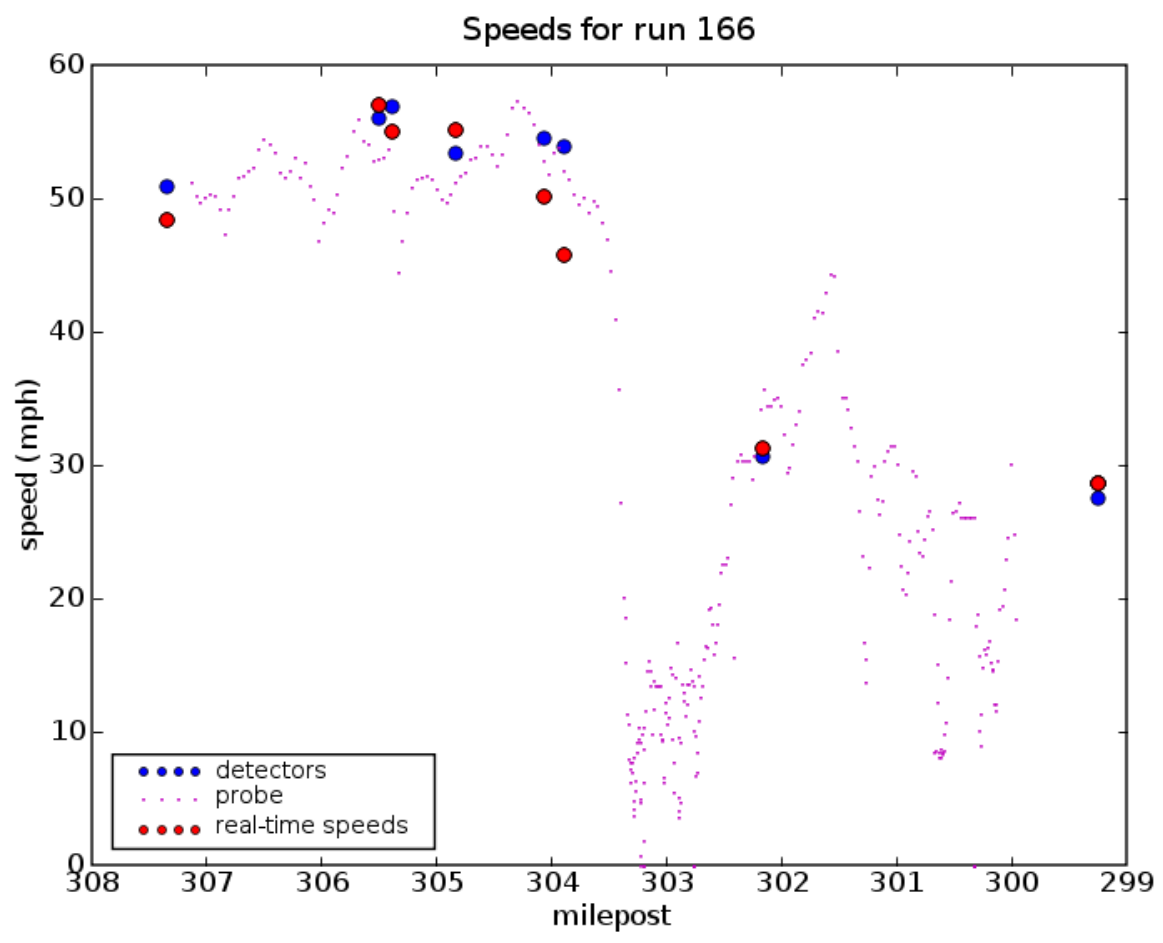

Figure 25 Speed Plot - Run 166

Table 8 I-5 SB (north of downtown) - High-Error Runs

\begin{tabular}{|c|c|c|c|c|c|c|}
\hline Runid & Start time & $\begin{array}{l}\text { Ground } \\
\text { Truth } \\
\text { Travel } \\
\text { Time } \\
\text { (hh:mm:ss) }\end{array}$ & $\begin{array}{l}\text { Average } \\
\text { Speed } \\
\text { (mi/hr) }\end{array}$ & $\begin{array}{l}\text { Midpoint } \\
\text { Travel } \\
\text { Time } \\
\text { (hh:mm:ss) }\end{array}$ & $\begin{array}{l}\text { Error } \\
\text { (min) }\end{array}$ & $\begin{array}{l}\text { Error } \\
(\%)\end{array}$ \\
\hline 130 & $2 / 12 / 20078: 00$ & 0:09:36 & 45.81 & $0: 13: 05$ & 3.48 & 36.28 \\
\hline 132 & $2 / 12 / 20078: 24$ & $0: 09: 54$ & 44.18 & $0: 12: 03$ & 2.15 & 21.72 \\
\hline 136 & $2 / 15 / 20078: 14$ & $0: 13: 12$ & 33.23 & $0: 19: 27$ & 6.25 & 47.35 \\
\hline 153 & $2 / 15 / 200716: 49$ & $0: 17: 10$ & 25.27 & 0:13:22 & -3.8 & -22.14 \\
\hline 155 & $2 / 15 / 200717: 40$ & $0: 14: 22$ & 30.49 & $0: 10: 23$ & -3.98 & -27.73 \\
\hline 157 & $2 / 15 / 2007$ 18:15 & $0: 12: 09$ & 35.79 & $0: 09: 41$ & -2.47 & -20.3 \\
\hline 160 & $2 / 15 / 2007$ 17:22 & $0: 17: 03$ & 25.31 & $0: 12: 19$ & -4.73 & -27.76 \\
\hline 166 & $2 / 15 / 200717: 13$ & $0: 16: 36$ & 26.23 & $0: 11: 05$ & -5.52 & -33.23 \\
\hline 168 & $2 / 15 / 200718: 00$ & $0: 13: 15$ & 32.82 & $0: 09: 56$ & -3.32 & -25.03 \\
\hline 308 & $4 / 24 / 2007$ 17:57 & $0: 10: 09$ & 42.92 & $0: 12: 21$ & 2.2 & 21.67 \\
\hline 316 & $4 / 25 / 2007$ 7:39 & $0: 15: 12$ & 28.69 & $0: 10: 58$ & -4.23 & -27.85 \\
\hline 322 & $4 / 24 / 200716: 18$ & $0: 15: 00$ & 29.22 & $0: 11: 47$ & -3.22 & -21.44 \\
\hline 324 & $4 / 24 / 200716: 49$ & $0: 18: 55$ & 23.29 & $0: 13: 53$ & -5.03 & -26.61 \\
\hline 329 & $4 / 25 / 2007$ 16:14 & $0: 17: 21$ & 25.27 & $0: 13: 23$ & -3.97 & -22.86 \\
\hline 331 & $4 / 25 / 2007$ 16:49 & $0: 21: 44$ & 19.93 & $0: 17: 00$ & -4.73 & -21.78 \\
\hline
\end{tabular}




\subsection{OR $217 \mathrm{NB}$}

Segment Description: This segment consists of OR 217's entire NB section from Lake Oswego to U.S. 26. This segment is illustrated in Figure 26.

Discussion: 45 runs were collected on this segment. Of those, $82 \%$ had estimation errors less than the $20 \%$ threshold. Of the runs with error greater than $20 \%$, all but one were underestimations. In addition, the statistical analysis shows a definite underestimation bias. The speed and trajectory plots for all high-error runs were examined; however, the results on this segment are somewhat inconclusive. One issue was detector failure. For all runs, the Allen Boulevard detector (milepost 2.16) was not functioning. In addition, the detectors at Greenburg (milepost 4.65) and $72^{\text {nd }}$ Avenue (milepost 6.61) were not functioning on several runs.

Visual observation indicates that one of the most problematic sections of this segment is the first portion, near milepost 7 . The congestion in this area may be due to the merge with traffic from Kruse Way and the $72^{\text {nd }}$ Avenue exit. Figures 27 and 28 show trajectory and speed plots for run 267, which had a 25\% underestimation and during which neither the Allen Boulevard (milepost 2.16) nor the $72^{\text {nd }}$ Avenue (milepost 6.61) detectors functioned. Had the $72^{\text {nd }}$ Avenue detector functioned during this run, the error might have been lower. However, other runs show high error near the start of the segment, even with a functioning $72^{\text {nd }}$ Avenue detector.

Conclusion: The overall error rate on this segment showed $82 \%$ of runs within the $20 \%$ threshold; however, at least one detector was unavailable for all runs. Additional analysis should be performed when all detectors function to determine the accuracy under those conditions. 
OR- 217 Segments

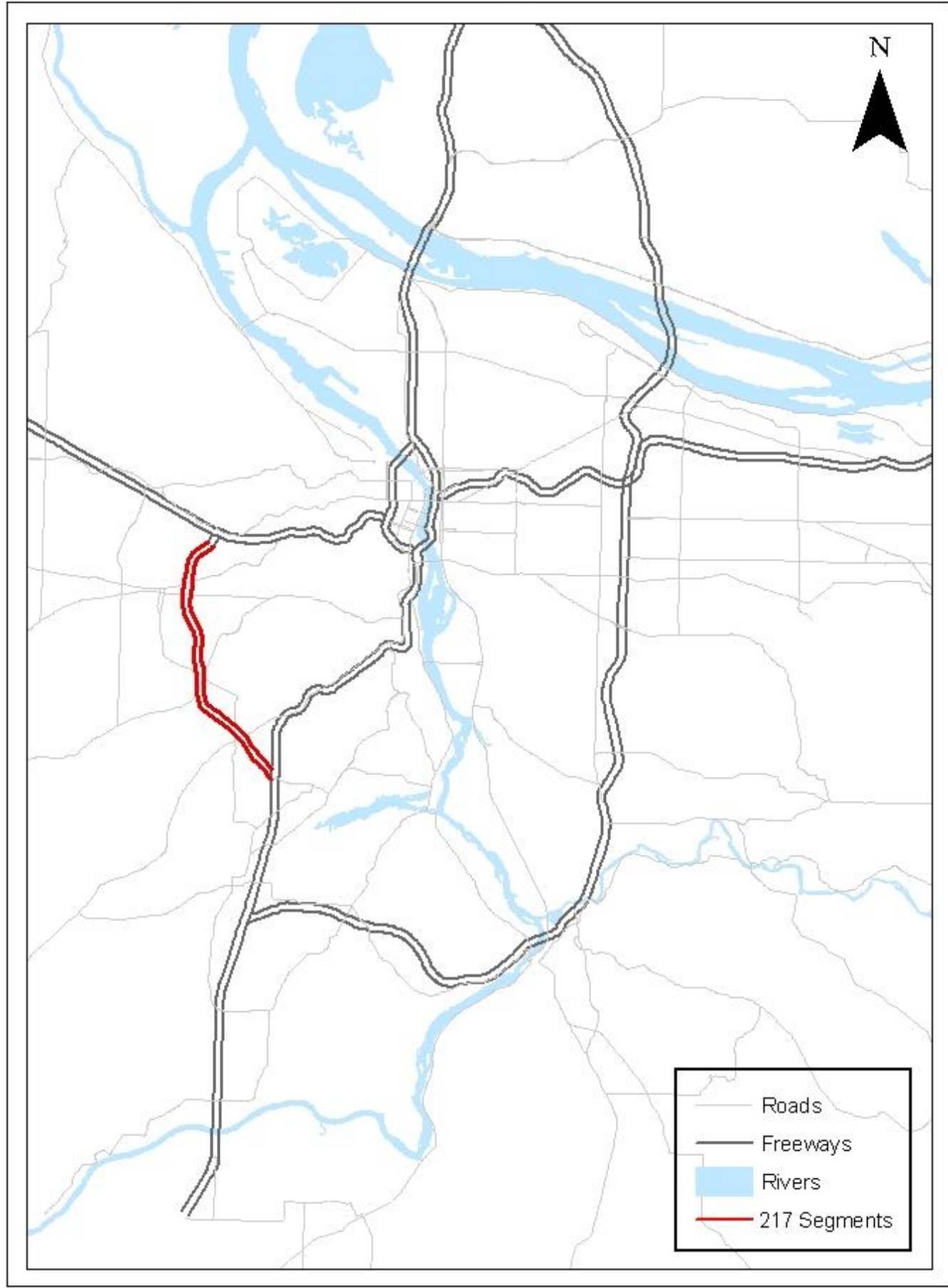

Figure 26 OR 217 Segments 
Trajectories for run 267

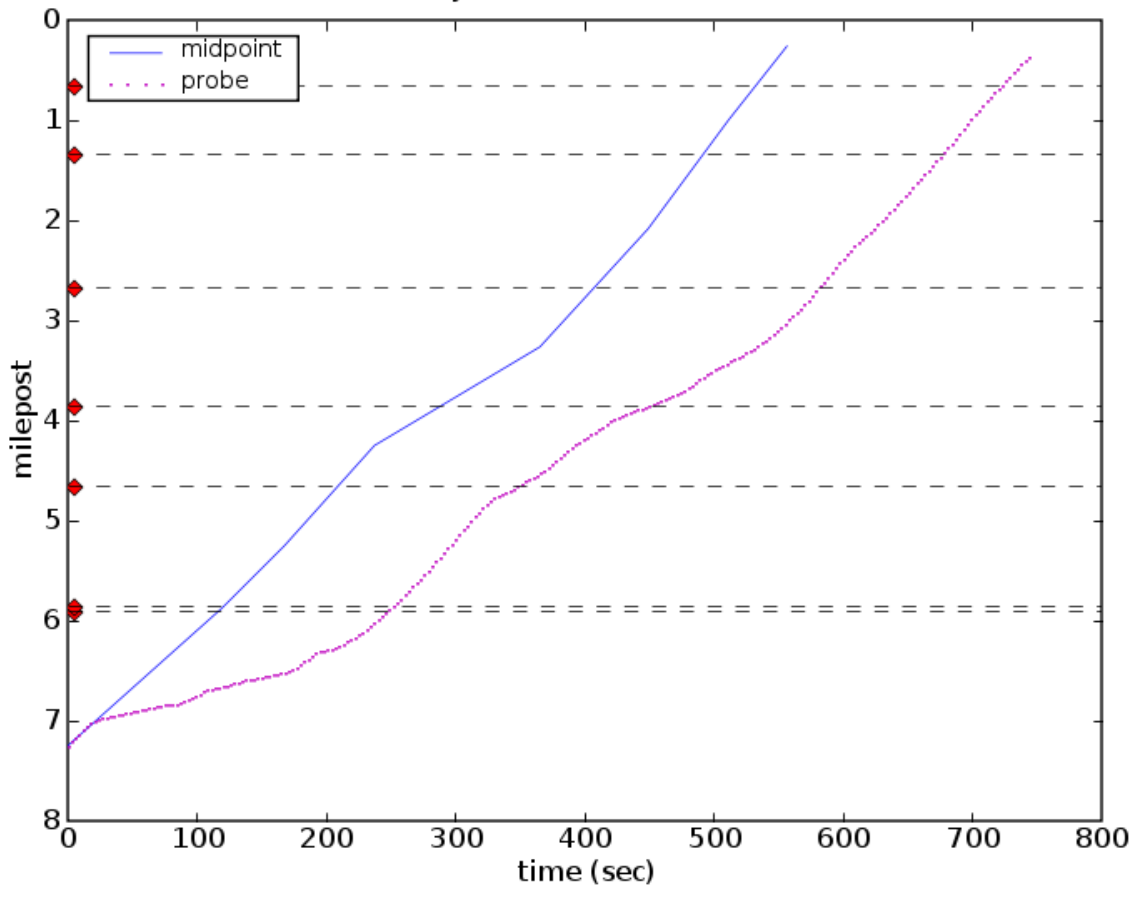

Figure 27 Trajectory Plot - Run 267

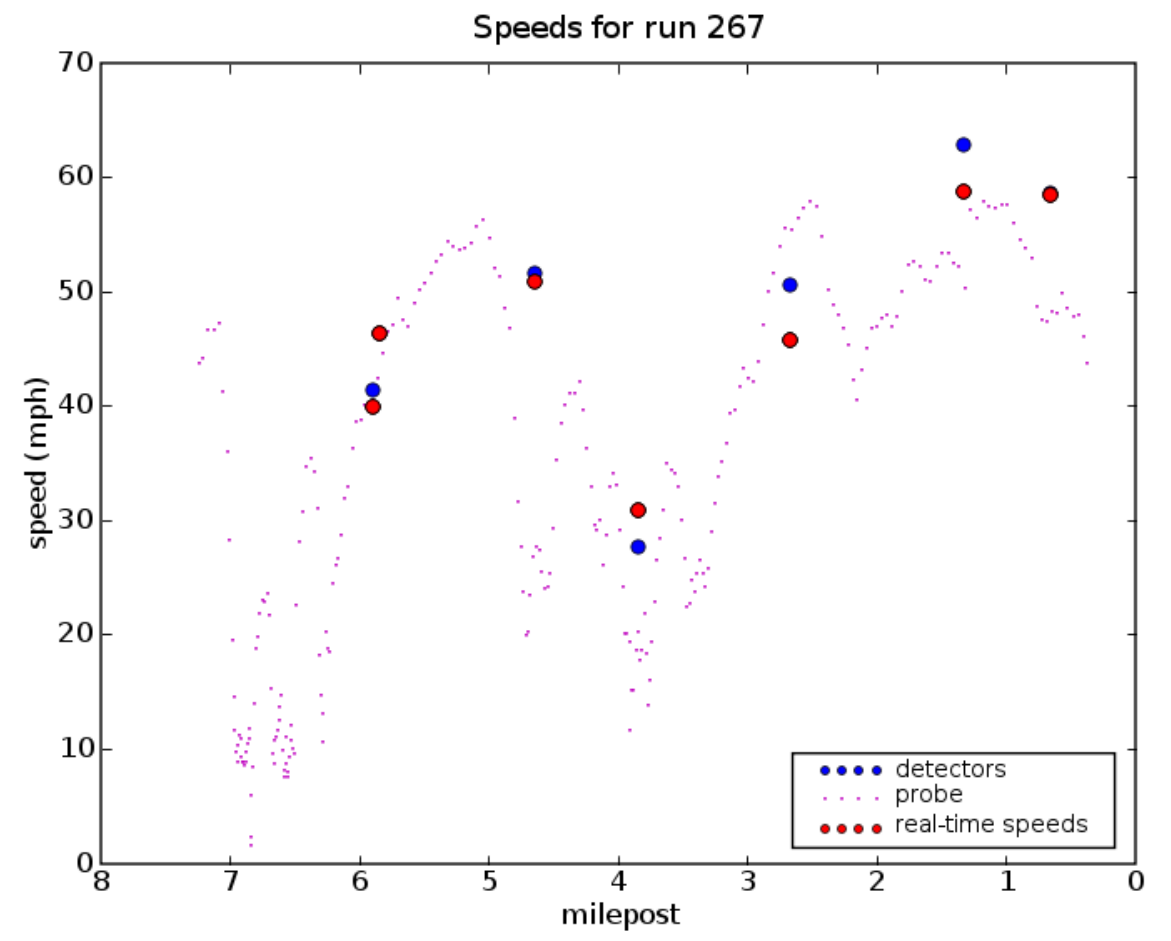

Figure 28 Speed Plot - Run 267 
Table 9 OR 217 NB - High-Error Runs

\begin{tabular}{|c|c|c|c|c|c|c|}
\hline Runid & Start time & $\begin{array}{l}\text { Ground } \\
\text { Truth } \\
\text { Travel } \\
\text { Time } \\
\text { (hh:mm:ss) }\end{array}$ & $\begin{array}{l}\text { Average } \\
\text { Speed } \\
\text { (mi/hr) }\end{array}$ & $\begin{array}{l}\text { Midpoint } \\
\text { Travel } \\
\text { Time } \\
\text { (hh:mm:ss) }\end{array}$ & $\begin{array}{l}\text { Error } \\
\text { (min) }\end{array}$ & $\begin{array}{l}\text { Error } \\
(\%)\end{array}$ \\
\hline 231 & $4 / 17 / 200716: 27$ & $0: 16: 48$ & 24.68 & $0: 13: 08$ & -3.67 & -21.83 \\
\hline 267 & 4/16/2007 16:16 & $0: 12: 24$ & 33.31 & $0: 09: 17$ & -3.12 & -25.13 \\
\hline 480 & 4/18/2007 15:59 & $0: 10: 21$ & 39.92 & $0: 12: 37$ & 2.27 & 21.9 \\
\hline 484 & 4/18/2007 17:14 & $0: 19: 30$ & 21.08 & $0: 13: 22$ & -6.13 & -31.45 \\
\hline 496 & 4/18/2007 16:26 & $0: 15: 36$ & 26.58 & $0: 11: 49$ & -3.78 & -24.25 \\
\hline 498 & 4/18/2007 17:10 & $0: 19: 24$ & 21.39 & $0: 14: 14$ & -5.17 & -26.63 \\
\hline 511 & 4/19/2007 7:46 & $0: 13: 03$ & 31.75 & 0:09:08 & -3.92 & -30.01 \\
\hline
\end{tabular}

\subsection{OR 217 SB}

Segment Description: This segment consists of the entire SB section of OR 217 from U.S. 26 to the exit ramp from OR 217 to I-5 SB. Drivers were instructed to take the exit to I-5 SB and turn around at the first exit on I-5; drivers did not take Kruse Way into Lake Oswego. Thus, probe travel times reflect the time to get from U.S. 26 onto I-5 SB.

Discussion: 45 runs were collected on this segment; of these, 82\% showed absolute estimation errors of less than $20 \%$. All but one of these errors were underestimation errors. In addition, the statistics show a significant underestimation bias. Finally, most errors occurred during the PM peak. Similar to $217 \mathrm{NB}$, detector failure played a role in the estimation error on this segment. The detectors at Walker (milepost 0.76) and Scholls Ferry roads (milepost 4.35) were not functional for all runs on this segment. Without the Walker Road detector, the first detector on the segment is at Beaverton-Hillsdale Highway at milepost 1.92. Five of the eight high-error runs exhibited congestion early in the segment which cleared before the probe reached the BeavertonHillsdale Highway junction. An additional two runs had errors that would likely have been smaller had the Scholls Ferry detector worked. It is likely that error on this segment would have been much lower had the Walker Road and Scholls Ferry detectors functioned. Figures 29 and 30 illustrate trajectory and speed plots for run 504 showing this error type.

Conclusion: Detector failure appears to be a primary source of error on this segment. To understand if the infrastructure is adequate to provide travel time estimation, additional analysis will need to be performed when the Walker and Scholls Ferry detectors are functional. 
Trajectories for run 504

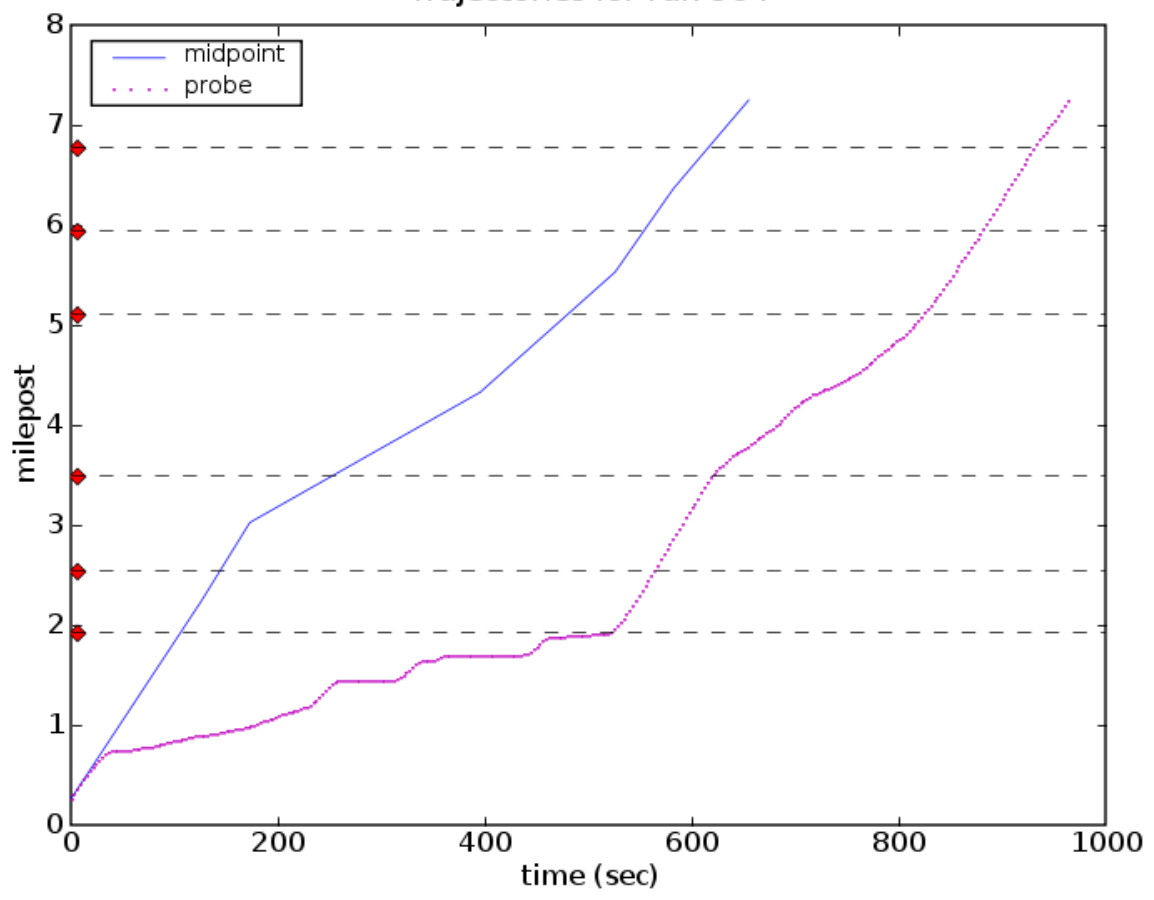

Figure 29 Trajectory Plot for Run 504

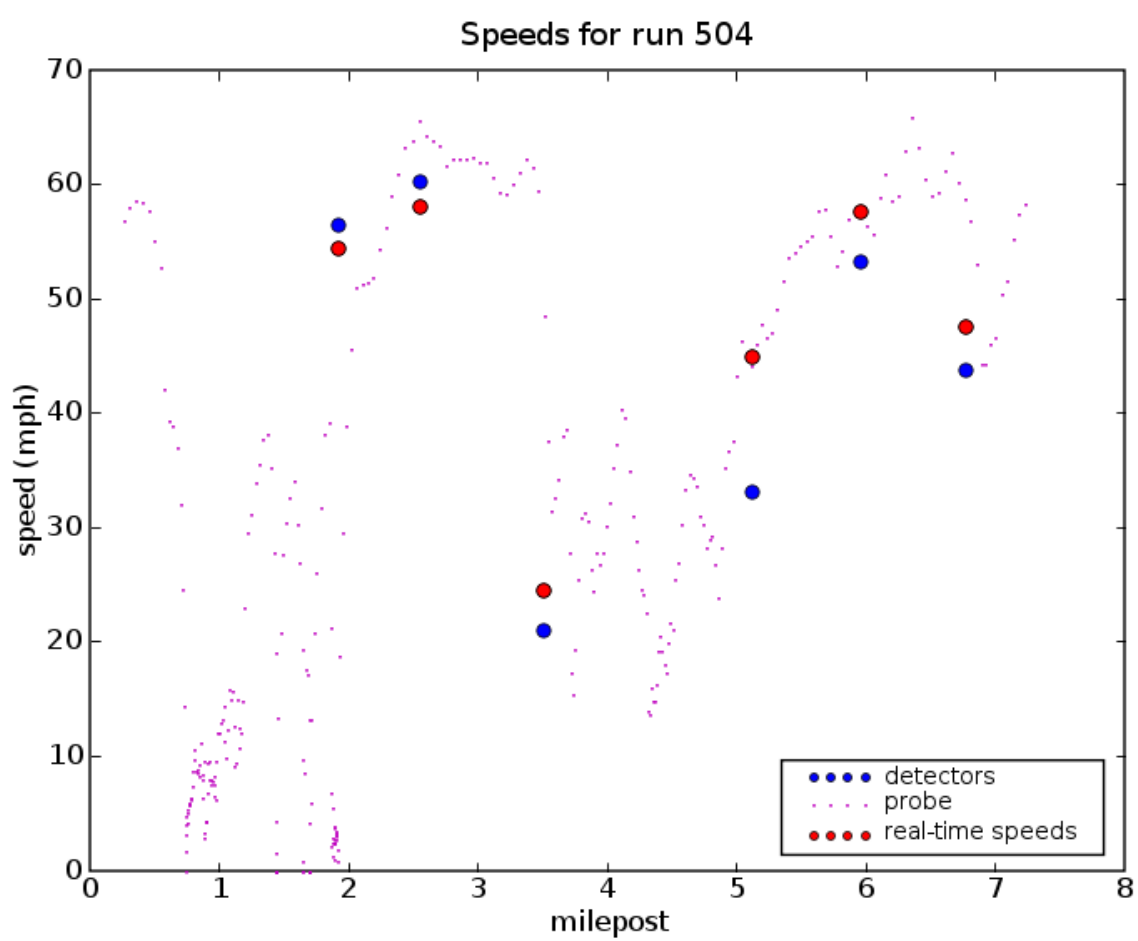

Figure 30 Speed Plot for Run 504 
Table 10 OR 217 SB - High-Error Runs

\begin{tabular}{|c|c|c|c|c|c|c|}
\hline Runid & Start time & $\begin{array}{l}\text { Ground } \\
\text { Truth } \\
\text { Travel } \\
\text { Time } \\
\text { (hh:mm:ss) }\end{array}$ & $\begin{array}{l}\text { Average } \\
\text { Speed } \\
\text { (mi/hr) }\end{array}$ & $\begin{array}{l}\text { Midpoint } \\
\text { Travel } \\
\text { Time } \\
\text { (hh:mm:ss) }\end{array}$ & $\begin{array}{l}\text { Error } \\
(\min )\end{array}$ & $\begin{array}{l}\text { Error } \\
(\%)\end{array}$ \\
\hline 230 & 4/17/2007 16:13 & 0:10:09 & 40.81 & $0: 12: 40$ & 2.52 & 24.79 \\
\hline 232 & 4/17/2007 16:49 & 0:13:22 & 31.03 & 0:08:47 & -4.58 & -34.29 \\
\hline 260 & 4/16/2007 16:00 & 0:10:45 & 38.76 & 0:08:35 & -2.17 & -20.16 \\
\hline 495 & 4/18/2007 16:02 & $0: 16: 18$ & 25.68 & $0: 12: 42$ & -3.6 & -22.09 \\
\hline 497 & 4/18/2007 16:47 & $0: 16: 15$ & 25.5 & $0: 11: 15$ & -5 & -30.77 \\
\hline 504 & 4/19/2007 7:52 & $0: 16: 03$ & 26.16 & $0: 10: 55$ & -5.13 & -31.98 \\
\hline 512 & 4/19/2007 8:03 & 0:18:27 & 22.65 & $0: 10: 45$ & -7.7 & -41.73 \\
\hline 520 & 4/17/2007 17:18 & $0: 17: 36$ & 23.68 & 0:10:05 & -7.52 & -42.71 \\
\hline
\end{tabular}

\subsection{I-84 EB}

Segment Description: The I-84 EB segment extends approximately from the I-84/I-5 junction to the I-84/I-205 junction, from milepost 0.44 to milepost 5.51. This segment and the I-84 WB segment are shown in Figure 31.

Discussion: Data collection on this segment was limited due to known detector spacing issues. In particular, the final detector on this segment is at $60^{\text {th }}$ Avenue (milepost 3.69), which is almost two miles from the segment's end. To exacerbate matters, this detector was not functioning during data collection, meaning there was an almost three-mile section at the end of this segment with no detection. We observe that when detector spacing is large, a detector failure has even greater impact. A total of 14 runs were collected on this segment. Surprisingly, the travel time estimation error was less than $20 \%$, except for two runs which showed errors greater than $40 \%$. Given the detector spacing issues, this accuracy level is surprising. At least in certain cases, the probes experienced limited congestion after milepost 2, so that the lack of detection was not an issue for those runs. Both runs with errors greater than $20 \%$ were overestimates. Figures 32 and 33 show the trajectory and speed plots for run 89, which had an estimation error of $43 \%$. The detector spacing issues are clear from the trajectory plot.

Conclusion: Detector spacing on I-84 EB is a known issue. On this segment, the detector spacing is poor in the section where I-84 EB approaches its junction with I-205, where there is a 2-mile section without detection. While the accuracy was acceptable for the runs collected, it is not recommended to provide travel time with such large detector spacing on congested freeways. The research team recommends adding detection on this segment before providing travel times. 
I-84 Segments

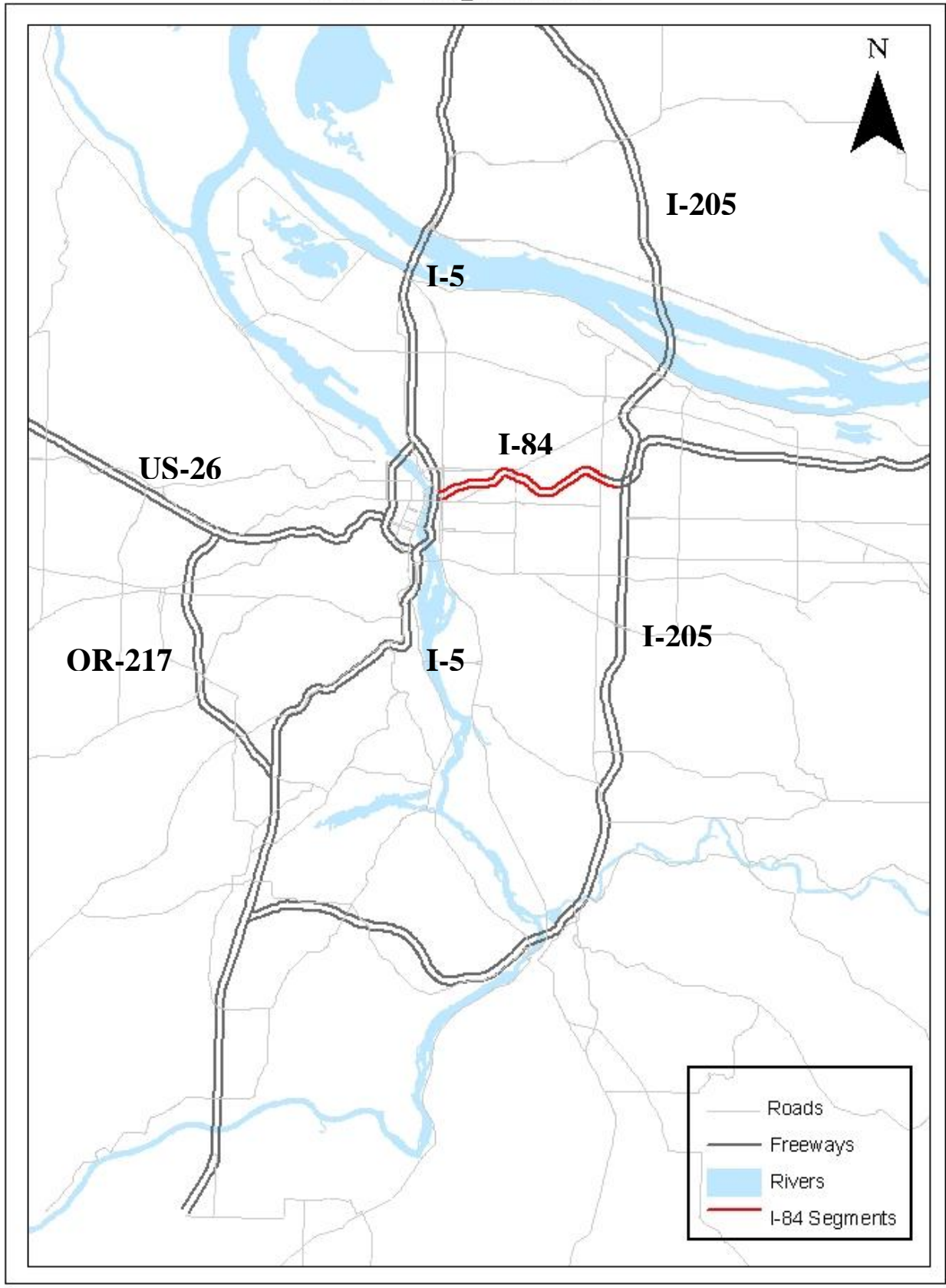

Figure 31 I-84 Segments 


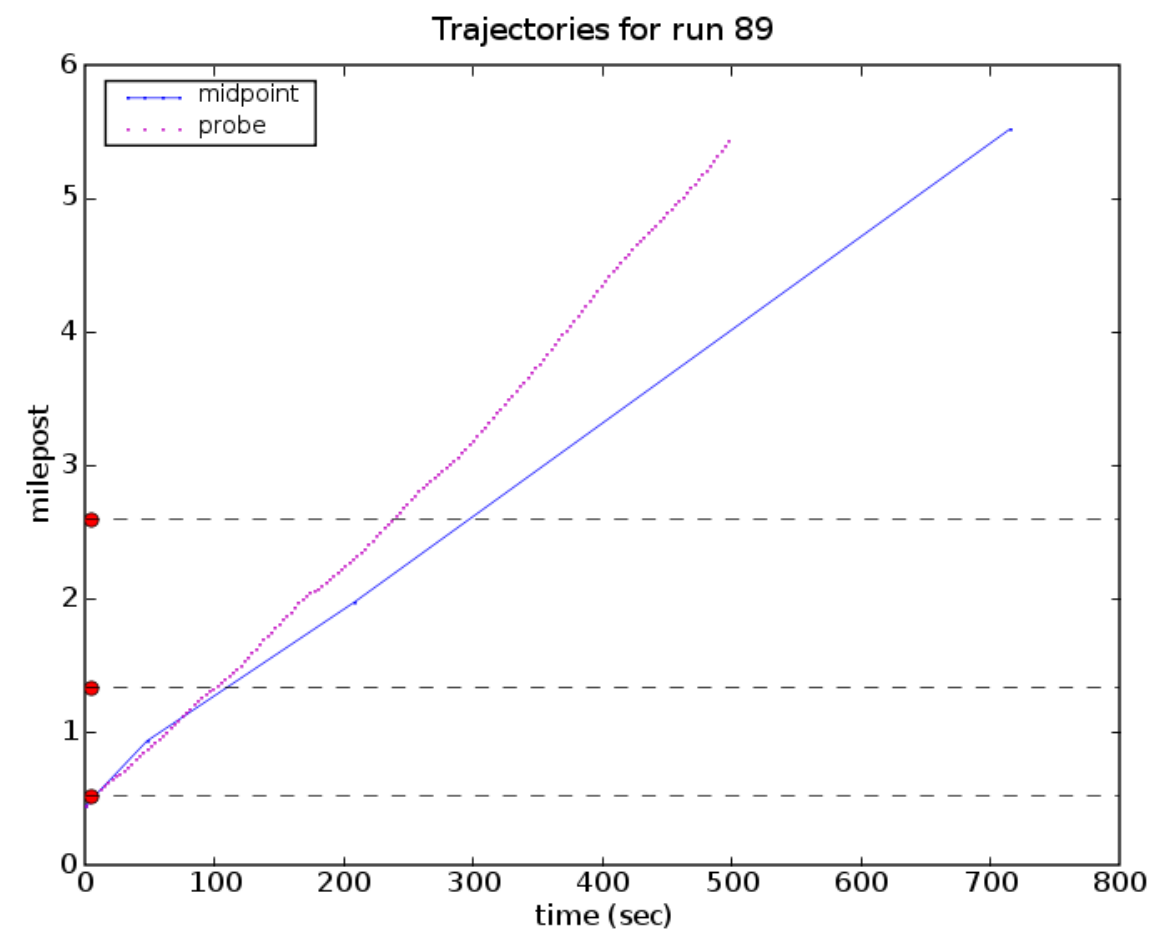

Figure 32 Trajectory Plot - Run 89

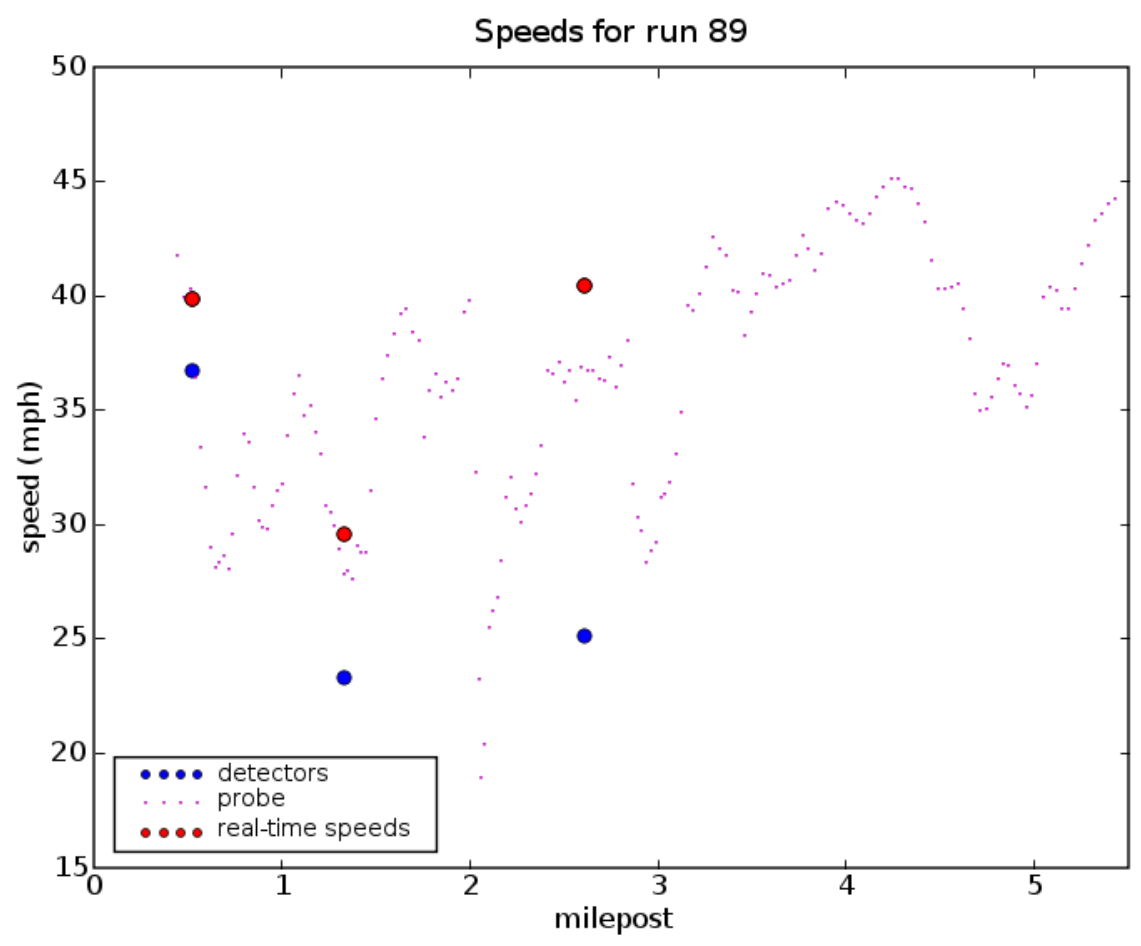

Figure 33 Speed Plot - Run 89 
Table 11 I-84 EB High-Error Runs

\begin{tabular}{|r|r|l|l|l|l|c|}
\hline & & $\begin{array}{l}\text { Ground } \\
\text { Truth } \\
\text { Travel } \\
\text { Time } \\
\text { Runid }\end{array}$ & $\begin{array}{l}\text { (hh:mm:ss) } \\
\begin{array}{l}\text { Average } \\
\text { Speed } \\
\text { (mi/hr) }\end{array}\end{array}$ & $\begin{array}{l}\text { Midpoint } \\
\text { Travel } \\
\text { Time } \\
\text { (hh:mm:ss) }\end{array}$ & $\begin{array}{l}\text { Error } \\
\text { (min) }\end{array}$ & $\begin{array}{l}\text { Error } \\
\text { (\%) }\end{array}$ \\
\hline 89 & $2 / 14 / 200717: 50$ & $0: 08: 18$ & 36.08 & $0: 11: 55$ & 3.62 & 43.57 \\
\hline 94 & $2 / 14 / 200716: 49$ & $0: 17: 48$ & 16.78 & $0: 27: 28$ & 9.67 & 54.31 \\
\hline
\end{tabular}

\subsection{I-84 WB}

Segment Description: The I-84 WB segment extends from the I-84/I-205 junction to the I-84/I-5 junction, from 5.17 to 0.4. This segment is illustrated in Figure 31.

Discussion: As with I-84 EB, detector spacing and functionality are known to be issues on I-84 WB. In particular, the last detector on this segment is at $33^{\text {rd }}$ Avenue (milepost 2.1). This spacing means that there is a 2-mile stretch at the end of this segment with no detection. As I-84 WB is inbound to downtown Portland, the last two miles of this segment are highly congested, particularly in the AM peak. Of the 15 runs collected on this segment, $53 \%$ exhibited an absolute error of greater than $20 \%$.

Table 12 shows the high-error runs for this segment.

Detector spacing and failure were large contributors to error on this run. In addition to the large section at the end of the segment without detection, as described above, the station at $56^{\text {th }}$ Avenue (milepost 3.43) was not working during data collection.

The trajectory and speed plots for run 76 (23\% underestimation) are shown in Figures 34 and 35, respectively. It is evident from these plots that sparse detector coverage is a significant factor in the estimation error.

Conclusion: The analysis of runs on I-84 WB showed that more than $50 \%$ of the runs demonstrated absolute errors of greater than $20 \%$. In addition, it is known that detector coverage is limited on this segment, leading to large estimation errors. Additional detection is necessary on this segment before travel times can be provided. 
Trajectories for run 76

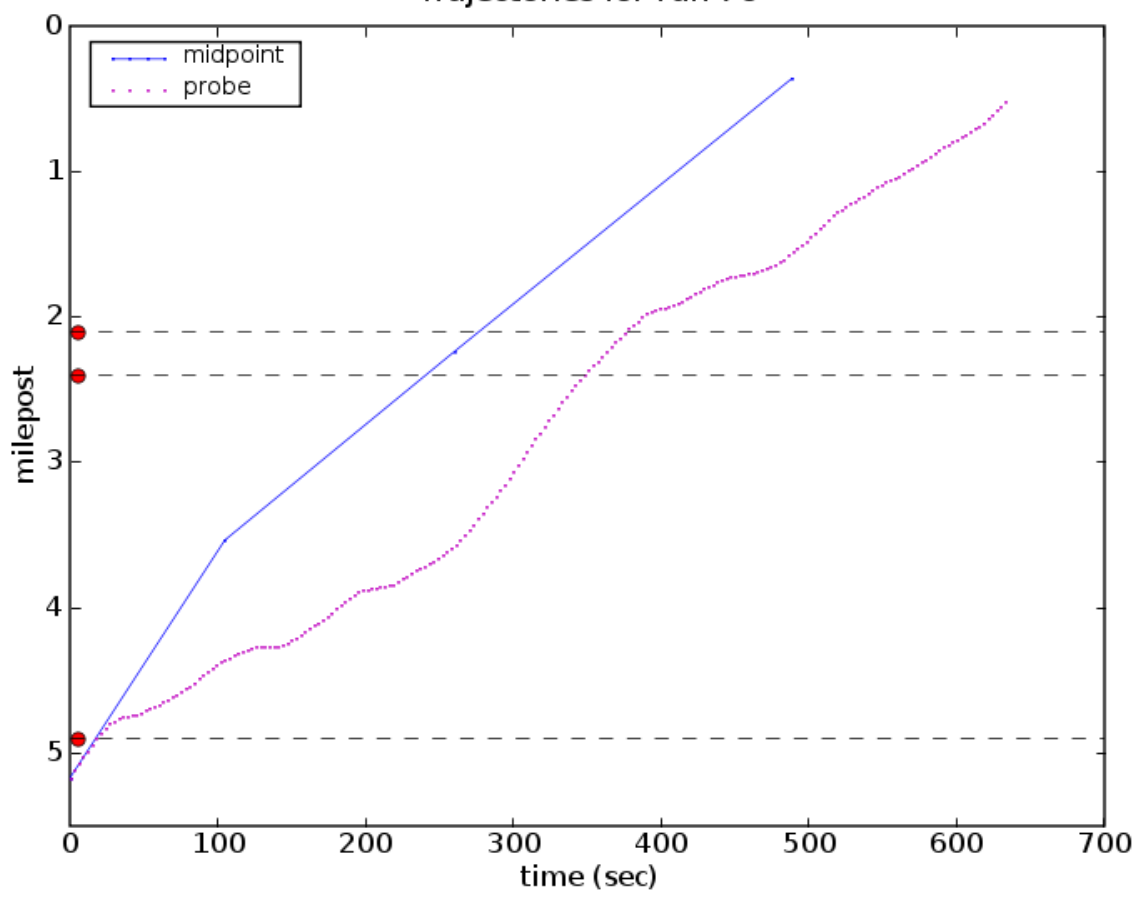

Figure 34 Trajectory Plot - Run 76

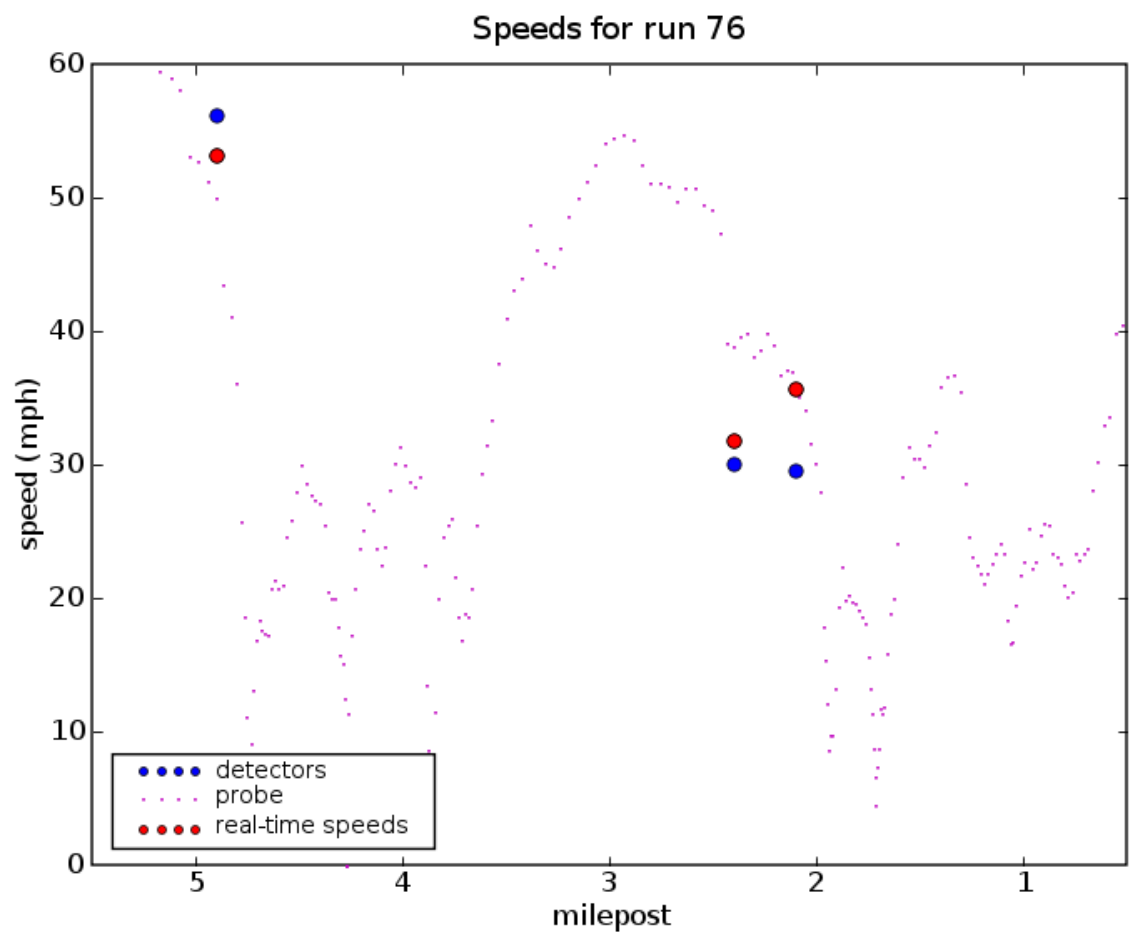

Figure 35 Speed Plot - Run 76 
Table 12 I-84 WB - High-Error Runs

\begin{tabular}{|c|c|c|c|c|c|c|}
\hline Runid & Start time & $\begin{array}{l}\text { Ground } \\
\text { Truth } \\
\text { Travel } \\
\text { Time } \\
\text { (hh:mm:ss) }\end{array}$ & $\begin{array}{l}\text { Average } \\
\text { Speed } \\
\text { (mi/hr) }\end{array}$ & $\begin{array}{l}\text { Midpoint } \\
\text { Travel } \\
\text { Time } \\
\text { (hh:mm:ss) }\end{array}$ & $\begin{array}{l}\text { Error } \\
\text { (min) }\end{array}$ & $\begin{array}{l}\text { Error } \\
(\%)\end{array}$ \\
\hline 72 & $2 / 14 / 20077: 53$ & 0:08:51 & 31.63 & 0:07:03 & -1.8 & -20.34 \\
\hline 76 & $2 / 14 / 20078: 53$ & $0: 10: 33$ & 26.62 & 0:08:09 & -2.4 & -22.75 \\
\hline 80 & 2/14/2007 8:31 & 0:09:45 & 28.93 & $0: 06: 39$ & -3.1 & -31.79 \\
\hline 82 & 2/14/2007 8:55 & $0: 10: 18$ & 27.22 & $0: 08: 03$ & -2.25 & -21.84 \\
\hline 88 & 2/14/2007 17:32 & $0: 05: 27$ & 50.99 & $0: 07: 21$ & 1.9 & 34.86 \\
\hline 90 & $2 / 14 / 2007$ 18:03 & 0:05:09 & 53.9 & 0:06:12 & 1.05 & 20.39 \\
\hline 95 & $2 / 14 / 200717: 13$ & $0: 07: 51$ & 35.81 & 0:06:10 & -1.68 & -21.44 \\
\hline 97 & 2/14/2007 18:01 & $0: 08: 57$ & 31.03 & 0:06:09 & -2.8 & -31.28 \\
\hline
\end{tabular}

\subsection{I-205 NB}

Segment Description: This segment extends from the I-205 and Highway 212/224 (Clackamas Highway) junction to Glisan Street. The limited extent of the segment is due to the lack of functioning detectors north of Glisan and construction on I-205 from near Oregon City to the I205/I-5 junction. This segment is illustrated in Figure 36.

Discussion: 32 runs were collected on this segment. Of those, $97 \%$ had errors less than $20 \%$ and $100 \%$ had errors less than $30 \%$. Somewhat limited data collection was performed on this segment due to the above-described detector and construction limitations.

Conclusion: The travel time accuracy levels appear OK for the section of I-205 examined; however, much congestion on I-205 is outside of this segment - near the junction with I-5 NB on the south end of I-205 and at the river crossing on the north end of I-205. If travel times are to be provided on the entire length of I-205, additional data collection and analysis are required after the new detectors at the segment's north end are functioning and after construction is complete at the south end.

\subsection{I-205 SB}

Segment Description: This segment extends from the junction of I-205 and Highway 212/224 (Clackamas Highway) to Glisan. The limited extent of the segment is due to the lack of functioning detectors north of Glisan and construction on I-205 from near Oregon City to the I205/I-5 junction. This segment is illustrated in Figure 36.

Discussion: 31 travel time runs were collected on this segment. Of those, $90 \%$ exhibited errors less than $20 \%$ and $96.8 \%$ exhibited errors less than 30\%. As with I-205 NB, limited data collection was performed on this segment due to the above-described detector and construction limitations.

Conclusion: The conclusion for this segment is very similar to that for I-205 NB. The accuracy levels for this segment appear OK; however, additional data collection and analysis are required if travel times are to be provided on the entire length of I-205. 
I-205 Segments

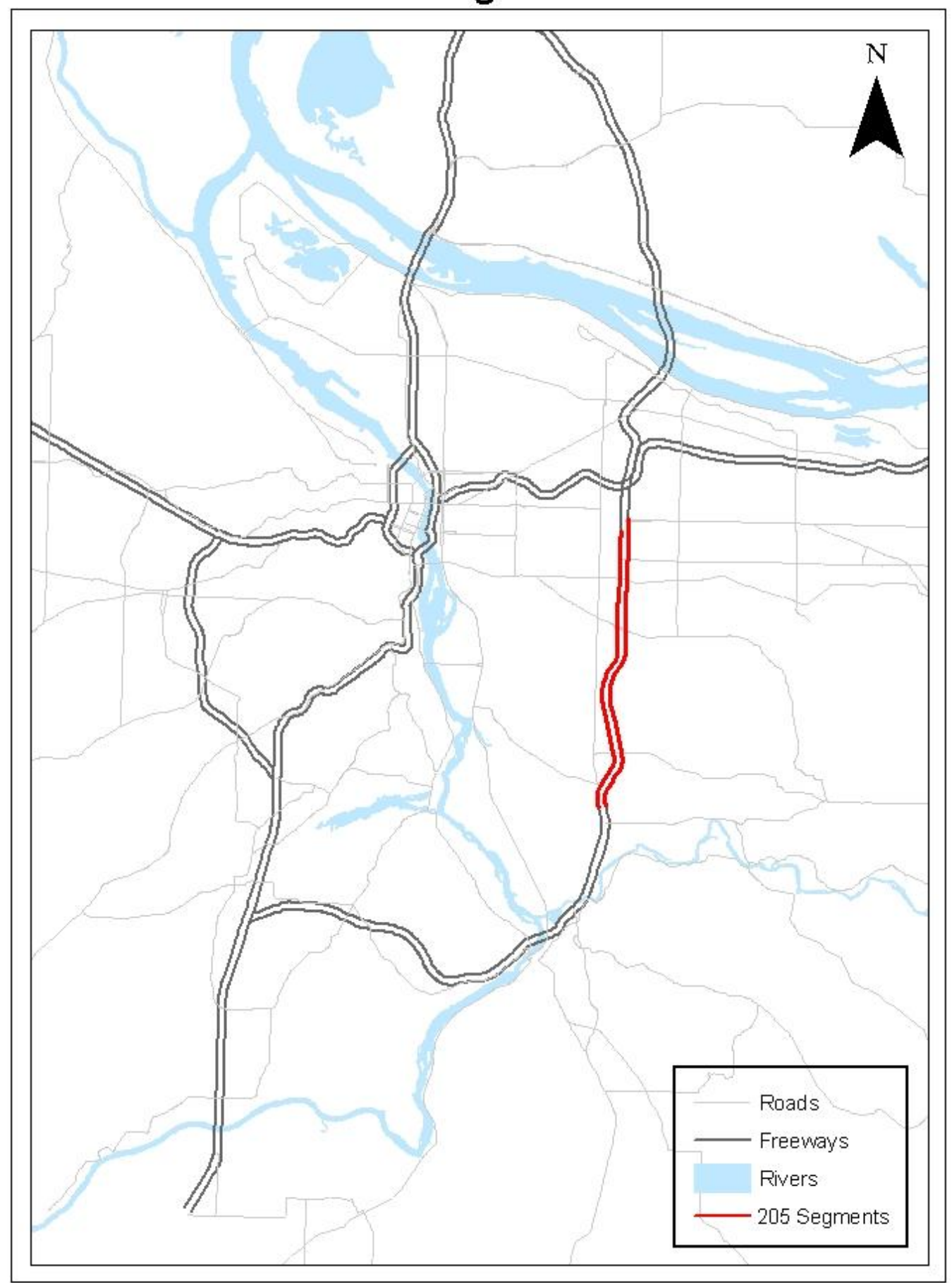

Figure 36 I-205 Segments 


\section{$4.15 \quad \mathrm{I}-405 \mathrm{NB}$}

Segment Description: This segment is approximately two miles long and extends from near Interstate Avenue to Broadway Avenue. Figure 37 shows this segment.

Discussion: 21 travel time runs were collected on this segment; all runs showed errors of less than $20 \%$. However, there are known detector spacing issues on I-405 NB. In particular, I-405 NB has only two detectors. The low error rate, despite limited detector spacing, is due to the fact that probe runs did not encounter much congestion; the lowest average speed for a probe vehicle on I-405 NB was $49 \mathrm{MPH}$.

Conclusion: The travel time runs on this segment exhibited acceptable error rates; however, that appears to be due to the lack of congestion. Additional data collection and analysis would be required to provide accurate numbers for congested conditions. As this segment is generally uncongested, collecting data for congested conditions is difficult. Travel times on this segment may be useful for the current common (uncongested) conditions; however, it would not be recommended to provide travel times on this segment during traffic incidents or other congestion without additional analysis.

\subsubsection{I-405 SB}

Segment Description: This segment extends the entire length of I-405 SB and is shown in Figure 37.

Discussion: As with I-405 NB, 21 travel time runs were collected on this segment. Of those, 95\% exhibited error less than $20 \%$, with only one run showing error greater than $20 \%$. The probe runs on this segment also encountered limited congestion. The minimum average probe speed for runs with errors less than $20 \%$ was $41 \mathrm{mph}$. On the one run with high error, a 28\% underestimation was due to conditions changing after the probe entered the segment.

Conclusion: Travel time estimation accuracy was good on this run, in part due to low congestion levels. The detection and accuracy appear appropriate for the current congestion levels. Accuracy in higher levels of congestion or in incident situations would require data collection and analysis under highly congested conditions. 


\section{|-405 Segments}

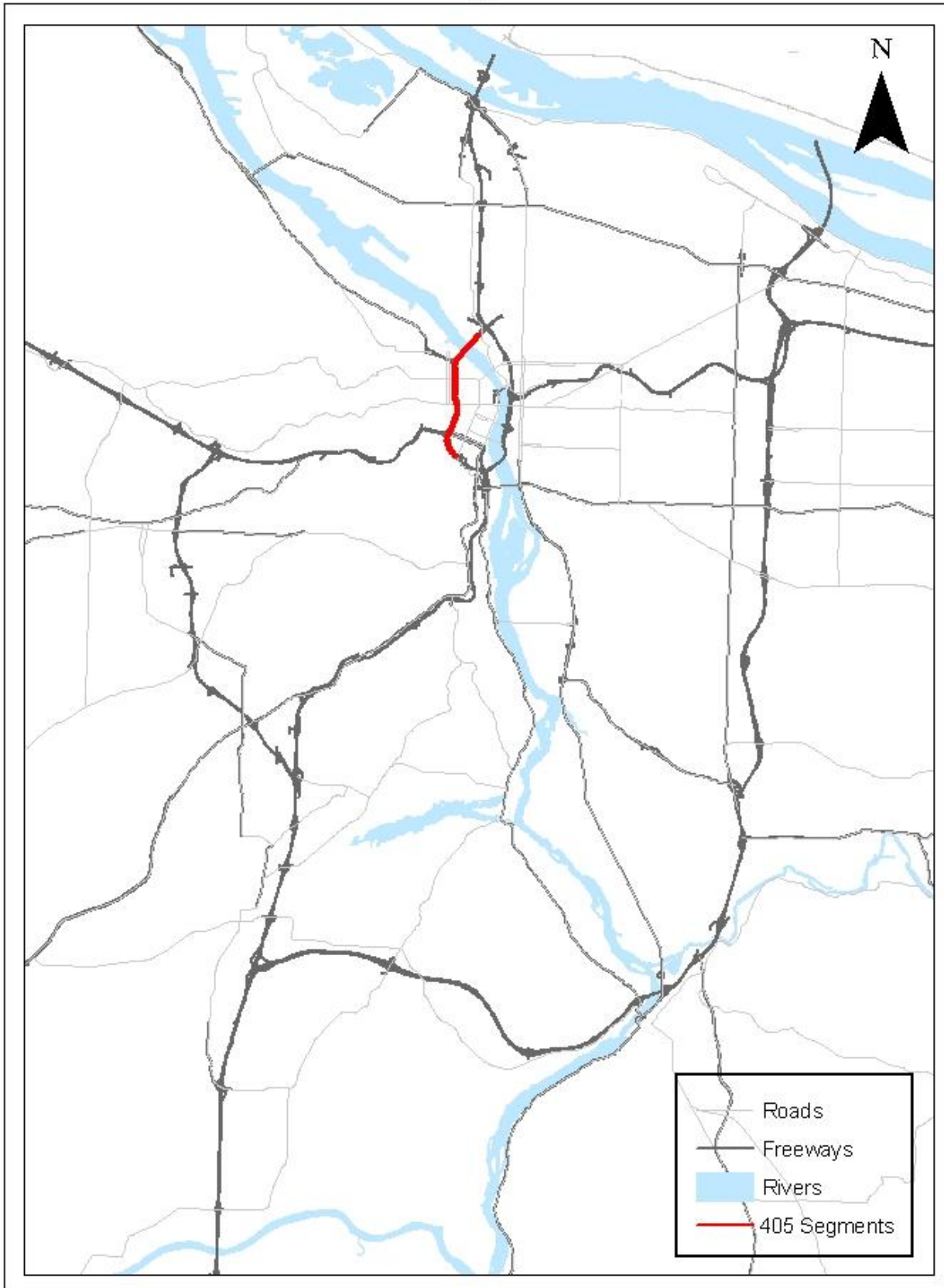

Figure 37 I-405 Segments 


\subsection{U.S. 26 EB}

Segment Description: The eastbound segment on U.S. 26 runs approximately from Murray Boulevard to the Vista Ridge Tunnel. Figure 38 shows a map of this segment.

Discussion: This segment is known to have poor detector coverage, particularly in areas of high congestion. As a result of the detector coverage issues, limited data collection was undertaken on this segment. As a result, 20 runs were collected. Of those, $80 \%$ had errors less than $20 \%$ and $100 \%$ had errors less than $30 \%$. This error level is surprisingly low given the detector coverage and congestion level. However, all runs were collected on May 1, 2007, which was a relatively uncongested day on this segment.

This segment runs from milepost 67.54 to milepost 73.75; however, the last detector in the segment is at milepost 71.37 (Skyline Road). Past Skyline, U.S. 26 EB heads into downtown Portland through the tunnel. Traffic in this area is congested and complex, as at the end of the segment, drivers may choose to go to downtown Portland or head north or south on I-405. We would expect that on a highly congested day, estimation accuracy would be much less than in our trial runs. Figures 9 and 40 show trajectory and speed plots for run 561, which had a 29\% underestimation error. The effect of the detector spacing issues is quite clear. Table 13 shows the data for this segment's high-error runs.

Conclusion: There are known detector infrastructure issues on U.S. 26 EB. For this reason, limited data collection and analysis were performed on this segment. The recommendation is to add additional detection beyond milepost 71 before providing travel times on this segment. Additional analysis may also be warranted after that detection is installed to verify travel time accuracy. The split at the end of this segment should be given special consideration as travel times for drivers going to downtown, I-405 NB and I-405 SB may differ significantly. 


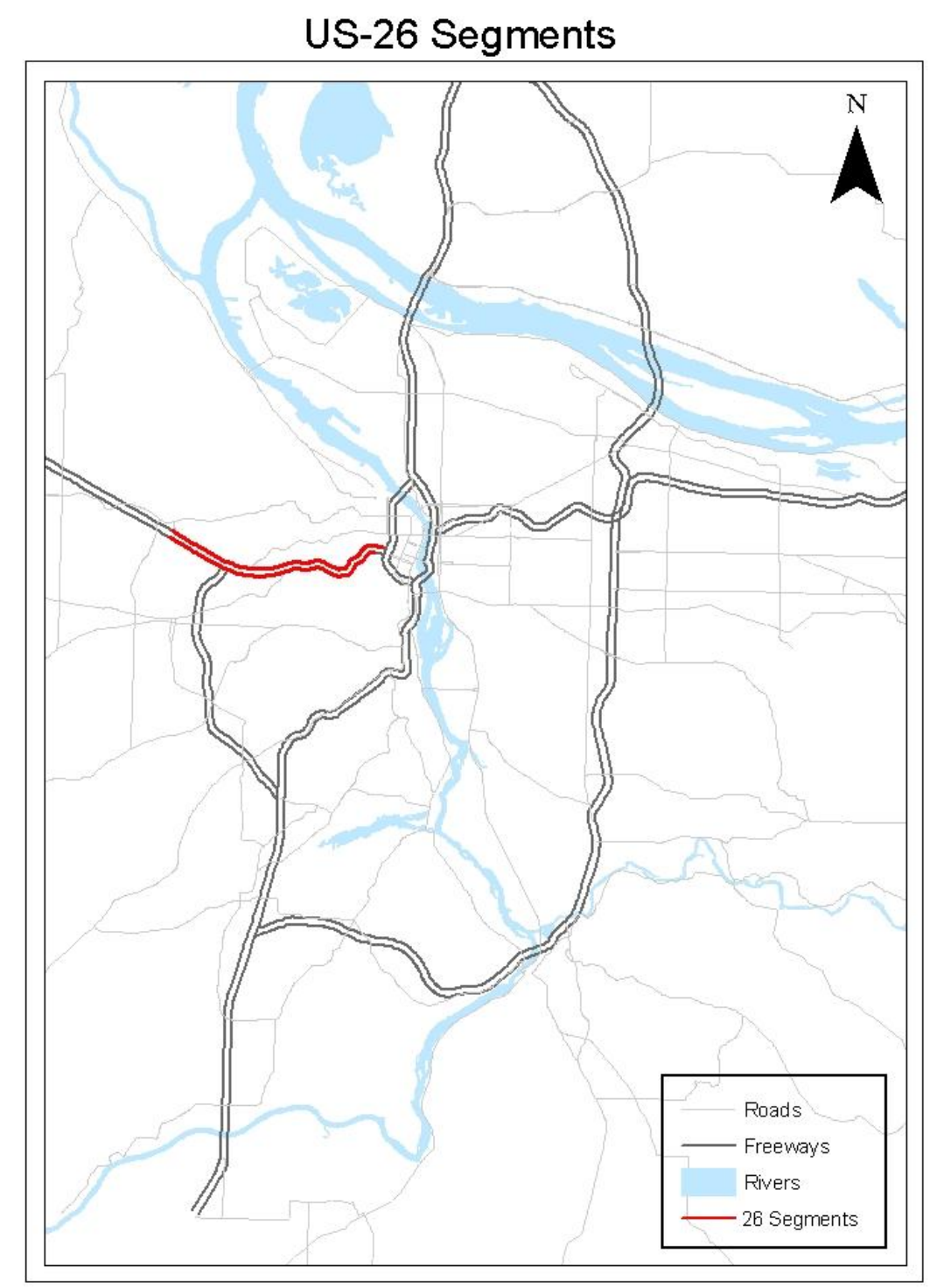

Figure 38 U.S. 26 Segments 


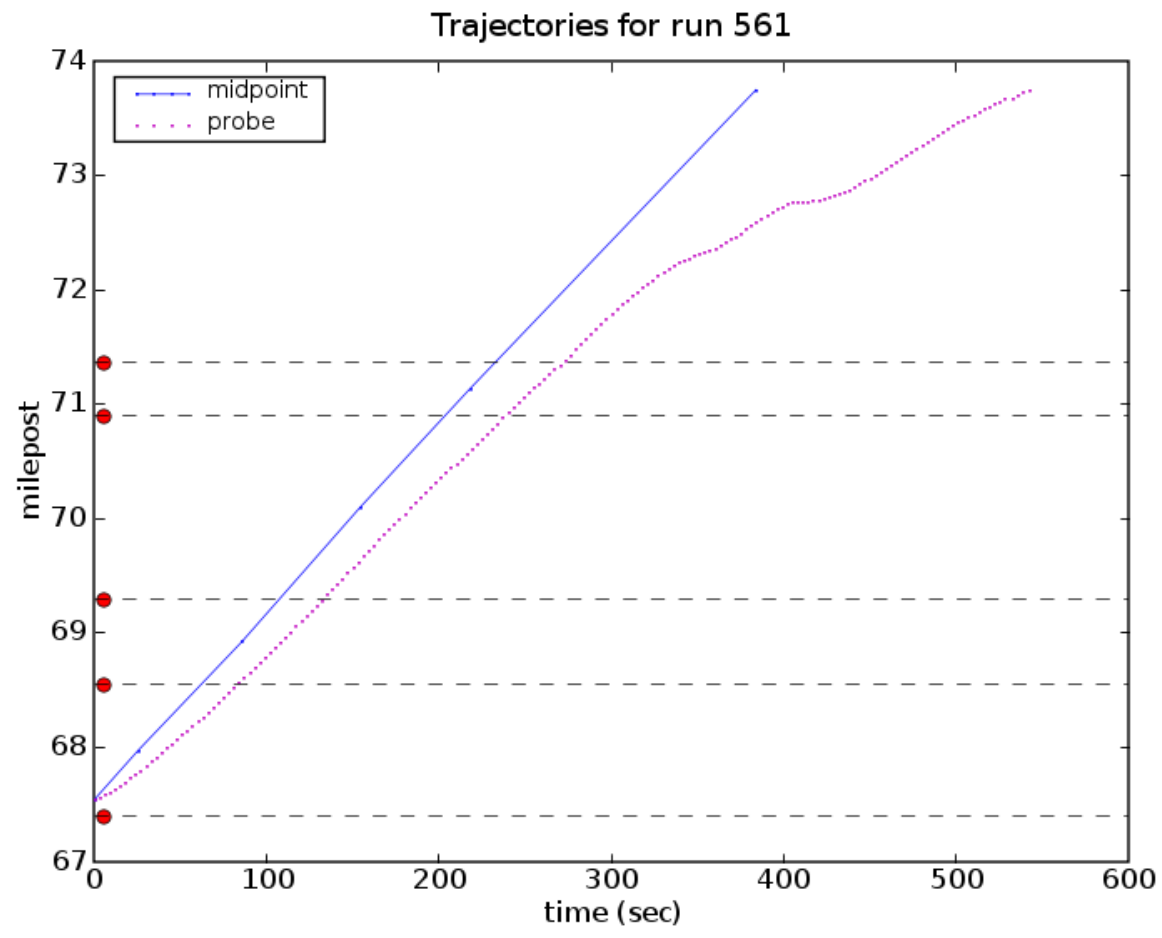

Figure 39 Trajectory Plot - Run 561

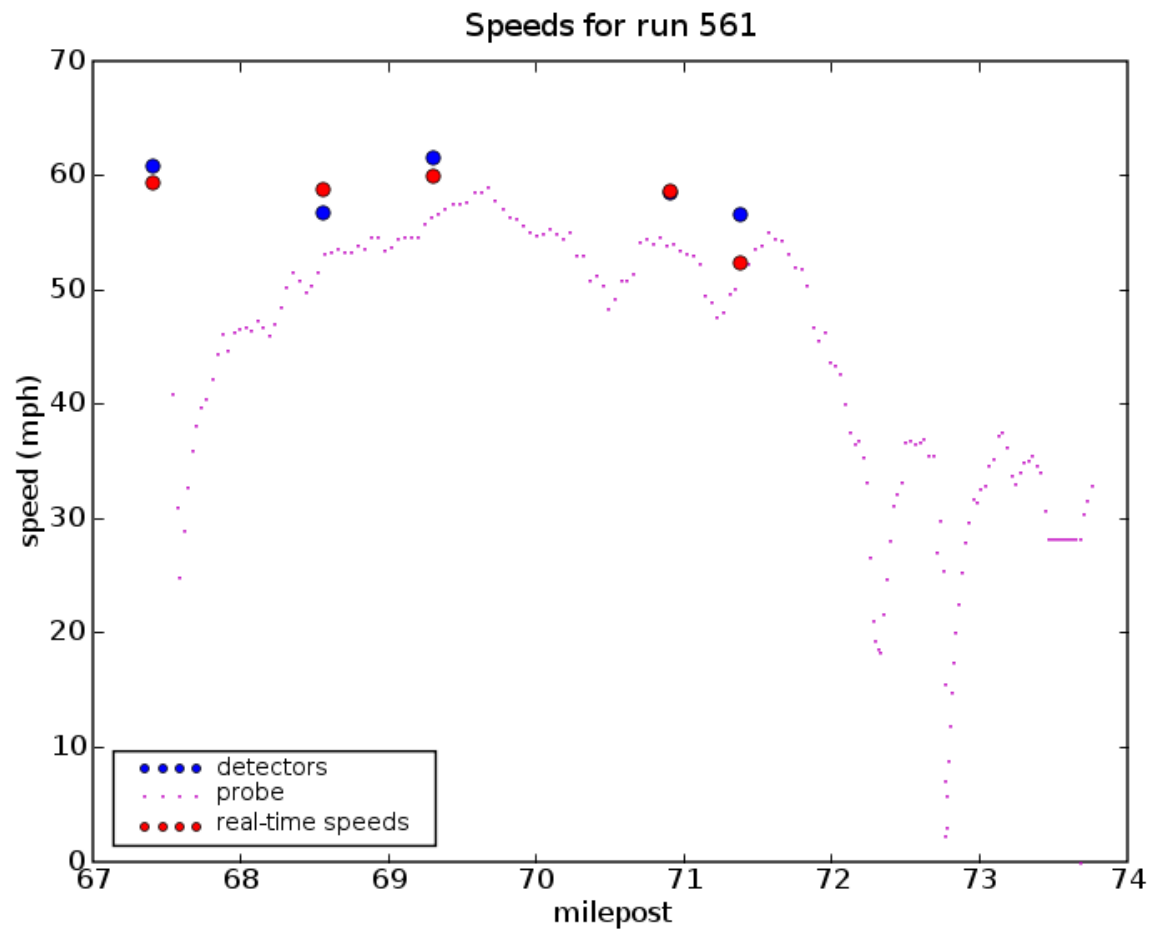

Figure 40 Speed Plot - Run 561 
Table 13 U.S. 26 EB - High-Error Runs

\begin{tabular}{|c|c|c|c|c|c|c|c|}
\hline Runid & Fileid & Start time & $\begin{array}{l}\text { Ground } \\
\text { Truth } \\
\text { Travel } \\
\text { Time } \\
\text { (hh:mm:ss) }\end{array}$ & $\begin{array}{l}\text { Average } \\
\text { Speed } \\
\text { (mi/hr) }\end{array}$ & $\begin{array}{l}\text { Midpoint } \\
\text { Travel } \\
\text { Time } \\
\text { (hh:mm:ss) }\end{array}$ & $\begin{array}{l}\text { Error } \\
\text { (min) }\end{array}$ & $\begin{array}{l}\text { Error } \\
(\%)\end{array}$ \\
\hline 525 & 68 & $5 / 1 / 2007$ 7:32 & $0: 10: 15$ & 36.64 & 0:07:24 & -2.85 & -27.8 \\
\hline 541 & 69 & 5/1/2007 17:31 & 0:08:21 & 45.28 & 0:06:24 & -1.95 & -23.35 \\
\hline 551 & 70 & 5/1/2007 8:38 & 0:10:09 & 36.81 & 0:12:21 & 2.2 & 21.67 \\
\hline 561 & 71 & 5/1/2007 17:32 & 0:09:02 & 41.41 & 0:06:24 & -2.63 & -29.15 \\
\hline
\end{tabular}

\subsection{U.S. 26 WB}

Segment Description: This segment extends from approximately the Vista Ridge Tunnel just west of downtown Portland to Murray Boulevard and is shown in Figure 38.

Discussion: As with U.S. 26 EB, U.S. 26 WB has poor detector coverage in highly congested areas. Similar to U.S. 26 EB, the area of concern is the freeway section just west of downtown Portland. In this section, there is a detector at Jefferson Street (milepost 73.33), but no other detector until Skyline Boulevard (milepost 71.07), more than two miles away. This area of freeway has several curves and grade changes and is congested during the PM peak. It is not expected that these two detectors can capture that congestion.

A total of 20 travel time runs were collected on this segment. Again, the collection was limited due to the known detector issues. Surprisingly, all runs had errors less than $20 \%$. This result is likely due to low congestion on the day the runs were collected (May 1, 2007). Of the 20 runs, 16 had average probe speed of greater than $50 \mathrm{MPH}$, and the lowest average probe speed was 44 $\mathrm{MPH}$.

Conclusion: The conclusion for U.S. $26 \mathrm{WB}$ is similar to the conclusion for $26 \mathrm{~EB}$. Due to known detector infrastructure issues on U.S. $26 \mathrm{WB}$, limited data collection and analysis were performed on this segment. The research team recommends adding additional detection between mileposts 71 and 73 before providing travel times on this segment. Additional analysis may also be warranted after that detection is installed to verify travel time accuracy. 


\subsection{ALGORITHM REFINEMENT}

The research team undertook an extensive literature search to identify related algorithms that could be used for travel time estimation. In addition, state transportation departments and the FHWA were contacted to identify algorithm alternatives. Several algorithm alternatives were identified; these include a traffic theory-based algorithm from the literature [5] and alternative algorithms used by the Washington Department of Transportation (WSDOT) and Texas Department of Transportation (TxDOT) in San Antonio. In addition, ODOT has experimented with modifying station influence areas to more accurately reflect the freeway areas that are effectively represented by which detectors. This section includes a summary of the analysis of the Coifman Algorithm, an analysis of the real-time portion of the algorithm used by the Washington Department of Transportation (WSDOT) and TxDOT in San Antonio, as well as a brief analysis of the influence-area modifications.

Further study is in progress on additional modifications that may improve accuracy. An initial study on simple trending was completed but inconclusive. Additional trending studies are expected to be completed during extensions of this project. In addition, as indicated below, influence-area adjustments show promise and, therefore, adjustments to influence areas will be investigated further in the OTREC-funded extension of this project. Finally, work continues on identifying a method for estimating accuracy in real time.

\subsection{COIFMAN ALGORITHM}

PSU researchers studied the Coifman Algorithm in detail [6]. This algorithm uses traffic theory about congestion wave propagation to attempt to better calculate travel time for an influence area for a given detector station. The algorithm has been found to be slightly more accurate than the midpoint algorithm. However, the Coifman Algorithm is complex and was developed as an offline algorithm. Therefore, it is not directly suitable for real-time use.

The algorithm proposed by Coifman uses traffic flow theory to estimate travel times for a link. Coifman proposed that the velocity of a vehicle can be represented by:

$v(x, t)=f(x+u . t)$

where $x$ is the distance, $t$ is time and $u$ can be either $u_{\mathrm{f}}$ the free flow signal velocity or $u_{\mathrm{c}}$ the congested signal velocity. The vehicle trajectories in a time space diagram can be represented by the differential equation:

$$
\frac{d x}{d t}=v(x, t)
$$

The vehicle's travel time across a link is the time taken by the corresponding trajectory to travel across the link as shown in Figure 41. 


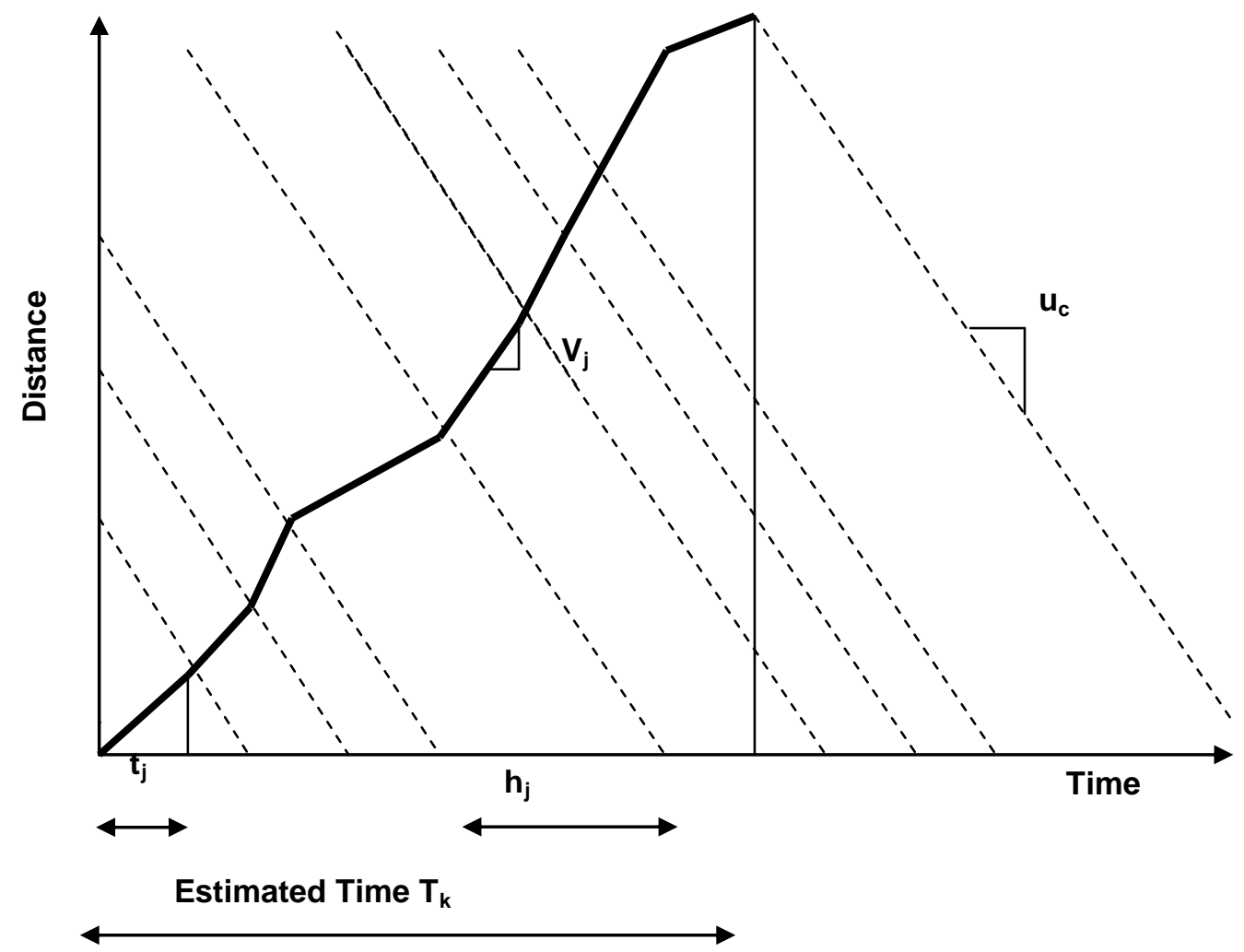

Figure 41 Coifman Travel Time Estimation

Travel time for a link can be estimated using vehicle velocity $\left(v_{\mathrm{j}}\right)$, headway $\left(h_{\mathrm{j}}\right)$ and congested signal speed using the relationship:

$\tau_{j}=\frac{h_{j}}{1+\frac{v_{j}}{u_{c}}}$

$x_{j}=v_{j} \tau_{j}$

By measuring headway $\left(h_{\mathrm{j}}\right)$ and velocity $\left(v_{\mathrm{j}}\right)$ from the loop data, and using equations (3) and (4), $t_{j}$ and $x_{j}$ can be calculated. The successive $x_{\mathrm{j}} \mathrm{s}$ are added to obtain the link distance. However, the total distance obtained can exceed the link distance. Therefore, to accurately estimate the link distance, a weight $p$ is calculated as shown in Equation 5:

$p=\frac{\left(x_{k+N_{k}+1}+\sum_{j=k}^{k+N_{k}} x_{j}\right)-d}{x_{k+N_{k}+1}}$ 
Finally, travel time is estimated as:

$T_{k}=p \cdot \tau_{k+N_{k}+1}+\sum_{j=k}^{k+N_{k}} \tau_{j}$

In order to compare and contrast the performance of the two algorithms, travel times obtained from a previous ground truth data collection effort were used. PSU researchers collected probe vehicle data (87 runs) during April-May 2005 for selected links on the Portland freeway network. A total of 15 hours of data - more than 516 miles of travel over 7 days - were collected. Figure 42 shows a map of these link locations. Typical probe vehicle headway ranged between 5-7 minutes. Travel time data for all the freeway links were collected using global positioning systems (GPS) devices as described in Section 3.3.

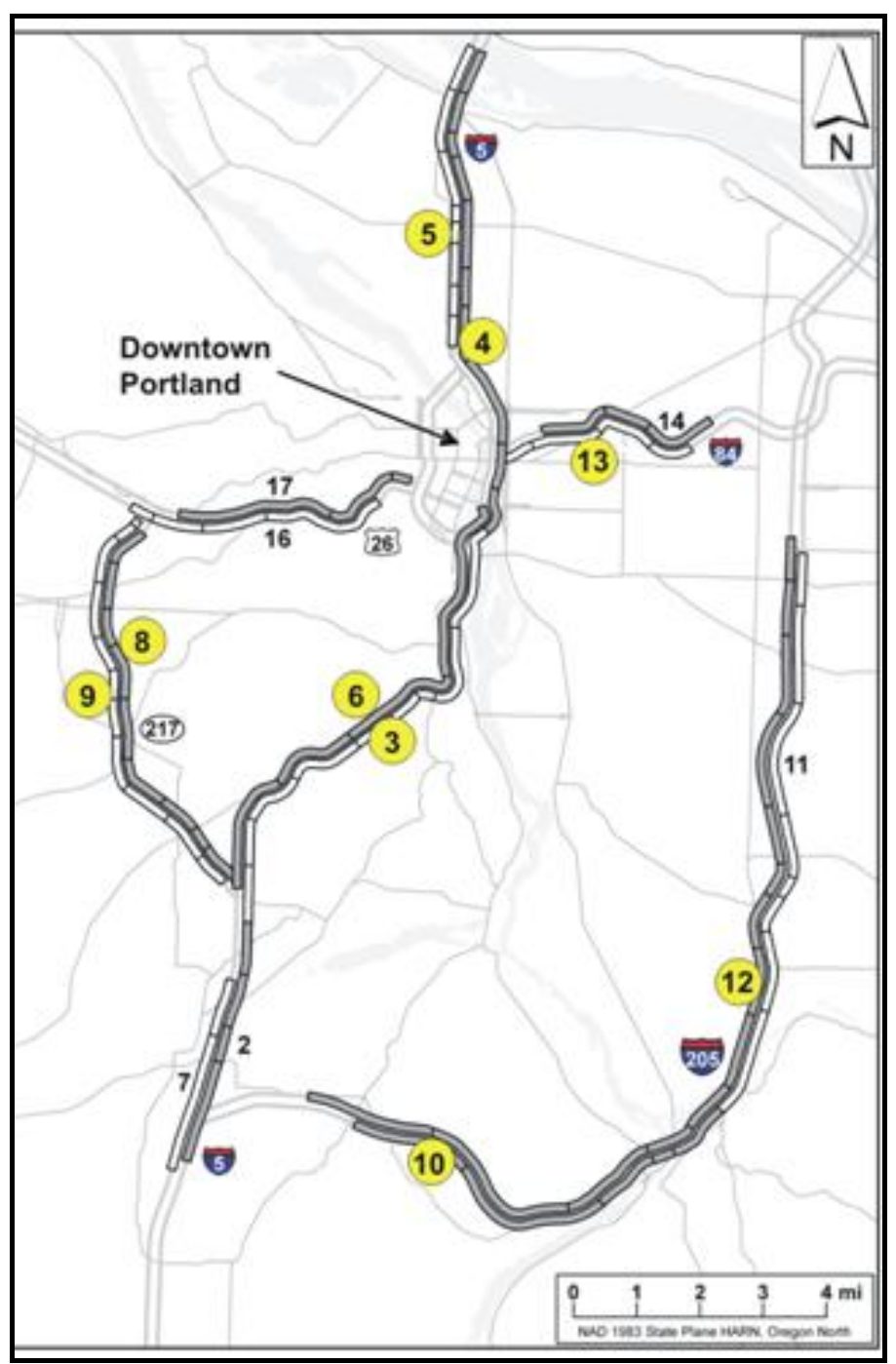

Figure 42 Map of Link Locations 
For this study, the links marked with a yellow circle were used for analysis and comparison. The travel time estimates were calculated using archived loop detector data.

Travel times from the ground truth data were compared to travel times estimated from the archived loop data using the Coifman and the Midpoint algorithms. Mean travel times (and standard deviations) for the probe vehicle and the mean estimates obtained from the Coifman and Midpoint algorithms are shown in Table 14. This table includes two variations on the Coifman algorithm: upstream $(\mathrm{u} / \mathrm{s})$ and downstream $(\mathrm{d} / \mathrm{s})$. To estimate travel times for a segment, the Coifman algorithm can use either the speeds from the upstream detector or from the downstream detector; thus the upstream and downstream variations.

Table 14 Probe, Coifman and Midpoint Travel Time Statistics

\begin{tabular}{|c|c|c|c|c|c|c|c|c|c|c|c|c|c|c|}
\hline \multirow[t]{2}{*}{ No. } & \multirow{2}{*}{$\begin{array}{c}\text { Distance } \\
m i\end{array}$} & \multirow{2}{*}{$\begin{array}{c}\text { Spacing } \\
m i\end{array}$} & \multirow{2}{*}{$\begin{array}{l}\text { No. } \\
\text { Runs }\end{array}$} & \multicolumn{2}{|c|}{ Probe } & \multicolumn{3}{|c|}{ Coifman (u/s) } & \multicolumn{3}{|c|}{ Coifman $(d / s)$} & \multicolumn{3}{|c|}{ Midpoint } \\
\hline & & & & $\mu$ & $\sigma$ & $\mu$ & $\sigma$ & \%Error & $\mu$ & $\sigma$ & $\%$ Error & $\mu$ & $\sigma$ & $\%$ Error \\
\hline 3 & 7.52 & 1.07 & 6 & 8.33 & 0.31 & 8.32 & 0.44 & 0.20 & 9.69 & 1.58 & 16.22 & 8.99 & 0.50 & 7.92 \\
\hline 4 & 5.40 & 1.08 & 5 & 14.08 & 5.91 & 12.71 & 5.96 & 10.72 & 13.96 & 4.22 & 15.02 & 15.10 & 8.73 & 10.35 \\
\hline 5 & 4.00 & 0.57 & 4 & 5.95 & 2.41 & 6.39 & 2.90 & 6.28 & 5.77 & 1.75 & 9.49 & 6.61 & 2.79 & 10.57 \\
\hline 6 & 5.89 & 1.96 & 9 & 6.99 & 0.51 & 7.64 & 2.18 & 19.31 & 6.43 & 0.09 & 7.72 & 7.65 & 1.95 & 16.89 \\
\hline 8 & 5.95 & 0.74 & 7 & 18.82 & 10.53 & 15.61 & 8.39 & 15.51 & 11.90 & 4.80 & 28.92 & 17.55 & 11.17 & 20.16 \\
\hline 9 & 6.32 & 0.70 & 4 & 7.11 & 0.60 & 6.41 & 0.32 & 9.70 & 6.96 & 0.38 & 4.02 & 6.50 & 0.12 & 8.71 \\
\hline 10 & 5.90 & 1.48 & 4 & 12.73 & 0.99 & 14.16 & 0.33 & 11.70 & 13.48 & 1.05 & 5.92 & 14.84 & 4.97 & 22.01 \\
\hline 12 & 16.39 & 1.26 & 4 & 17.29 & 0.54 & 17.66 & 0.11 & 3.03 & 16.96 & 0.11 & 2.22 & 17.15 & 0.18 & 2.26 \\
\hline 13 & 3.70 & 1.06 & 11 & 4.92 & 2.26 & 4.93 & 2.09 & 5.07 & 4.63 & 1.58 & 9.54 & 4.93 & 2.01 & 8.31 \\
\hline
\end{tabular}

The results from the analysis of the Coifman and the Midpoint algorithms indicated that although the Coifman algorithm was more accurate than the midpoint algorithm and produced errors of lower magnitude in most cases, the algorithm was complex and could not be implemented in its current form for real-time applications.

\subsection{MIDPOINT ALGORITHM VARIATIONS}

Several algorithms are used by various transportation departments around the United States. These algorithms are similar to the standard midpoint algorithm analyzed in Section 4.0; however, they vary the definition of detector influence area. First, three such algorithms are described, followed by a comparison of these algorithms to the standard midpoint algorithm.

\subsubsection{WSDOT Algorithm}

The Washington Department of Transportation has developed an algorithm for real-time travel time estimation. This algorithm uses average of the speeds from the upstream and downstream detectors to estimate travel time. Travel time is estimated as the ratio of distance between the detectors to the average speed obtained from the detectors. The algorithm used by WSDOT to display travel times on the Web also includes an historical component not considered for this analysis.[11]

\subsubsection{San Antonio Algorithm}

The travel times posted on the Web and the VMS in San Antonio are derived from speeds obtained from loop detector data. To estimate travel time for a segment bounded by two detectors at either end of the segment, the lower of the upstream and downstream speeds is used in the calculation [8]. 


\subsubsection{Mn/DOT Algorithm}

The Mn/DOT has studied an algorithm that divides freeway segments into thirds. The upstream detector is used for the first third. The downstream detector is used for the last third. The average of the two is used for the middle third.

\subsubsection{Comparison}

Figure 43 shows a comparison of estimation errors using standard midpoint algorithm, WSDOT algorithm and the San Antonio algorithm on the I-5 NB (south of downtown) segment. Note that Figure 43 (and

Table 15 below) do not necessarily reflect on the accuracy of the WSDOT algorithm as the WSDOT algorithm also incorporates historical data. The full algorithm may be evaluated in future work. In general, the Midpoint, WSDOT and Minnesota algorithms have similar performance; due to its nature, the San Antonio algorithm has an overestimation bias.

Table 15 provides a statistical comparison of the algorithms. The Midpoint, WSDOT and MnDOT algorithms perform similarly. The MnDOT algorithm has the lowest error numbers; however, the difference does not appear to be significant.

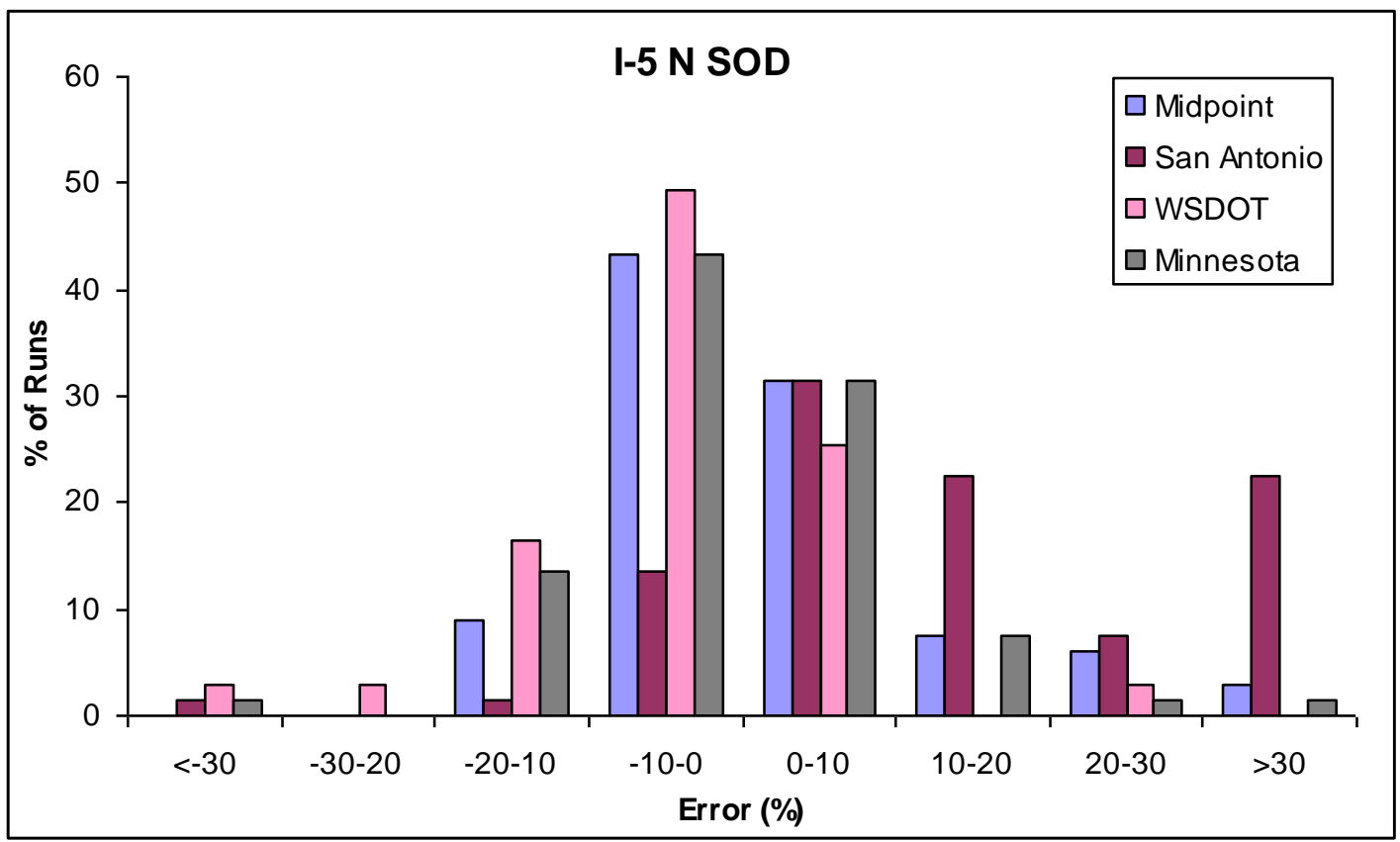

Figure 43 Algorithm Comparison for I-5 NB (south of downtown)

Table 15 Statistical Algorithm Comparison

\begin{tabular}{|l|r|r|r|r|}
\hline & $\begin{array}{l}\text { Standard } \\
\text { Midpoint }\end{array}$ & $\begin{array}{l}\text { San } \\
\text { Antonio }\end{array}$ & $\begin{array}{l}\text { WSDOT (Real- } \\
\text { time portion) }\end{array}$ & MnDOT \\
\hline $\begin{array}{l}\text { Average Absolute Error } \\
\text { Percent }\end{array}$ & 12.50 & 22.86 & 11.98 & 12.12 \\
\hline $\begin{array}{l}\text { Standard Deviation } \\
\text { Error Percent }\end{array}$ & 20.82 & 38.56 & 16.77 & 19.68 \\
\hline Average Error Percent & 1.59 & 19.10 & -5.94 & -1.00 \\
\hline Standard Error & 1.24 & 2.30 & 1.00 & 1.18 \\
\hline
\end{tabular}




\subsection{INFLUENCE AREA ADJUSTMENTS}

ODOT has adjusted the lengths of detector influence areas in an attempt to provide more accurate travel time estimates. In particular, length adjustments have occurred on the I-5 SB (south of downtown) segment. While additional data are required, initial investigation showed that these influence-area modifications hold promise. For runs on I-5 SB (south of downtown), the average error was reduced to $10 \%$ from $11 \%$ and the maximum absolute error was reduced from $42.5 \%$ to $27.4 \%$. In addition, influence area adjustments were tried on the I-5 NB (downtown to Columbia River Segment) - these adjustments also show promise.

Table 166 ODOT Adjusted Influence Areas

\begin{tabular}{|c|c|c|c|c|c|c|c|c|}
\hline $\begin{array}{l}\text { Segment } \\
\text { Description }\end{array}$ & $\begin{array}{l}\text { Avg } \\
\text { Abs } \\
\text { Pct } \\
\text { Error }\end{array}$ & $\begin{array}{l}\text { Std } \\
\text { Dev } \\
\text { Pct } \\
\text { Error } \\
\text { (SDPE) }\end{array}$ & $\begin{array}{l}\text { Avg } \\
\text { Pct } \\
\text { Error }\end{array}$ & $\begin{array}{l}\text { Std } \\
\text { Error }\end{array}$ & $\begin{array}{l}\text { Num } \\
\text { Runs }\end{array}$ & $\begin{array}{l}\text { Percent } \\
\text { Estimates } \\
\text { with } \\
\text { Error < } \\
20 \%\end{array}$ & $\begin{array}{l}\text { Percent } \\
\text { Estimates } \\
\text { with } \\
\text { Error < } \\
\mathbf{3 0 \%}\end{array}$ & $\begin{array}{l}\text { Min } \\
\text { Max } \\
\text { Error } \\
\text { Pct }\end{array}$ \\
\hline $\begin{array}{l}\text { I-5 SB } \\
\text { Terwilliger } \\
\text { VMS to } \\
\text { Tualatin- } \\
\text { Sherwood }\end{array}$ & 11.0 & 14.4 & -2.4 & 1.9 & 60 & 86.7 & 95.0 & $\begin{array}{l}-42.5 \\
16.0\end{array}$ \\
\hline $\begin{array}{l}\text { I-5 SB } \\
\text { Terwilliger } \\
\text { VMS to } \\
\text { Tualatin- } \\
\text { Sherwood } \\
\text { ADJUSTED }\end{array}$ & 10.0 & 11.4 & 2.8 & 1.5 & 60 & 92.0 & 96.7 & $\begin{array}{l}-27.4 \\
23.4\end{array}$ \\
\hline $\begin{array}{l}\text { I-5 NB } \\
\text { Downtown to } \\
\text { Columbia } \\
\text { River }\end{array}$ & 16.9 & 31.5 & 7.9 & 3.59 & 77 & 82.0 & 87.0 & $\begin{array}{l}-59.6 \\
144.2\end{array}$ \\
\hline $\begin{array}{l}\text { I-5 NB } \\
\text { Downtown to } \\
\text { Columbia } \\
\text { River } \\
\text { ADJUSTED }\end{array}$ & 14.0 & 22.0 & 4.9 & 2.6 & 77 & 81.0 & 85.7 & $\begin{array}{l}-60.2 \\
72.9\end{array}$ \\
\hline
\end{tabular}




\subsection{ALGORITHM BREAKDOWN}

One goal of this project was to determine at what point or under what conditions the travel time estimation algorithm "broke down" or began to make estimations with high error. Figures 44 and 45 show correlation plots between travel time estimation error and estimated travel time (Figure 44 ) and average probe speed (Figure 45). Neither plot shows a strong correlation. It is concluded that estimation error is not directly correlated to the estimated travel time or to average probe speed (average probe speed can be seen as a measure of congestion). Traffic theory predicts that travel time estimations will be accurate when traffic is in a steady state. More specifically travel time estimation is expected to be accurate during free flow and during high levels of congestion, but to be inaccurate during transitional periods. An extension of this study, funded by OTREC, will study in detail the conditions under which travel time estimates break down.

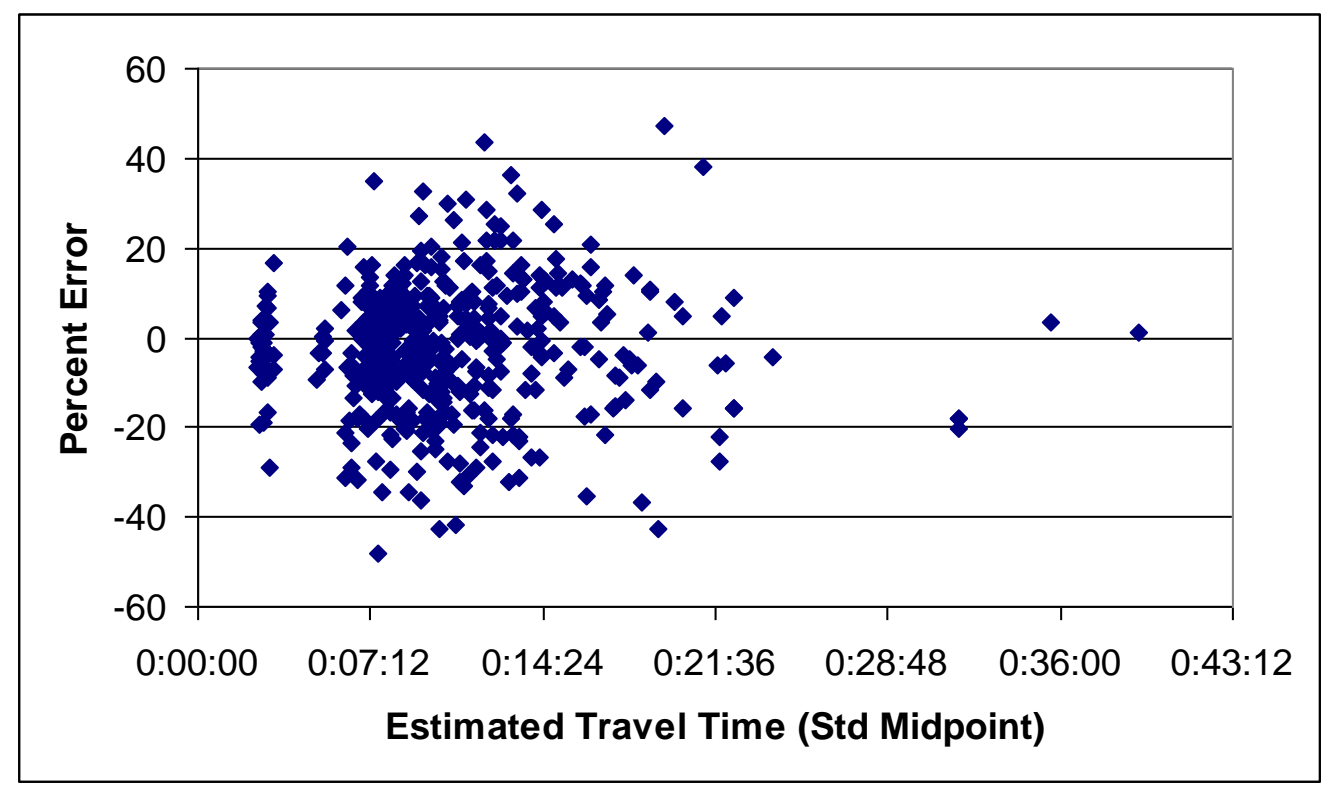

Figure 44 Correlation Between Estimated Travel Time and Estimation Error

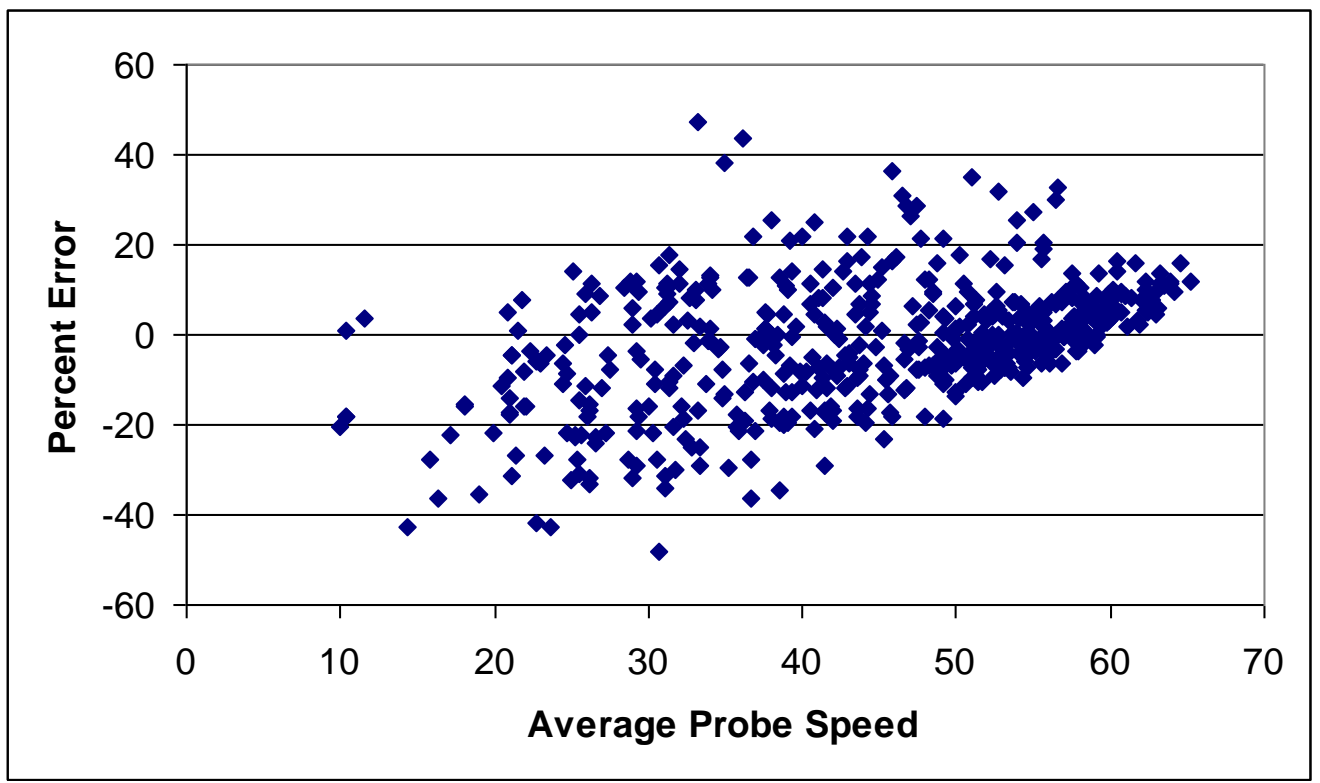

Figure 45 Correlation Between Average Probe Speed and Estimation Error 


\subsection{EFFECT OF INCIDENTS}

All runs were checked for incidents using data from the ATMS system from ODOT. Runs with incidents are flagged when discussed in this report. Table 17 shows the effects of incidents on error rates. In total, 19 runs were affected by incidents. Note that stalls were not included as incidents - visual inspection and brief statistical analysis indicated that the stalls that occurred during data collection had very limited effect on freeway speeds. Table 17 shows that runs with incidents generally had higher errors; however, the occurrence of incidents was low enough that their presence did not affect overall error rates.

Table 177 Effect of Incidents on Error Rates

\begin{tabular}{|l|l|l|l|l|}
\hline \multirow{2}{*}{$\begin{array}{l}\text { Segment } \\
\text { Description }\end{array}$} & Run Type & $\begin{array}{l}\text { Avg } \\
\text { Abs Pct } \\
\text { Error }\end{array}$ & $\begin{array}{l}\text { Std Dev } \\
\text { Pct Error } \\
\text { (SDPE) }\end{array}$ & Num Runs \\
\hline $\begin{array}{l}\text { I-5 NB Carmen } \\
\text { VMS to Downtown }\end{array}$ & All & 7.7 & 10.8 & 67 \\
\cline { 2 - 5 } & No Incidents & 7.8 & 10.9 & 66 \\
\cline { 2 - 5 } & Incidents & 1.93 & $\mathrm{n} / \mathrm{a}$ & 1 \\
\hline $\begin{array}{l}\text { I-5 SB Terwilliger } \\
\text { VMS to Tualatin- } \\
\text { Sherwood }\end{array}$ & All & 11.0 & 14.4 & 60 \\
\cline { 2 - 5 } & No Incidents & 10.8 & 14.0 & 58 \\
\cline { 2 - 5 } & Incidents & 16.8 & 23.8 & 2 \\
\hline \multirow{2}{*}{$\begin{array}{l}\text { I-5 NB Downtown } \\
\text { to Columbia River }\end{array}$} & All & 16.9 & 31.5 & 77 \\
\cline { 2 - 5 } & No Incidents & 15.9 & 31.5 & 70 \\
\cline { 2 - 5 } & Incidents & 26.2 & 33.9 & 7 \\
\hline $\begin{array}{l}\text { I-5 SB Columbia } \\
\text { River to Downtown }\end{array}$ & All & 13.5 & 16.5 & 76 \\
\cline { 2 - 5 } & No Incidents & 13.3 & 16.4 & 74 \\
\cline { 2 - 5 } & Incidents & 20.4 & 3.4 & 2 \\
\cline { 2 - 5 } & All & 12.6 & 15.1 & 45 \\
\cline { 2 - 5 } OR 217 SB & No Incidents & 12.7 & 15.8 & 38 \\
\hline
\end{tabular}




\subsection{CONCLUSIONS}

This project has collected and analyzed a large amount of ground truth travel time data. Statistical and graphical analyses have been used to understand the accuracy of the standard midpoint algorithm and four additional algorithms. The results indicate that infrastructure and detector reliability are significant issues in the Portland metropolitan area. More specifically, the analysis indicates that there are several areas of high congestion with moderately high detector spacing that cause significant error. Additional detection is recommended in those locations. The Terwilliger Curves and the OR 217 - I-5 SB merge are examples of such areas. Additionally, there are several freeways in the Portland area, including U.S. 26 and I-84, which have very large (greater than 2-mile) detector spacing in areas of high and complex congestion. Provision of travel times on these highways is not recommended without additional detection and analysis.

Detector reliability is also an issue; $50 \%$ of ground truth runs had at least one detector station not providing data during the run. This lack of data had many causes including construction, physical damage to the infrastructure and intermittent detector failures. The lack of detection due to construction could be addressed by having semi-portable, off-pavement detection facilities available for use during construction. As part of the project, various algorithms and algorithm adjustments were also studied, with influence-area adjustment being the most promising algorithm or algorithmic adjustment tested by the team. The project team will continue this project with additional extension funding from OTREC. Issues such as conditions under which travel time estimations are inaccurate and additional influence-area adjustments will be investigated. 


\subsection{REFERENCES}

[1] Evaluation of Freeway Travel Time Estimates. Final Report, Prepared for: The Oregon Department of Transportation. Prepared by: Castle Rock Consultants, Inc., Portland State University.

[2] http://mutcd.fhwa.dot.gov/res-memorandum_dms.htm

[3] Bertini, R.L., Matthews, S., Hansen, S., Delcambre, A., and Rodriquez, A. ITS Archived Data User Service in Portland, Oregon: Now and Into the Future. $8^{\text {th }}$ International IEEE Conference on Intelligent Transportation Systems, Vienna, Austria, September 13-16, 2005.

[4] Bickel, P., Chen, C., Kwon, J., Rice, J., van Zwet, E., Varaiya, P. Measuring Traffic. May 24, 2004. (http://www.stat.berkeley.edu/ rice/traffic.pd

[5] Coifman, B. Estimating Travel Times and Vehicle Trajectories on Freeways Using Dual Loop Detectors. Transportation Research. Part A: Policy and Practice, Vol. 36, No. 4., 2002, pp 351-364.

[6] Kothuri, S., Tufte, K. Ahn, S., and Bertini, R.L. Using Archived ITS Data to Generate Improved Freeway Travel Time Estimates. Proceedings of the $86^{\text {th }}$ Annual Meeting of the Transportation Research Board, Washington D.C., 2007.

[7] Meehan, B. Transportation Information Management Team, Federal Highway Administration. Travel Times on Dynamic Message Signs. September 28, 2005 - Travel Time Messages on Dynanic Message Signs National Transportation Operations Center (NTOC) Web Casts Archive http://www.ntoctalks.com/web_casts_archive.php

[8] San Antonio Travel Time Algorithm. http://www.transguide.dot.state.tx.us/docs/travel_times.pdf

[9] Toppen, A., Wunderlich, K. Travel Time Data Collection for Measurement of Advanced Travler Information Systems Accuracy. Project Report, MTS Systems. June 2003. http://www.itsdocs.fhwa.dot.gov/JPODOCS/REPTS_TE/13867_files/13867.pdf

[10] Travel Time Data Collection Handbook. Office of Highway Information Management, Federal Highway Administration, U.S. Department of Transportation and Texas Transportation Institute, Texas A\&M University System. Report FHWA-PL-98-035, March 1998, http://www.fhwa.dot.gov/ohim/timedata.htm.

[11] Washington DOT Travel Time Estimation Algorithm http://www.wsdot.wa.gov/Traffic/seattle/questions/traveltimesdetail.htm

[12] Zhang, X., Rice, J. Short-Term Travel Time Prediction Using A Time-Varying Coefficient Linear Model. (http://www.stat.berkeley.edu/ rice/xTTfinal.pdf) 
P.O. Box 751

Portland, OR 97207

www.otrec.us

OTREC is dedicated to stimulating and conducting collaborative multi-disciplinary research on multi-modal surface transportation issues, educating a diverse array of current practitioners and future leaders in the transportation field, and encouraging implementation of relevant research results. 